\title{
Allosteric feed-forward activation of AP-2 via FCHO- BMP2K axis promotes clathrin-mediated endocytosis
}

\author{
Shikha T. Ramesh ${ }^{1}$, Kolaparamba V. Navyasree ${ }^{1}$, Anjitha B. Ashok ${ }^{1}$, Nishada \\ Qathoon $^{1}$, Suryasikha Mohanty ${ }^{2}$, Rajeeb K. Swain ${ }^{2}$, Perunthottathu K. Umasankar \\ $1, \#$
}

\author{
Affiliations \\ ${ }^{1}$ Intracellular Trafficking Laboratory, Interdisciplinary Biology Research \\ Program, Rajiv Gandhi Centre for Biotechnology, Thiruvananthapuram, Kerala, India \\ ${ }^{2}$ Institute of Life Sciences, Bhubaneswar, Orissa, India \\ ${ }^{\text {\#Correspondence to: umasankarpk@ @rgcb.res.in }}$
}

\footnotetext{
Abstract

Spatio-temporal regulation of central adaptor complex, AP-2 is pivotal for clathrin-mediated endocytosis (CME). We recently discovered that $\mathrm{FCHO}$ proteins trigger clathrin- coated pit $(\mathrm{CCP})$ formation by allosterically activating AP-2 on plasma membrane (Umasankar et al., 2014). Here, we demonstrate that this activation promotes AP-2 phosphorylation via recruitment and stabilization of BMP-2 inducible kinase (BMP2K), a bona fide AP-2 kinase leading to CCP maturation. Accordingly, BMP2K mislocalizes and degrades in FCHO knockout/ AP-2 depleted cells. Functional inactivation of kinase impairs AP-2 phosphorylation leading to altered lattice morphology and CME phenotypes reminiscent of CCP maturation defects. Reexpression of FCHO rescues AP-2 phosphorylation defects in FCHO knockout cells implying membrane activation of AP-2 is a prerequisite for kinase function. Furthermore, gain- and loss-of function phenotypes of FCHO and BMP2K are analogous and mirror altered AP-2 functions
} 
12 during zebrafish embryogenesis. Together, our findings reveal an in vivo allosteric feed-forward axis for 13 operation of CME.

\section{Introduction}

15 Clathrin-mediated endocytosis (CME) is a major vesicular transport mechanism in eukaryotes for

16 internalization of cell surface transmembrane protein cargo (Traub, 2009). The process involves

17 sequential transition of a flat piece of membrane into a cargo-laden pit (CCP) decorated with a cytosolic coat protein, clathrin (Merrifield and Kaksonen, 2014, Mettlen et al., 2018). CCP ultimately buds into cell interior with the help of dynamin GTPase, to become clathrin-coated vesicle (CCV) that after uncoating fuses with endosomes to deliver cargo (Schmid and Frolov, 2011; Ferguson and De Camilli,

21 2012). CCV biogenesis occurs in $\sim 60$ seconds and is efficiently choreographed through temporally co-

22 ordinated recruitment of adaptors and accessory proteins on the membrane (Taylor et al., 2011; Kaksonen

23 and Roux, 2018). The incapability of clathrin to bind membrane and cargo necessitates evolution of a

24 special set of adaptors generally termed clathrin-associated sorting proteins (CLASPs). CLASPs

25 translocate from cytosol to the inner leaflet of plasma membrane to sort cargo, recruit clathrin and

26 accessory proteins for CCP assembly (Traub and Bonifacino, 2013).

27 Adaptor protein complex-2 (AP-2) is a major heterotetrameric CLASP that consists of $\alpha, \beta 2, \mu 2$ and $\sigma 2$

28 subunits (Robinson, 2004). The trunk domains of $\alpha$ and $\beta 2$ together with the entire $\mu 2$ and $\sigma 2$ form AP-2

29 core (Kirchhausen et al., 2014). The extended domains of $\alpha$ and $\beta 2$ subunits form appendages that

30 connect to the core through long flexible hinges (Traub et al., 1999; Owen et al., 2004). AP-2 facilitates

31 two major functions in CME. First, through its core, AP-2 mediates binding to plasma membrane

32 phospholipids (PIP2) and to sorting signals on cargo. AP-2 sorts cargo containing tyrosine based (YXXØ)

33 and di-leucine based [DE]XXXL[LI] sorting motifs through $\mu 2$ and $\sigma 2$ subunits respectively (Traub,

34 2009). Second, AP-2 recruits clathrin and late stage accessory proteins through hinge and appendages.

35 Together it promotes CCP initiation (Cocucci et al., 2012; Godlee and Kaksonen, 2013), assembly and 
maturation (Shih et al., 1995; Edeling et al., 2006). Thus, AP-2 efficiently orchestrates CCV biogenesis by co-ordinating multiple low-affinity interactions with binding partners (Schmid and Macmahon, 2007).

AP-2 undergoes series of conformational changes that functionally translate into distinct stages in CCV biogenesis (Kadlecova et al., 2017). Crystal structures suggest at least three functionally distinct conformations of AP-2; (1) closed, inactive state in which binding surfaces for PIP2, cargo and clathrin are masked (Collins et al., 2002), (2) open, active state in which these binding surfaces are exposed and aligned in a co-planar fashion (Kelly et al., 2008; Jackson et al., 2010; Kelly et al., 2014), and (3) a new open+ active conformation in which an additional threonine (T156) residue on the flexible linker region of $\mu 2$ is exposed for phosphorylation (Wrobel et al., 2019). Accordingly, large-scale mutagenesis screens in the nematode, C.elegans identify phenotypic functional mutations reflecting different conformations of AP-2 (Hollopeter et al., 2014; Beacham et al., 2018, Partlow et al., 2019).

Several allosteric regulators have been proposed in mediating AP-2 conformational transitions. In vitro structural and biochemical studies supported by quantitative live-cell imaging analyses suggest PIP2 and cargo binding promotes transition from closed to open state stabilizing AP-2 on membrane (Honing et al., 2005; Jackson et al., 2010; Kadlecova et al., 2017). Recent investigations establish role of muniscin family of proteins (FCHO1, FCHO2 and neuronal SGIP1) (Reider et al., 2009; Henne et al., 2010;

52 Umasankar et al., 2012) in this process. In genome-edited HeLa cells lacking FCHO (Umasankar et al.,

53 2014) and in C. elegans fcho mutants (Hollopeter et al., 2014), majority of AP-2 fails to recruit on

54 membrane, hampering CCP inception. Residual CME still persists in these cells (Mulkearns et al., 2012,

55 Umasankar et al., 2014) by virtue of additional AP-2 interactions mediated by coat-initiating proteins, EPS15/R (Ma et al., 2016). Consistently; nanobody-mediated disruption of EPS15/R-AP-2 interaction

57 further deteriorates CME in 1.E cells by completely inactivating AP-2 (Traub, 2019) suggesting parallel mechanisms for AP-2 activation. In all these cases, actual in vivo conformation of AP-2 remains unclear. Nevertheless, expression of intrinsically disordered linker region of muniscins that binds AP-2 core 
61 confirming allosteric activation. More recent studies demonstrate role of another endocytic protein,

62 NECAP in allosteric regulation of AP-2 (Ritter et al., 2013; Beacham et al., 2018). It has been shown that

63 in mammalian cells, NECAP promotes AP-2 activation by coupling open+ phosphorylated forms to

64 downstream effectors of CCV biogenesis (Wrobel et al., 2019). On the contrary, studies in C. elegans

65 suggest that NECAP inactivates AP-2 by converting open to closed state (Beacham et al., 2018; Partlow

66 et al., 2019).

67 Reversible phosphorylation of $\mathrm{T} 156 \mu$ has been proposed an important allosteric regulator of AP-2

68 function (Wild and Brodsky, 1996; Smythe, 2002). However, several aspects of AP-2 phosphorylation

69 remain unclear and have been largely debated. For instance, when AP-2 phosphorylation occurs during

$70 \mathrm{CCV}$ biogenesis and its functional significance remain poorly understood. Some studies indicate

71 phosphorylation associates with open AP-2 based on the phenotypes in C. elegans and on the structural

72 predictions of T156 $\mu$ linker positioning (Hollopeter et al., 2014; Beacham et al., 2018; Partlow et al.,

73 2019). It is also disputed whether phosphorylation opens AP-2 (Höning et al., 2005; Jackson et al., 2010),

74 closes AP-2 (Beacham et al., 2018; Partlow et al., 2019) or induces an entirely different conformation

75 (Wrobel et al., 2019). In addition, earlier in vitro structural and biochemical studies predict AP-2

76 phosphorylation may increase cargo binding affinity (Pauloin and Thurieau, 1993; Olusanya et al., 2001;

77 Ricotta et al., 2002).

78 Recent structural and live-cell imaging approaches attempt to bring in more clarity to this picture

79 (Kadlecova et al., 2017; Wrobel et al., 2019; Partlow et al., 2019). New crystal structures of

80 phosphorylated AP-2 clearly indicate that T156 $\mu$ site is not accessible in open state, thus cannot be

81 phosphorylated by kinases. However, it is predicted that active kinase can phosphorylate open+ or closed

82 states and has access to AP2 where those conformations exist (Wrobel et al., 2019). These studies also

83 show that phosphorylated AP-2 creates new sites for NECAP engagement without perturbing cargo and

84 clathrin binding to either couple CCP for maturation (Wrobel et al., 2019) or to inactivate and recycle AP-

852 (Partlow et al., 2019). Additionally, these studies find T156 $\mu$ phosphorylates early at CCP formation 
and increases as CCP grows suggesting a positive role for AP-2 phosphorylation (Kadlecova et al., 2017;

87 Wrobel et al., 2019).

88 Incongruity in AP-2 phosphorylation studies may arise largely due to lack of understanding of specific

89 kinases that phosphorylate AP-2 and their regulatory mechanisms in cells and organisms. Earlier

90 investigations help identify Adaptor associated kinase-1 (AAK1) that phosphorylates AP-2 $\mu 2$ in in vitro

91 assays (Conner and Schmid, 2002). Accordingly, AAK1 co-purifies with AP-2 in CCV, binds to AP-2/

92 clathrin and localizes to CCPs in cells (Conner et al., 2003; Jackson et al., 2003). Yet, RNAi-mediated

93 silencing of AAK1 fails to induce any significant changes in AP-2 phosphorylation status or cargo uptake

94 in cells (Conner and Schmid, 2003; Henderson and Conner, 2007). This leaves the possibility of potential

95 redundant kinases and novel regulatory mechanisms for AP-2 phosphorylation.

96

97

BMP2K was originally identified as a serine-threonine kinase regulating osteoblast differentiation whose gene product is sharply up-regulated by BMP-2 stimulation (Kearns et al., 2001). Later, various genetic and proteomic screens link BMP2K to HIV entry (Zhou et al., 2008), developmental dysplasia of the hip (Zhao et al., 2017), myopia (Liu et al., 2009), leukemia (Brehme et al., 2009; Pandzic et al., 2016), breast cancer metastasis (Mercado-Matos et al., 2018) etc. Recent multivariate proteomic profiling approaches identify BMP2K as a component of purified CCV from HeLa cells (Borner et al., 2012). Moreover, structural similarities of kinase domains (75\% identical) and in vitro inhibition profiles categorize BMP2K as a member of Numb- associated protein kinase (NAK) family and as the closest homolog of AAK1 (Krieger et al., 2013; Elkins et al., 2016; Sorrell et al., 2016).

Here, by integrating reverse genetic, pharmacological and biochemical approaches in genome-edited cells and D. rerio (zebrafish) embryos, we unravel BMP2K as a bona fide AP-2 kinase that reversibly phosphorylates $\mu 2$ at T156 in a spatio-temporally controlled fashion to regulate AP-2 functions. We demonstrate that membrane activated AP-2 induced by FCHO triggers recruitment and stabilization of BMP2K at CCPs. Accordingly, FCHO knockouts defective in membrane activation of AP-2 or BMP2K 
mutants that cannot localize to CCPs fail to induce AP-2 phosphorylation. Inhibition of BMP2K activity in HeLa cells abolishes AP-2 phosphorylation and elicits CME phenotypes temporally distinct from FCHO knockouts. In D. rerio embryos, gain- and loss-of-function of FCHO and BMP2K perturb AP-2 functions leading to aberrant CME during development. Together, our findings propose a feed-forward allosteric axis involving FCHO-BMP2K that activates AP-2 for proper functioning of CME.

\section{Results}

\section{Loss of FCHO identify BMP2K as a bona fide AP-2 kinase}

117 Previously, we had identified CME defects in 1.E (FCHO knockout) cells occurring due to altered distribution and function of AP-2 in the absence of FCHO. Immunofluorescence with the AP.6 monoclonal antibody confirms the altered distribution of AP-2 positive structures in 1.E cells (Figure 1A and B, quantified in Figure 7C). A 5 minute pulse of fluorescent transferrin followed by acid stripping of surface ligands (endocytosis assay- protocol \#2) shows reduced fluorophore in peripheral endosome compartments in 1.E cells validating endocytic defects (Figure 1A', A', B' and B”). To investigate if membrane activation of AP-2 is required for phosphorylation, we compared phosphorylation status of AP-2 in 1.E cells and parental HeLa SS6 cells. A commercial antibody specific to phosphorylated T156 $\mu$

125 (pT156 $\mu$ ) reveals the extent of AP-2 phosphorylation in HeLa cells. On blots, steady-state levels of $126 \mathrm{pT} 156 \mu$ dramatically reduce in 1.E as compared to HeLa SS6 (Figure 1C), indicating defective $\mu 2$ 127 phosphorylation in the absence of FCHO. Reduction in phosphorylation is not due to destabilization and degradation of AP-2 complex as steady state levels of $\mu 2$ and other AP-2 subunits are similar in 1.E and phosphorylation defect is due to loss of AAK1 or BMP2K in 1.E cells. Though both these kinases are invariably present in low copy numbers across cell types, BMP2K is reported to be slightly more abundant (Hein et al., 2015) and more membrane associated (Itzhak et al., 2016) than AAK1 in HeLa cells. Consistently, immunoblotting with different commercially available antibodies against both these 
BMP2K drastically decline in 1.E cells compared to HeLa SS6 with unchanged levels of AP-2, clathrin and other clathrin-associated adaptor and accessory proteins (Figure 1D).

Since reduced phosphorylation correlates with loss of BMP2K, we examined if BMP2K is a bona fide AP-2 kinase in cells. Quantitative immunofluorescence analyses with pT156 $\mu$ and AP.6 antibodies reveal basal mean fluorescent intensity ratios of phosphorylated AP-2 to total AP-2 in majority of CCPs in HeLa SS6 cells (Figure 2A, B and Figure 2- figure supplement 1). Transient expression of a C-terminally GFP- tagged BMP2K (BMP2K-GFP) populates AP-2 positive CCP on the ventral surface of HeLa SS6 cells (Figure 2A). Strikingly, mean fluorescent intensity ratio of pT156 $\mu$ / AP-2 increases $~ 3$ fold in BMP2K-GFP positive CCP (Figure 2A, B and Figure 2- figure supplement 1) suggesting enhanced AP-2 phosphorylation by excess kinase. GFP- tagging at the C-terminus causes negligible effect on kinase function. Immunoblots show comparable increase in the steady state levels of pT156 $\mu$ in cells transfected with GFP- tagged and- untagged versions of BMP2K (Figure 2C). In addition, AP-2 phosphorylation status in BMP2K transfected cells is comparable to that of cells treated with calyculin, a pan- serine/threonine phosphatase inhibitor that reversibly arrests proteins in phosphorylated state (Figure 2C). Recent pharmacological studies identify SGC-AAK1-1 (Elkins et al., 2016; Agajanian et al., 2019), a small molecule functionally similar to the earlier version of brain-penetrant inhibitor LP-935509 (Wrobel et al., 2019) that potently and selectively inhibits NAKs both in vitro and in vivo. Co-crystal structures of inhibitor-bound kinase confirm that inhibition is mediated through competitive binding to the conserved ATP site on the kinase domain (Agajanian et al., 2019). We used SGC-AAK1-1 to inhibit AP-2 kinase (AAK1 and BMP2K) functions in HeLa cells. Steady state levels of pT156 $\mu$ decrease on blots with increasing concentrations of SGC-AAK1-1 confirming specificity and efficiency of the inhibitor (Figure 2D). The inhibitor also suppresses elevated levels of pT156 $\mu$ in BMP2K expressing cells suggesting AP-2 phosphorylation impedes upon BMP2K inactivation (Figure 2E). Together, these results establish BMP2K a valid AP-2 kinase in cells.

\section{BMP2K localizes to CCPs through extended C-terminus}


BMP2K positive CCPs also contain FCHO binding partners, clathrin-associated SNARE adaptor, HIV-1 Rev- binding protein (HRB) (Pryor et al., 2008) (Figure 3- figure supplement 1A) and pioneer adaptor complex protein, intersectin (Henne et al., 2010; Mayers et al., 2013) (Figure 3- figure supplement 1B), further confirming endocytic association of kinase. Yet, distribution of BMP2K-GFP appears slightly different from that of GFP-FCHO1. In abundantly expressing cells, larger structures that concentrate more AP-2 (Figure 3A) are seen in both, but membrane-tethered population evident with higher expression levels of GFP-FCHO1 (Figure 3B) (Umasankar et al., 2012) is not observed with higher amounts of BMP2K-GFP. This likely indicates differential mode of CCP recruitment and stabilization for FCHO and BMP2K. We used deletion mutants to delineate mode of CCP recruitment of BMP2K. BMP2K follows domain architecture typical of the parental NAK -consisting of $\mathrm{NH}_{2}$-terminal kinase domain $(\mathrm{KD})$ and an extended $\mathrm{COOH}$-terminus with proximal glutamine/histidine $(\mathrm{Q} / \mathrm{H})$ rich region and distal intrinsically disordered region (CT) (Figure 3C). Deletion of CT (BMP2K $\Delta \mathrm{CT}$ ) completely

172 abolishes CCP localization (Figure 3D). Yet, deletion of KD and Q/H together, retaining CT alone 173 (BMP2KCT) or deletion of $\mathrm{Q} / \mathrm{H}$ alone retaining $\mathrm{KD}$ and $\mathrm{CT}(\mathrm{BMP} 2 \mathrm{~K} \Delta \mathrm{Q} / \mathrm{H})$ shows reduced localization 174 at CCPs (Figure 3E and F). Strikingly, deletion of KD alone (BMP2K $\Delta$ KD) completely restores CCP 175 localization (Figure 3G), suggesting localization happens through co-ordination of Q/H and CT regions 176 independent of KD. This is in contrast to the structured, domain-dependent CCP targeting of FCHO 177 (Umasankar et al., 2012).

\section{BMP2K binds to AP-2 and clathrin}

179 To identify endocytic interactions involved in BMP2K recruitment to CCP, we performed GST-pull180 down assays with HeLa SS6 cell extracts. CT contains known and predicted short linear motifs (SLiMs) 181 distributed across proximal (CT\#1) and distal (CT\#2) segments that can potentially engage AP-2 182 appendages, clathrin and muniscins (Figure 4A). Accordingly, both GST-CT\#1 and GST-CT\#2 affinity 183 purify $\alpha$ and $\beta$ subunits of AP-2 from cell lysate (Figure 4B). EPS15 C-terminus (595-896) binds directly 184 to appendages through multiple low affinity DPF motifs and indirectly to clathrin through AP-2 (Figure 
4B, Benmerah et al., 1998). Compared to EPS15, CT shows weaker binding to AP-2 and to clathrin in our pull-down experiments despite having an array of potential binding motifs. Additionally, EPS15 contains three tandem, optimally spaced DPFXXDPF consensus motifs that engage FCHO for CCP initiation (Ma et al., 2016). We identify nine, similar DXFXXXPF consensus motifs scattered throughout BMP2K-CT

(Figure 4A); one of these motifs can directly engage FCHO2 (Mulkearns et al., 2012). Yet, BMP2K does not show any obvious interaction with FCHO (Figure 4B). This confirms the importance of spatial arrangement of SLiMs or redundant mechanisms in mediating diverse interactions to build clathrin-coat (Ma et al., 2016). Surprisingly, Q/H region, despite showing definitive role in CCP targeting, shows negligible AP-2 or clathrin binding and is comparable to KD (Figure 4C).

\section{AP-2-dependent BMP2K stabilization at CCPs is pivotal for phosphorylation}

195 AP-2 interacts with accessory endocytic proteins through $\alpha$ and $\beta$ appendages to regulate their recruitment to CCP (Mishra et al., 2004; Praefcke et al., 2004; Keyel et al., 2008). Accordingly, in reciprocal pulldown assays, both GST- $\alpha$ and - $\beta$ appendages affinity purify endogenous BMP2K from HeLa lysate

We checked if functional AP-2 is indeed required for BMP2K stabilization at CCP. siRNA targeting AP$2 \alpha$ subunit efficiently suppresses AP-2 function in HeLa cells (Motley et al., 2003, Hinrichsen et al., 2003). Immunofluorescence with AP-2 monoclonal antibody AP.6 clearly distinguishes AP-2 depleted

203 cells from adjacent normal cells in the same field (Figure 5A). In addition, fluorescent transferrin

204 (endocytosis assay- protocol \#1) completely stalls at the cell surface of AP-2 depleted cells and fails to 205 internalize into peripheral endosomes confirming functional inactivation of AP-2 in these cells (Figure 
levels of endogenous BMP2K also sharply decline in AP-2 depleted cells indicating destabilization and degradation of kinase (Figure 5E). Further, we checked if AP-2 phosphorylation is regulated through

211 CCP localization of the kinase. As expected, steady-state intensity of pT156 $\mu$ considerably increases in

212 CCPs populated with BMP2K-GFP (Figure 5F). However, phosphorylation status of AP-2 remains

213

214

215 unaffected in BMP2K $\Delta$ CT-GFP (that cannot engage AP-2) expressing cells, despite having functional

$$
\text { KD. (Figure 5G). Together, it implies that membrane AP-2 stabilizes kinase at growing CCPs for }
$$
catalysis.

\section{BMP2K regulates CCP morphology and cargo uptake}

Silencing BMP2K using specific pool of siRNAs did not cause any discernible alterations in CCP morphology or cargo uptake in our experiments. This is consistent with lack of CME phenotype in AAK1 knockdown cells in earlier studies suggesting functional redundancies in AP-2 kinases (Conner and Schmid, 2003). Hence, we took a pharmacological approach to functionally inactivate BMP2K/AAK1 in HeLa SS6 cells. Our biochemical experiments reveal that $10 \mu$ M SGC-AAK1-1 (NAK inhibitor) shows maximum inhibition of AP-2 phosphorylation in 2 hours beyond which it remains unchanged (Figure 2D), hence $10 \mu \mathrm{M}$ was selected for inhibition experiments. BMP2K inhibited parental HeLa SS6 cells $(B M P 2 K i)$ show visible alterations in the steady-state CCP morphology. Quantitative analyses of CCP density and distribution in mock cells show predominantly small, spherical structures (Figure 6A and Figure 6- figure supplement 1A) ranging $0.2-0.6 \mu \mathrm{m}^{2}$ size that occupy $\sim 40 \%$ of total membrane bound AP-2 (Figure 6D and E). BMP2K $i$ cells exhibit a clear shift in the distribution and density of CCPs toward enlarged, sparsely distributed, brighter structures (Figure 6B and Figure 6- figure supplement 1B), above $0.6 \mu \mathrm{m}^{2}$ size that occupy $\sim 60 \%$ of total AP-2 (Figure 6D and E) on the membrane. These spatially remodelled AP-2 positive structures in BMP2K $i$ cells morphologically resemble flat, planar, clathrin-coated plaques in 1.E cells (Figure 6C, Umasankar et al., 2014). To see if altered CCP morphology in $B M P 2 K i$ cells translates into functional defects similar to 1.E cells, we compared kinetics of transferrin internalization in mock, $B M P 2 K i$ and 1 .E cells using endocytosis assay protocol \#1. A flux 
of fluorescent transferrin in mock cells separates AP-2 positive CCPs from peripheral early endosomes in 2 minutes (Figure 6A') and from large juxtanuclear recycling endosomes in 10 minutes (Figure 6- figure supplement 1A-A"). Consistent with our earlier reports, the bulk of transferrin appears diffused throughout the cell surface with very low amounts in peripheral endosomes suggesting cargo sorting defects in 1.E cells (Figure 6C' and C'). Strikingly, in BMP2Ki cells, bulk of transferrin co-localizes with AP-2 positive structures (Figure 6B") with reduced internalization into endosomes in 2 minutes (Figure 6B'). In addition, after 10 minutes of pulse, the fluorescent transferrin puncta appears more distributed in peripheral early endosome compartments instead of juxtanuclear recycling endosome suggest persistent CME delay in the absence of functional kinase. However, transferrin diffusion at cell surface seen in 1 .E cells is not clearly evident in $B M P 2 K i$ cells likely indicates temporally distinct functions for FCHO and BMP2K in CME or, in part, reports differences in acute (pharmacological) or chronic (genome- editing) interference defects in CME. Together, these findings argue a late endocytic function for kinase, which is consistent with recent reports indicating role of AP-2 phosphorylation in CCP maturation (Wrobel et al., 2019).

\section{FCHO- BMP2K feed-forward axis in HeLa cells}

250 We surmise if BMP2K drives AP-2 functions in the absence of FCHO, then re-expression of BMP2K in

251 1.E cells could restore normal CCP morphology and function. Ectopic expression of BMP2K-GFP in 1.E 252 cells marks AP-2 positive structures on membrane (Figure 7A) but does not alter CCP morphology or 253 distribution; large bright plaques still persist in these cells (Figure 7A' and C). To check if BMP2K

254 positive structures in 1.E cells are functional, we assessed cargo uptake using endocytosis assay protocol

255 \#3 that clearly discerns small changes in internalization kinetics (Reis et al., 2015; Ma et al., 2016).

256 Negligible difference is seen in the amount of internalized transferrin in BMP2K-GFP transfected cells

257 compared to surrounding untransfected 1.E cells; suggesting BMP2K activation fails to rescue AP-2 
and cargo uptake defects occurs with expression of a membrane-binding segment of FCHO1 GFPFCHO1 (1-609) containing the linker region (316-467) that interacts with AP-2 core (Umasankar et al.,

2014; Hollopeter et al., 2014). Within linker transfected 1.E cells, CCP population density shifts predominantly toward 0.2-0.6 $\mu \mathrm{m}^{2}$ sized AP-2 positive structures (Figure 7B, B' and C). Linker transfected cells also show considerable increase in the amount of intracellular transferrin further confirming rescue of CME defects through allosteric activation of AP-2 (Figure 7B” and D).

We asked if FCHO could restore normal AP-2 phosphorylation in 1.E cells by activating functional

kinase. Similarly to linker, reexpression of GFP-FCHO1 in 1.E cells restores normal AP-2 distribution on the membrane (Figure 8A, A' and C-F). Interestingly, mean pT156 $\mu$ intensity increases $\sim 2.5$ fold in AP-2 positive structures containing GFP-FCHO1 as compared to the surrounding AP-2 positive plaques devoid of GFP-FCHO1 in the same field of view (Figure 8B, B', G-K). Together, these findings suggest AP-2 functions through FCHO-BMP2K feed-forward axis in mammalian cells.

\section{FCHO misexpression phenocopies BMP2K gain-of-function in vivo}

272 Next, we investigated if FCHO-BMP2K axis functions at organismal level for AP-2 activation, by using 273 zebrafish (Danio rerio) embryos. Single genes each code for Dr FCHO1 (fcho1), Dr FCHO2 (fcho2) and $274 D r$ AP-2 $\alpha$ (ap2al) subunit (Umasankar et al, 2012). However, $D r$ BMP2K and $D r$ AAK1 are encoded by

275 two genes each that might have formed due to teleost-specific genome duplication during evolution

276 (Howe et al., 2013). Whole mount in situ hybridization analyses using riboprobes designed from common

277 kinase domain of $b m p 2 k 1$ and $b m p 2 k 2$ reveal maternal deposition and ubiquitous expression of kinase in

278 all developmental stages till 24 hour post- fertilization (hpf) (Figure 9- figure supplement 1A). Spatio-

279 temporal expression pattern of BMP2K is identical to that of ap2al (Figure 9- figure supplement 1B)

280 and fchol/2 transcripts; (Umasankar et al, 2012) and is in stark contrast to that of dusp6 (dual specificity

281 phosphatase-6), a non-endocytic transcript that is not maternally deposited but shows specific domains of

282 expression during zygotic phase of development (Figure 9- figure supplement 1C) (Tsang et al., 2004; 
Molina et al., 2009). This spatio-temporal expression pattern shows CME is functional in all stages of embryonic development. plate), shortened and upward twisted A-P axis with reduced yolk extension, disrupted notochord tissue, misshapen somites and accumulated caudal hematopoietic cells (classified as severe) (Figure 9B, B' and E). $20 \%$ of the injected embryos show only mild notochord and somite defects without cyclopia or upward twisted body axis (classified as mild) and 15\% appear similar to control (classified as normal)

292 (Figure 9E). These phenotypes closely resemble $H s$ FCHO1 mRNA misexpression phenotypes noticed in 293 our earlier in vivo studies (Umasankar et al, 2012). Strikingly, ectopic expression of $H s B M P 2 K$ mRNA 294 phenocopies FCHO misexpression with 58\% severe, 25\% mild and 17\% normal embryos (Figure 9C and E). However, expression of BMP2K mutant that cannot engage AP-2 (Hs BMP2KACT), fails to elicit severe embryonic defects (Figure 9D and E). Only 20\% of embryos injected with 5 times higher concentration of $H S B M P 2 K \triangle C T$ mRNA exhibit mild phenotypes further confirming in vivo significance of BMP2K-AP-2 interaction (Figure 9D', D” and E). This suggests that hyperactivation of AP-2 by misexpressing FCHO or BMP2K could increase CME rates leading to multiple but similar defects during embryogenesis. Thus, gain-of- function studies confirm FCHO and BMP2K are functionally linked in vertebrates.

\section{Functional FCHO-BMP2K axis in vivo}

303 Next, we compared loss-of-function phenotypes of FCHO and BMP2K with respect to specific AP-2 304 functions during development. Since AP-2 knockout is embryonically lethal in vertebrates (Mitsunari et 305 al., 2005), we used anti-sense morpholino approach to transiently knockdown ap2al in D. rerio embryos. 306 We have used this approach previously to functionally inactivate AP-2 and other endocytic proteins in 307 developing embryos. In addition, target specificity and knockdown efficiency of these morpholinos have 
been validated previously by control/ mismatch morpholinos, GFP-tagged target silencing and functional rescue experiments (Umasankar et al., 2012).Translational silencing of ap2al causes severe defects in morphogenetic cell movements during embryonic gastrulation. Through an unbiased morphological screen, we classified these gastrulation phenotypes into two categories. Category-1 embryos are severely

312 affected and show slow and incomplete epiboly during early gastrulation. Compared to normally

313 developing control morpholino-injected embryos (Figure 9- figure supplement $2 \mathbf{A}$ and $\mathbf{A}^{\prime}$ ), category-1

314 morphants perish during blastopore closure at $~ 9-10 \mathrm{hpf}$ due to dysmorphic extrusion of yolk (Figure 9-

315 figure supplement 2B and B'). Embryonic culture of blastomeres from category-1 embryos reveals

316 defects in cell adhesion. Unlike control cells that exhibit typical fibroblast-like appearance (Figure 9-

317 figure supplement 2D), majority of ap2al morphant cells appear rounded and dissociated, indicative of failure to adhere and spread out on laminin containing extracellular matrix (Figure 9- figure supplement 2E). Endocytosis promotes epiboly by removing the yolk-cell membrane just ahead of the advancing blastoderm (Solnica-Krezel., 2006) and also by recycling cell adhesion protein, E-cadherin which contains di-leucine sorting signal for AP-2 (Song et al., 2013). Consistent with this idea, ap2al category-

3221 embryos phenocopy dynamin mutants (Lepage et al., 2014) Rab5 morphants (Kenyon et al., 2015) and half baked/E-cadherin mutants (Kane et al., 2005).

324 Category-2 embryos undergo normal epiboly but display convergent- extension (CE) defects during late gastrulation. WISH analyses using molecular markers no tail (for notochord cells) and myoD (for somite and adaxial cells) reveal chordamesoderm cells undergoing normal CE in all control morpholino injected

327 embryos (Figure 9F and Figure 9- figure supplement 2C). In vertebrates, CE is governed by non-

328 canonical Wnt-PCP signaling that co-ordinate cell movements via Rho GTPase- actin axis (Tada and 329 Heisenberg, 2012; Roszko et al., 2009). Strength and duration of Wnt-PCP signaling rely on endocytosis 330 of Wnt-signalosome complex consisting of Wnt (ligand)-Frizzled (receptor)-Dishevelled (adaptor 331 containing tyrosine sorting signal) through functional AP-2 (Yu et al., 2007; Ohkawara et al., 2011). 332 Accordingly, ap2al morphants display severe CE defects; territory of both no tail and myoD expressing 
cells shorten across A-P axis and expands laterally, reminiscent of Wnt-PCP mutants (Hammerschmidt et phenotypically mimic ap2al category-2 embryos showing CE defects with respect to no tail and myoD expression pattern (Figure 9H and Figure 9- figure supplement 2C). These findings suggest redundant mechanisms for AP-2 activation during embryogenesis (Umasankar et al., 2012). Pharmacological approaches suppress BMP2K function in developing embryos. Consequently, gastrulating embryos treated with SGC-AAK1-1 (BMP2Ki) show clear CE defects (60\% embryos fall into category-2) analogous to $f c h o 2$ and ap $2 a 1$ morphants (Figure 9I and Figure 9- figure supplement 2C). Together, these findings certify FCHO-BMP2K axis functions across vertebrates to regulate AP-2.

\section{Discussion}

344 GTPase-independent initiation mechanisms impose multiple layers of regulation in CME and mark it 345 different from other vesicular transport pathways (Ren et al., 2013; Nie et al., 2003; Umasankar et al., 346 2014; Hollopeter et al. 2014; Godlee and Kaksonen, 2013). Activation of AP-2 through hierarchical,

347 allosteric conformational modifications has been proposed a major regulatory mechanism that drives

348 CCV biogenesis (Kadlecova et al., 2017; Mettlen et al., 2018). Additionally, interplay of various

349 checkpoints at multiple stages of CCV biogenesis- initiation, cargo selection, maturation, and fission are 350 also suggested to ensure quality control of endocytosis such as incorporation of cargo into CCP before 351 maturation, disassembly of defective coated-pits etc. (Loerke et al., 2009; Mettlen et al., 2009; Aguet et 352 al., 2013). Recent investigations revealing functionally distinct conformations of AP-2 viz; closed (AP-

$\left.3532_{\text {close }}\right)$, open $\left(\mathrm{AP}-2_{\text {open }}\right)$, open+ $\left(\mathrm{AP}-2_{\text {open+ }}\right)$ and phosphorylated open+ $\left(\mathrm{AP}-2_{\text {phospho }}\right)$ provide valuable clues 354 about spatial subunit rearrangements in AP-2 activation. (Collins et al., 2002; Kelly et al., 2008; Jackson 355 et al., 2010; Kelly et al., 2014; Wrobel et al., 2019).

356 Our study proposes a model that consolidates recent findings and provides novel in vivo mechanisms to 357 define AP-2 activation (Figure 10). Here, we have identified two allosteric AP-2 activators viz; FCHO 
and BMP2K that entropically alter conformational equilibrium (Buchenberg et al., 2017; Wieteska et al., 2018) from cytosolic inactive AP-2 to membrane-bound phosphorylated AP-2 by co-ordinating a feedforward axis. We also show that this allosteric axis enables vectorial progression of CCV biogenesis. Spatial proteome analyses denote $\sim 80 \%$ of AP-2 is membrane bound in mammalian cells (Itzhak et al., 2016). Yet, a large pool of AP-2 remains unphosphorylated in FCHO knockout cells. These findings argue that FCHO must be functioning together with EPS15/R to allosterically drive the equilibrium from cytosolic inactive AP- $2_{\text {close }}$ to membrane active AP- $2_{\text {open }} / \mathrm{AP}-2_{\text {open+ }}$ (Ma et al., 2016; Traub, 2019). This equilibrium is further driven toward CCP maturation by downstream kinase that phosphorylates open+ state of AP-2 (Wrobel et al., 2019). Thus, absence of FCHO or kinase would perturb this axis and reverse the equilibrium leading to defects in cargo sorting, clathrin assembly and maturation (this study and Umasankar et al., 2014). kinases and novel regulatory mechanisms for AP-2 activation. Albeit, it appears that BMP2K can

371 associate with all conformations of AP-2, it is likely prone to ubiquitination and degradation in cytosol 372 and hence has a short half-life in cells (Lu and Hunter, 2009). Extremely low abundance of BMP2K in 373 HeLa cells observed in this study, low copy numbers of kinase assessed by proteomic analyses (Hein et 374 al., 2015; Itzhak et al., 2016) and presence of several possible ubiquitination sites on kinase domain 375 (Akimov et al., 2018) suggest this possibility. Thus, recruitment to CCP could extend the longevity of 376 kinase by protecting it from cytosolic E3 ubiquitin ligases (Piper et al., 2014). CCP recruitment pattern of 377 BMP2K further substantiates this idea. Despite having a long C-terminus ( 600 aminoacids) containing 378 an array of SLiMs to co-ordinate multitude of interactions (Sorkin, 2004), BMP2K binds mainly to AP-2 379 and appears to depend on AP-2 for CCP recruitment and stabilization. Lack of membrane-binding 380 domains (Itoh and De Camilli, 2006; Hurley, 2006) and presence of poly-glutamate (poly-Q) rich region 381 in kinase playing a definitive role in CCP recruitment implies unique trafficking route for BMP2K. PolyQ stretches are reported in many proteins but to our knowledge BMP2K (and AAK1) is the only 
endocytic protein identified in this category (Totzeck et al., 2017). Poly-Q tracts are predicted to play role in protein-protein interactions in a context dependent manner (Schaefer et al., 2012) and also in aggregation and accumulation of proteins leading to degenerative diseases (Orr and Zoghbi, 2007). Thus, our results argue a similar function for poly-Q tract in enhancing C-terminus-AP-2 interactions to accumulate and stabilize BMP2K at CCP. Hence, it is logical to conclude that decreasing the amount of membrane active AP-2, either by reducing gross AP-2 levels (AP-2 RNAi) or by inhibiting its allosteric activation (FCHO knockout cells), could retain BMP2K in cytosol for degradation. This mode of kinase regulation may have significance in providing spatio-temporal fidelity to AP-2 activation (Ghosh and

391 Kornfeld, 2003a). Thus, together with active cytosolic phosphatases (Ricotta et al., 2008), stringent regulation of kinases could prevent phosphorylation of AP-2 in the cytosol (Wrobel et al., 2019) that may lead to conformational changes unfavourable for subunit assembly (Gulbranson et al., 2019), membrane binding and activation (Ghosh and Kornfeld, 2003b). We assume that most of the BMP2K attributes are redundant to AAK1. It has been reported that clathrin activates AAK1, so could be similar for BMP2K (Jackson et al., 2003). However, C-terminus and SLiMs appear distinct in both kinases; hence recruitment and stabilization mechanisms may vary and are open for future investigations. morphology and status of CME in mammalian cells. According to our model, delay in $\mathrm{CME}$ in $B M P 2 K i$

400 cells may account for shift in equilibrium toward AP-2 conformations that can still bind cargo and 401 assemble clathrin but cannot couple downstream effectors of endocytosis viz; NECAP (Wrobel et al., 402 2019; Partlow et al., 2019). This could cause kinetic uncoupling of early and late stages of CCP formation 403 leading to delayed maturation and reduced CME (Nunez et al., 2011; Lampe et al., 2016). Alternatively, 404 accumulation of excess unphosphorylated AP-2 in kinase inactive CCPs could interfere with auxilin/ 405 Hsc70- dependent clathrin exchange during coat assembly leading to aberrant kinetic proofreading 406 controls of endocytosis (Avinoam et al., 2015; Chen et al. 2019). Another possibility is the activation of a compensatory endocytosis mechanism which could bypass sequential AP-2 activation events so as to 
408

409

410

411

412

413

414

415

416

417

418

419

420

421

422

423

424

425

426

427

428

429

430

431

432

ensure slow but steady actin-based endocytosis in HeLa cells (Leyton-Puig et al., 2017). Regardless, all these cases would result in deposition of excess AP-2 and immobile clathrin population on membrane giving rise to structures $>0.6 \mu \mathrm{m}^{2}$ as seen in this study as well as in previous studies (Umasankar et al., 2014; Ma et al., 2016; Traub., 2019). Since our current investigation is limited to qualitative analyses of endocytosis phenotypes, these possibilities are speculative and require future investigations to delineate precise mechanisms. However, such effects of kinase and AP-2 phosphorylation are very well consistent with our own results as well as with similar phenotypes observed in C. elegans mutants of related NIMA family of kinases (Yochem et al., 2015; Lazetic and Fay, 2017; Lazetic et al., 2018) or in mammalian cells upon depletion of late endocytic effectors (NECAP/ SNX9/ Amphiphysin) (Wrobel et al., 2019). Considering our speculations, BMP2K not correcting lattice morphology defects in FCHO knockout cells would argue AP-2 conformations that are not favourable for phosphorylation in these cells. Alternatively, in FCHO knockout cells, AP-2 may not fully open out and so cannot function regardless of phosphorylation status. Along with supporting these possibilities, reexpression of FCHO correcting defects associated with CCP morphology, AP-2 phosphorylation and function further reveals directionality and sequentiality of allosteric axis.

Though fundamentally similar, modalities of CME are different in invertebrates and vertebrates (McMahon \& Boucrot, 2011). 60\% of CME proteins have paralogs in vertebrates as compared to $12 \%$ in invertebrates (Dergai et al., 2016). Furthermore, AP-2 depletion is viable in C.elegans (Gu et al., 2013; Hollopeter et al., 2014), but embryonically lethal in zebrafish (Umasankar et al., 2012 and this study) and mice (Mitsunari et al., 2005). Mechanisms of allosteric regulation of AP-2 and its significance also reflect differently in C. elegans and mammals (Hollopeter et al., 2014; Umasankar et al., 2014; Beacham et al., 2018; Partlow et al., 2019; Wrobel et al., 2019). Our in vivo studies in zebrafish are consistent with mammalian cell-based results and show FCHO-BMP2K axis co-ordinates AP-2 activation during embryogenesis. Further, human FCHO2 and BMP2K can activate zebrafish AP-2 to drive CME implies allosteric axis is evolutionarily conserved across vertebrates. Perturbing the axis by silencing fcho 2 alone 
433 (this study) or together with $f$ chol (Umasankar et al., 2012) seem to affect only a subset of AP-2 functions

434 during embryonic development. This would argue FCHO-BMP2K axis independent in vivo activation

435 mechanisms, differential cargo sorting requirements (Kelly et al., 2008) or conformation-independent

436 functions (Gu et al., 2013) for AP-2 during embryogenesis. Thus FCHO and BMP2K appear to have

437 evolved their role in vertebrates as positive modulators of AP-2 function. Hence, we propose that by

438 inducing functionally distinct AP-2 conformations, FCHO-BMP2K axis provides a mechanism to link

439 CCP initiation with CCP maturation to control spatio-temporal mechanodynamics of CME in vertebrates.

440 Since $\mu \mathrm{T} 156$ residue is conserved in other clathrin adaptor protein complexes, it is tempting to speculate

441 similar feed-forward mechanisms for regulation of membrane trafficking events in various cellular

442 compartments. 


\section{Acknowledgements:}

444 PKU dedicates this manuscript to Prof. Linton Traub for being a great mentor and for providing endless

445 support and advice. PKU acknowledges Prof. M. Radhakrishna Pillai, Director, Rajiv Gandhi Centre for

446 Biotechnology, for lab facilities and support. PKU is thankful to Prof. Ajay Parida, Director, Institute of

447 Life Sciences for timely help with zebrafish facility. PKU thankfully acknowledges valuable suggestions

448 of Scientific Advisory Council, Rajiv Gandhi Centre for Biotechnology, Prof. Vijayalakshmi

449 Ravindranath and Prof. Balachandran Ravindran in this study. We are extremely grateful to Prof. Linton

450 Traub for graciously providing important reagents for this study. We thank Dr. T. R. Santhoshkumar and

451 Central Imaging Facility, RGCB for help with microscopy. We are grateful to Dr. Sachin Holkar for

452 helping us with quantitation of fluorescence confocal images. We acknowledge technical assistance of

453 Yedukrishnan M., Reshmi P. B. and Merlin Jeejo in the early stages of this work and also thank Anup

454 Biswal for maintaining zebrafish facility.

\section{Funding:}

456 This work was supported by Ramalingaswami Fellowship (BT/RLF/Re-entry/18/2014) of Department of

457 Biotechnology (DBT), Ministry of Science and Technology, Government of India awarded to PKU and

458 partly by the SERB-DST Core Research Grant (EMR/2016/007982) and RGCB intramural funds to PKU.

459 RKS is supported by DBT grant (6242-P64/RGCB/PMD/DBT/RJKS/2015), SERB-EMR

460 (EMR/2016/003780) and intramural funds from Institute of Life Sciences. SRT is supported by

461 University Grants Commission (UGC) and NKV is supported by RGCB for graduate research

462 fellowships.

463 Declaration of interests: The authors declare no competing interests. 


\section{Figure Legends}

465 Figure 1: AP-2 phosphorylation defects in 1.E cells lacking FCHO1/2. (A and B) Representative

466 confocal optical sections of the basal plane of parental HeLa SS6 cells (A-A”) and 1.E cells (B-B”)

467 pulsed with Alexafluor 488- transferrin (green) for 5 minutes followed by acid stripping (protocol \#2) and

468 immunolabeling with anti- AP-2 $\alpha$ subunit mAb AP.6 (red) and Hoechst DNA dye (blue) as indicated.

469 Images with all three colours merged are shown in A" and B". Scale bar- $10 \mu \mathrm{m}$. (C and D) SDS-PAGE

470 and immunoblot analysis of whole cell lysates from HeLa SS6 and 1.E. Gels were either stained with

471 Coomassie blue (upper panel in C) or transferred to nitrocellulose and probed with the indicated

472 antibodies. Low, intermediate and high exposures of autoradiographic films detecting large (BMP2K) and

473 small (BMP2Ks) isoforms of kinase are indicated. Molecular mass standards (in kDa) are shown on the

474 left.

475 Figure 2: BMP2K is a bona fide AP-2 kinase in cells. (A) Representative confocal optical section of the

476 basal plane of HeLa SS6 cells transfected with BMP2K-GFP (green), fixed and immunolabeled for

477 phosphorylated AP-2 (pT156 $\mu$, red) and AP-2 (blue). Colour separated channels of the boxed region are

478 shown on the right. Scale bar- $10 \mu \mathrm{m}$. (B) Bar graphs comparing the ratio of mean fluorescence intensities

479 of phosphorylated AP-2 (pT156 $\mu$ ) to total AP-2 in CCPs in transfected (BMP2K-GFP) versus

480 untransfected (Control) HeLa SS6 cells. Data represent mean SD of 29 cells analysed from 3 independent

481 experiments. (C) Immunoblot analysis of whole cell lysates from HeLa SS6 either DMSO or calyculin

482 treated or transfected with BMP2K or BMP2K-GFP as indicated. Blots are probed with the indicated

483 antibodies. (D) Immunoblot analysis of whole cell lysates from HeLa SS6 treated with either DMSO or

484 increasing concentrations of SGC-AAK1-1 for 2 hours. Blots are probed with the indicated antibodies.

485 (E) Immunoblot analysis of whole cell lysates from HeLa SS6 either mock transfected or transfected with

486 BMP2K-GFP and treated with either DMSO or increasing concentrations of SGC-AAK1-1 for 2 hours.

487 Blots are probed with the indicated antibodies. 
Figure 2- figure supplement 1: Phosphorylation of AP-2 increases in BMP2K overexpressed cells. Quantification of ratios of mean fluorescence intensities of phosphorylated AP-2 (pT156 $\mu$ ) to total AP-2 in CCPs. Graphs show mean SD of individual BMP2K-GFP transfected (BMP2K-GFP) or untransfected (Control) HeLa SS6 cells randomly picked from 5 confocal data sets.

Figure 3: CCP localization of BMP2K via C-terminal region. (A and B) Representative confocal optical sections of the basal plane of HeLa SS6 cells transfected with BMP2K-GFP (green) (A) or GFP-FCHO1 (green) (B), fixed and immunolabeled for AP-2 (red). Colour separated views of the boxed regions are shown on the right. (C) Schematic depiction of the overall domain organization of BMP2K (1-1161) and relative locations of the various $\mathrm{C}$-terminal GFP tagged truncation and deletion mutants of BMP2K tested. Efficiency of CCP localization of each mutant is marked. (D-G) Representative confocal images of HeLa SS6 cells transiently transfected with BMP2K $\Delta$ CT-GFP (D), BMP2KCT-GFP (E), BMP2K $\Delta$ Q/HGFP (F) and BMP2K $\triangle$ KD-GFP $(\mathbf{G})$. Fixed cells were stained for AP-2 and DNA. Colour separated channels of boxed regions are shown under each image. Scale bar- $10 \mu \mathrm{m}$.

Figure 3- figure supplement 1: BMP2K co-localizes with CME proteins. (A and B) Representative 502 confocal optical sections of the basal plane of HeLa SS6 cells transfected with BMP2K-GFP (green), 503 fixed and immunolabeled for the endocytic proteins, HRB (red) (A) or intersectin (B). Colour separated 504 channels of the boxed regions are shown on the right. Scale bar- $10 \mu \mathrm{m}$.

Figure 4: Reciprocal interactions of BMP2K and AP-2. (A) Cartoon diagram showing distribution of various short linear interacting motifs (SLiMs) on the distal (CT\#1) and proximal (CT\#2) segments of the BMP2K C-terminus. (B-D) Biochemical pull-down assays of Triton-X-100 lysates of HeLa SS6 cells with fixed concentrations of GST (B and C), GST-EPS15 (595-896) (B) increasing concentrations of GST- BMP2K-CT \#1, GST- BMP2K-CT \#2 (B), GST-BMP2K-KD, GST-BMP2K-Q/H (C) or with equal concentrations of GST, GST- $\alpha_{c}$ and GST- $\beta 2$ appendages (D). (E) Biochemical pull-down assays with 511 equal concentrations of GST and GST- $\alpha_{c}$ appendage and equal amounts of Triton-X-100 lysates of HeLa 512 SS6 cells expressing either BMP2KCT-GFP or BMP2K $\Delta$ CT-GFP. After pull down assays, samples of 
513

514

515

516

517

518

519

520

521

522

523

524

525

526

527

528

supernatant (S) and pellet (P) fractions were analysed on SDS-PAGE and either stained with Coomassie blue along with molecular mass standards (in $\mathrm{kDa}$ ) on the left as indicated (B-E, top panels) or transferred to nitrocellulose membrane and immunoblotted for the indicated proteins using specific antibodies (B-E, bottom panels).

Figure 5: AP-2 interaction is important for CCP recruitment, stabilization and function of BMP2K. (AB") Representative confocal optical sections of HeLa SS6 cells transfected with siRNA targeting AP-2 $\alpha$ subunit (A1 and A2). Cells were stained with anti- AP-2 $\alpha$ subunit mAb AP.6 (red) as indicated (A), after 2 minute pulse with Alexafluor488- transferrin (green) (B). Boxed regions of AP-2 containing (A', B') and AP-2 depleted (A”, B”) cells in the same field (A, B) are shown as enlarged and colour separated images on the right. (C and D) Representative confocal images of HeLa SS6 cells expressing BMP2KGFP. Mock transfected (C) or AP-2 $\alpha$ siRNA transfected (D) cells were labeled for AP-2 and DNA as indicated (C, D). Zoomed, colour separated and merged images of the boxed regions are displayed on the right. (E) Comparative immunoblot analysis of whole cell lysates of either mock transfected or AP-2 $\alpha$ siRNA transfected HeLa SS6 showing extent of AP-2 and BMP2K depletion. Blots are probed with the indicated antibodies. (F and G) Representative confocal sections of HeLa SS6 cells transiently transfected with either BMP2K-GFP $(\mathbf{F})$ or BMP2K $\Delta$ CT-GFP $(\mathbf{G})$ (green) and immunolabeled for phosphorylated AP-2 (pT156 $\mu$, red) and AP-2 (blue). Colour separated channels of the boxed region are enlarged and shown on the right. Scale bar- $10 \mu \mathrm{m}$.

Figure 6: Functional inactivation of BMP2K and FCHO shows temporally distinct CME phenotypes in HeLa cells. (A-C") Colour separated and merged channels from representative confocal images of HeLa SS6 cells treated with $10 \mu \mathrm{M}$ DMSO (Mock) (A-A"), $10 \mu \mathrm{M}$ SGC-AAK1-1 inhibitor (BMP2K $i)$ (B-B") for 2 hours or 1.E cells (C-C”), pulsed with Alexafluor488- transferrin (green), immunostained for AP-2 (red) to compare CCP morphology and endocytic efficiency. Scale bar- $10 \mu \mathrm{m}$. (D and E) Bar graphs represent quantification of number of AP-2 positive structures in each area category bin (previously classified based on size and dynamics as explained in Ma et al., 2016) per $\mu \mathrm{m}^{2}$ cellular area (D) or 
538

539

540

541

542

543

544

545

546

547

548

549

550

551

552

553

554

555

556

557

558

559

560

561

562

percentage of total AP-2 occupied by each bin size (color-coded) (E) in Mock or inhibitor treated $(B M P 2 K i)$ HeLa SS6 cells. Data represent mean SD from total cellular areas of mock $\left(30589.55 \mu \mathrm{m}^{2}\right)$ and $B M P 2 K i\left(28527.73 \mu \mathrm{m}^{2}\right)$.

Figure 6- figure supplement 1: Persistent CCP maturation defects in BMP2K inhibited cells. (A and B) Representative confocal optical sections showing separated and merged colour channels of HeLaSS6 cells treated with $10 \mu \mathrm{M}$ DMSO- Mock (A) or SGC-AAK1-1 inhibitor (BMP2Ki) (B) for 2 hours, pulsed with Alexafluor488- transferrin (green) for 10 minutes, stained for AP-2 (red) and DNA (blue). Scale bar- 10 $\mu \mathrm{m}$.

Figure 7: Differential effects of BMP2K and FCHO linker expression on CCP morphology and function in 1.E cells. (A- B") Representative confocal images of 1.E cells transiently transfected with BMP2KGFP (A-A”) or GFP-FCHO1 (1-609) (B-B”), pulsed with Alexafluor568- transferrin (pseudocolored grey) for 2 minutes, surface stripped and allowed to internalize for another 2 minutes (protocol\#3), and immunostained for AP-2 (blue). Single basal optical planes (A, A', B, B') or merged stack of several optical planes along Z-axis (A”, B”) are displayed. Scale bar- $10 \mu \mathrm{m}$. BMP2K-GFP and GFP-FCHO1 (1609) expressing cells are outlined (purple) in corresponding optical sections. (C and D) Quantification of number of AP-2 positive structures in each area category bin per $\mu \mathrm{m}^{2}$ cellular area (C) or mean fluorescence intensity of internalized transferrin (D) in 1.E, 1.E + BMP2K-GFP and 1.E + GFP-FCHO1 (1-609). Graphs show mean SD from total cellular areas analysed for 1.E $\left(12874.71 \mu \mathrm{m}^{2}\right), 1 . \mathrm{E}+\mathrm{BMP} 2 \mathrm{~K}-$ $\operatorname{GFP}\left(6740.73 \mu \mathrm{m}^{2}\right)$ and 1.E + GFP-FCHO1 (1-609) $\left(3716.3 \mu \mathrm{m}^{2}\right)$.

Figure 8: FCHO expression restores AP-2 phosphorylation in 1.E cells. (A-J) Representative single confocal optical sections of 1.E cells transiently transfected with GFP-FCHO1, fixed and immunolabeled for AP-2 (A and A') and phosphorylated AP-2 (pT156 $\mu$ ) (B and B'). Scale bar- $10 \mu \mathrm{m}$. GFP-FCHO1 expressing cells are outlined (purple) in corresponding optical sections. Colour separated and merged channels of the boxed regions from transfected and untransfected areas are displayed (C-J). (K) Bar graphs showing increase in mean fluorescence intensity ratio of phosphorylated AP-2 (pT156 $\mu$ ) to total 

mean SD from 14 cells.

Figure 9: FCHO, AP-2 and BMP2K co-ordinate CME functions during embryonic development. (A-D”) Representative bright field live images of control (A), 50 pg human (Hs) FCHO2 mRNA (B), 50 pg $H s$ $B M P 2 K$ mRNA (C), $50 \mathrm{pg} H s B M P 2 K \triangle C T$ mRNA (D) and $250 \mathrm{pg} H s B M P 2 K \Delta C T$ mRNA (D') injected D. rerio embryos at 30 hours post-fertilization (hpf). Enlarged images focusing the caudal region of embryos (A', B' and D”). Black arrows indicate different structures in the embryo E: eye, Y: yolk, YE: yolk extension, N: notochord, S: somites, HC: haematopoetic cells. Cyclopic eye phenotype is denoted with yellow arrow heads in $\mathbf{B}$ and $\mathbf{C}$. Colour coded as in $\mathbf{E}$. Scale bar- $250 \mu \mathrm{m}(\mathbf{E})$ Bar graphs showing quantification of normal (pale blue), mild (orange) and severe (brown) mRNA overexpression phenotypes. $n$ : number of embryos analysed. (F-I) Representative whole- mount in situ images showing mRNA expression patterns of no tail (top panels) and myoD (bottom panels) in 6- somite stage D.rerio embryos injected with control (F), ap2 morpholino targeting $\alpha$ subunit (ap2al MO) (G), fcho2 morpholino $(f c h o 2 \mathrm{MO})(\mathbf{H})$ or treated with SGC-AAK1-1 (BMP2Ki) (I) as indicated. A: anterior, P: posterior. Red brackets and yellow arrow heads indicate lateral and axial expression territory of markers respectively. Blue arrows denote adaxial cell boundary in myoD stained embryos. Colour coded as in 579 figure supplement-2C.

Figure 9- figure supplement 1: Analogous expression pattern of AP-2 and BMP2K during embryonic development. (A-C) Whole mount in situ analysis showing bmp2k (A), ap2al (B) and dusp6 (C) transcript localization in wild-type $D$. rerio embryos at the indicated maternal and zygotic developmental stages.

Figure 9- figure supplement 2: Embryonic defects in AP-2 morphants. (A-B') Representative bright

585 field live images showing comparative morphology of control (A) and ap2al morphant (B) D. rerio 586 embryos in clusters at 9 hpf. Dead or dying embryos (red arrows) during epiboly due to yolk extrusion 587 through the blastopore (red arrow heads) are indicated. Zoomed images indicate morphology of typical 
normal (A') and category-1 morphants (B'). Colour coded as in C. (C) Bar graphs showing quantification of normal (pale blue), and loss-of-function phenotypes belonging to category-1 (dark blue) that show epiboly defects and category-2 (pale green) that show convergent extension defects (CE) $n$ : number of embryos analysed. (D and E) Representative phase- contrast images of cells isolated and cultured from epiboly stage D. rerio embryos injected with control (D) or ap2al (E) morpholinos. Yellow arrow heads denote difference in cell morphology and adherence in control and ap $2 a 1$ morphants. Scale bar- $50 \mu \mathrm{m}$

Figure 10: Schematic model depicting role of allosteric FCHO-BMP2K axis in AP-2 activation. FCHO proteins together with EPS15/R allosterically drive the AP-2 equilibrium from cytosolic closed state (AP-

601 late effector proteins.

\section{Materials and Methods}

\section{Molecular cloning and constructs}

604 Sequences encoding human BMP2K (1-1161), BMP2K (1- 560) and BMP2K (561-1161) were PCR amplified from the template ORF clone \# RC215795 (Origene) and inserted into HindIII restriction site of pEGFP-N1 vector using In-Fusion cloning technology (Clontech) to generate BMP2K-GFP, BMP2K $\triangle \mathrm{CT}-\mathrm{GFP}$ and BMP2KCT-GFP respectively. Cloning of PCR amplified BMP2K (1-345) or BMP2K (346-560) into an upstream in-frame NheI site in the BMP2KCT-GFP construct yielded $\mathrm{BMP} 2 \mathrm{~K} \Delta \mathrm{Q} / \mathrm{H}-\mathrm{GFP}$ or BMP2K$\Delta \mathrm{KD}-\mathrm{GFP}$ respectively. GFP-FCHO1 and GFP-FCHO1 (1-609) were

610 designed as described previously (Umasankar et al., 2014). Constructs encoding BMP2K regions fused to

611 N-terminal GST viz; GST-BMP2K-KD (38-345), GST- BMP2K-Q/H (346-560), GST-BMP2K-CT\#1

612 (561-850) and GST-BMP2K CT\#2 (851-1161) were generated by the insertion of corresponding PCR 
613

614

615

616

617

618

619

620

621

622

623

624

625

626

627

628

629

630

631

632

633

634

635

636

637

amplicons between EcoRI and NotI restriction sites in pGEX-4T-1 vector through directional cloning.

GST-rat $\beta 2$ appendage (701-937), GST-mouse $\alpha_{C}$ appendage (701-938) and GST-human EPS15 (595-

896) have been described previously (Umasankar et al., 2012). pCS2- Hs BMP2K and pCS2- Hs FCHO2

were generated by cloning human BMP2K (1-1161) and human FCHO2 (1-810) (Dharmacon) coding sequences respectively into the $E c o R I$ site of $\mathrm{pCS}^{+}$vector using In-Fusion cloning. Introducing stop codon at residue 561 in pCS2- Hs BMP2K plasmid using QuikChange site-directed mutagenesis (Agilent Technologies) yielded pCS2- $H s$ BMP2K $\Delta \mathrm{CT}$. All constructs were verified by automated dideoxynucleotide sequencing (Eurofins). Complete details of sequences and plasmid maps are available upon request.

\section{Cell culture and transfections}

The authenticated and validated parental HeLa SS6 cell line (Umasankar et al., 2014, Traub 2019) was a kind gift from Prof. Linton Traub. HeLa clone \#64/1.E (1.E cells) was generated previously by bi-allelic disruption of the FCHO2 and FCHO1 gene loci using TALEN gene-editing technology (Umasankar $e t$ al., 2014). HeLa SS6 and 1.E cells were cultured in complete medium-Dulbecco's modified Eagle's medium (DMEM, Hyclone) supplemented with 10\% fetal bovine serum (FBS, Gibco) and $2 \mathrm{mM} \mathrm{L-}$ glutamine (Gibco) and were maintained at $37^{\circ} \mathrm{C}$ in a $\mathrm{CO}_{2}$ incubator (Thermo scientific) under $5 \% \mathrm{CO}_{2}$. Cells were passaged at $90 \%-100 \%$ confluence and were periodically checked for mycoplasma contamination using commercially available kits.

For all transfections, HeLa SS6 or 1.E cells were seeded into $35 \mathrm{~mm}$ tissue culture dishes or 6 well tissue culture plates (Eppendorf) with or without pre-cleaned, $12 \mathrm{~mm}$ round sterile glass coverslips, one day before transfection and were grown in complete medium at $37^{\circ} \mathrm{C}$ under $5 \% \mathrm{CO}_{2}$. All transfections were done when cells reached 50\%- 60\% confluence. Transfected cells grown on coverslips were used for endocytosis assays and immunofluorescence, whereas those in dishes without coverslips were lysed for immunoblotting. Endotoxin-free miniprep or midiprep plasmid DNA transfections were performed using Lipofectamine 2000 (Invitrogen). On the day of transfection, $6 \mu$ l Lipofectamine 2000 was added to 0.5- 
638

639

640

641

642

643

644

645

646

647

648

649

650

651

652

653

654

655

656

657

658

659

660

661

$1.0 \mu \mathrm{g}$ plasmid DNA diluted in $375 \mu \mathrm{l}$ Opti-MEM I Reduced Serum medium (Gibco) to make a

transfection mixture and incubated for 40 minutes at room temperature (RT). This transfection mixture

was added drop wise to cells replenished with $1.5 \mathrm{ml}$ fresh complete medium. Cells were further grown at $37^{0} \mathrm{C}, 5 \% \mathrm{CO}_{2}$ for $18-24$ hours post-transfection, and were used for various experiments.

\section{RNAi and inhibitor treatments}

RNAi experiments were performed by knocking down the gene targets in HeLa SS6 cells growing in 35 mm cell culture plates with two rounds of siRNA transfections using Oligofectamine (Invitrogen) as described (Motley et al., 2003). Custom synthesized siRNA (10 nmol) and siGENOME SMARTPOOL siRNA (5 nmol) oligonucleotides (Key Resources Table) were obtained from Dharmacon and resuspended in $1 \mathrm{X}$ siRNA buffer (Dharmacon) to make $20 \mu \mathrm{M}$ stock. On Day-1, $10 \mu \mathrm{l}$ siRNA stock solution was diluted in $175 \mu$ l Opti-MEM I in a sterile microfuge tube. $5 \mu$ l Oligofectamine was diluted in $10 \mu \mathrm{l}$ Opti-MEM I in a separate tube. After incubating for 10 minutes at RT, solutions in two tubes were mixed and incubated for another 20 minutes at RT for transfection- complex formation. Meanwhile, 800 $\mu 1$ Opti-MEM I was added into each dish after removing complete medium. $200 \mu 1$ transfection mix was added drop wise into each dish and cells were incubated for 4- 6 hours post-transfection in serum freemedium. Then, $500 \mu \mathrm{l}$ opti-MEM I containing 30\% FBS was added into cells and incubated for another 18-24 hours at $37^{\circ} \mathrm{C}$ in 5\% CO2 atmosphere. On Day-2, transfected cells were trypsinized and seeded into new dishes in duplicates or triplicates for second round of knockdown. On Day-3, second round of siRNA transfections were performed in the same fashion. On Day-4, cells were ready for various experiments. Co-transfection of plasmid DNA was performed along with second round of siRNA transfections using Lipofectamine 2000 instead of Oligofectamine. All RNAi experiments were repeated at least three times and each experiment included control dishes with mock transfected cells that received all reagents except siRNA. Each set of experiments were analyzed for knockdown efficiency by comparing the levels of target gene expression in mock and RNAi samples through immunoblotting. 

experiments as mentioned in the text. HeLa SS6 cells in culture dishes received a final concentration of $50 \mathrm{nM}$ calyculin for 1 hour or $10 \mu \mathrm{M}$ SGC-AAK1-1- for 2 hours in complete medium at $37^{0} \mathrm{C}, 5 \% \mathrm{CO}_{2}$. Control dishes with mock treated cells were included in all experiments that received same concentration of DMSO for the same time period as cells in experimental dishes. Calyculin treatment caused cells to

667 round up and detach from the substratum. After treatment, cells were stripped from dishes using Non668 enzymatic Cell Dissociation Solution (Sigma) at RT and collected into microfuge tubes on ice. PBS

669 containing calyculin or SGC-AAK1-1 or DMSO was used to rinse corresponding dishes and pooled with

670 Cell Dissociation solution in respective tubes. Cells were pelleted by centrifuging at $500 \times g_{\max }$ for 5

671 minutes at $4^{0} \mathrm{C}$. After discarding the supernatant, cell pellets were resuspended in pre-heated SDS-

672 Laemmli buffer. Alternatively, cells grown on coverslips, incubated for one hour with complete medium 673 followed by another hour with starvation medium, both containing appropriate concentrations of SGC-

674 AAK1-1 or DMSO were used directly for endocytosis assays.

\section{Endocytosis assays}

676 Endocytosis assays were performed using three different protocols. In all protocols, cells growing on 677 coverslips in complete medium (DMEM, 10\% FBS, $2 \mathrm{mM} \mathrm{L-glutamine)} \mathrm{at} 37^{\circ} \mathrm{C}$ in $5 \% \mathrm{CO} 2$ atmosphere 678 were first starved by incubating in starvation medium (DMEM, 25mM HEPES, pH-7.2, 0.5\% BSA, 2mM 679 L-glutamine) for 1 hour. This will undock bound apo-transferrin from cell surface transferrin receptors 680 thereby making the receptors available for fluorescent transferrin binding. After removing the starvation 681 medium, cells were subsequently pulsed at $37^{\circ} \mathrm{C}$ for different time points with $25 \mu \mathrm{g} / \mathrm{ml}$ Alexa flour- 488 682 or- 568- conjugated human transferrin (Invitrogen, ThermoFisher Scientific) reconstituted in starvation 683 medium and clarified by centrifugation at $15,000 \times \mathrm{g}_{\max }$ at $4^{0} \mathrm{C}$ for 10 minutes. In protocol \#1, after a 2

684 minute or 10 minute pulse at $37^{\circ} \mathrm{C}$, cells were immediately transferred on ice, washed three times with 685 ice-cold PBS and fixed with 2\% paraformaldehyde (Electron Microscopy Sciences) for 20 minutes at RT. 686 In protocol \#2, after 5 minute pulse, cells were washed three times with stripping buffer $(0.2 \mathrm{M}$ acetic 
687

688

689

690

691

acid, 0.2 M sodium chloride, $\mathrm{pH}$ 2.5) on ice to remove surface- bound pool of transferrin and fixed with paraformaldehyde. In protocol \#3, a modified endocytosis assay was used. In this assay, after 2 minute pulse of fluorescent transferrin at $37^{\circ} \mathrm{C}$, cells were surface stripped with stripping buffer on ice as in protocol \#2. Then, cells were rewarmed to $37^{\circ} \mathrm{C}$ for another 2 minutes to continue endocytic transport before paraformaldehyde fixation (Reis et al., 2015; Ma et al., 2016).

\section{Immunofluorescence analysis}

Immunofluorescence analysis was performed as described (Umasankar et al., 2014; Ma et al., 2016).

Paraformaldehyde fixed cells on $12 \mathrm{~mm}$ round glass cover slips were washed three times in ice-cold PBS.

Then, cells were blocked and permeabilized by incubating in $10 \%$ normal goat serum (Himedia), $0.2 \%$ saponin (Sigma) in PBS at RT for 30 minutes. Primary antibodies at appropriate concentrations were diluted in antibody dilution buffer (10\% normal goat serum, $0.05 \%$ saponin in PBS) and centrifuged at15,000 x $g_{\max }$ for 10 minutes before adding into permeabilized cells. Primary antibody incubation was for 1 hour at RT followed by three washes with PBS. Anti-mouse/ rabbit secondary antibodies conjugated with the fluorophores- Alexafluor 488/568/647 (Invitrogen, ThermoFisher Scientific and Cell Signaling Technologies) were diluted 1:500 in antibody dilution buffer and were clarified by centrifugation. After secondary antibody incubation for one hour at RT in the dark, cells were washed three times with ice-cold PBS. Cells were further incubated with $1 \mu \mathrm{g} / \mathrm{ml}$ Hoechst 33342 DNA dye (Invitrogen, ThermoFisher Scientific) for 10 minutes at RT and washed twice with ice-cold PBS before mounting onto glass slides with $5 \mu$ l Fluoromount-G mounting medium (Electron Microscopy Sciences).

\section{Confocal Microscopy and Image Processing}

Images were acquired using Nikon A1R Eclipse Ti Confocal Laser Scanning Microscope equipped with Plan Apo VC 60x oil objective, NA- 1.4. Different lasers were used to excite fluorophores at various wavelengths - $405 \mathrm{~nm}$ laser for Hoechst, $488 \mathrm{~nm}$ laser for Alexa Fluor 488, the $561 \mathrm{~nm}$ laser for Alexa Fluor 568 and $638 \mathrm{~nm}$ laser for Alexa Fluor 647 as programmed in the Nikon NIS Elements software. Emission signals from different channels were collected as 1024 x 1024 pixel images in sequential scan 
712

713

714

715

716

717

718

719

720

721

722

723

724

725

726

727

728

729

730

731

732

733

734

735

736

mode with line averaging function. Z- stacks were obtained by sequential scans of $0.3 \mu \mathrm{m}$ step size between each optical section and were merged to obtain max-Z projection. All images were saved in nd2 format and later converted to TIFF files using NIS Elements software. All images were equally cropped, adjusted and processed in Adobe Photoshop CS3 for better visualization, arranged and labelled in Adobe Illustrator CS6.

\section{Quantitation of confocal micrographs}

Quantitation of fluorescence confocal images was done as described previously (Ma et al., 2016) using Nikon NIS Elements AR 3.2 analysis package and Fiji (ImageJ). Before analysis, confocal optical sections of single plane or Z-stacks for AP-2, pT156 $\mu$ or transferrin channels were deconvoluted using AutoQuant X3-2D/ 3D deconvolution software and merged into single maximum projection images.

Images of individual cells to be analyzed were dissected out from the whole field by creating region-ofinterests (ROI), converted to binary images by thresholding and background subtraction. Single cell masks were generated from binay images and were used to analyze size (area) or fluorescent intensity of objects in the background corrected raw images for corresponding original channels. For CCP morphology analysis, objects were binned into area- based categories as described previously (Ma et al., 2016) and as explained in the figure legends. Area in pixels was converted to $\mu \mathrm{m}^{2}(1$ pixel $=0.1 \mu \mathrm{m})$ and used in all calculations. In all analysis, total cellular areas were measured from ROIs to determine density and mean intensity per $\mu \mathrm{m}^{2}$. Mostly, images from 3 independent experiments were separately analysed before compiling the data. Data was compiled and analyzed in Microsoft Excel and graphs were plotted in GraphPad Prism.

\section{Recombinant protein expression and purification}

Control GST and GST-fusion proteins were expressed through pGEX-plasmids in E.coli BL21 codon plus RIL strains and purified using standard procedure (Umasankar et al., 2012; Umasankar et al., 2014; Ma et al., 2016). Large volumes of 2x YT media (Sigma) inoculated with overnight grown bacterial culture was grown at $37^{\circ} \mathrm{C}$ till absorbance $\mathrm{A}_{600}$ reaches $\sim 0.6$ and induced with $100 \mu \mathrm{M}$ IPTG for 4 hours at 
737

738

739

740

741

742

743

744

745

746

747

748

749

750

751

752

753

754

755

756

757

758

759

760

761

$22^{\circ} \mathrm{C}$. Bacterial pellets were collected by centrifugation at $15,000 \times \mathrm{g}_{\max }$ at $4^{0} \mathrm{C}$ for 10 minutes and frozen at $-80^{\circ} \mathrm{C}$. Frozen pellets were resuspended in ice-cold bacterial lysis buffer (50 mM Tris-HCl, $\mathrm{pH}-8.0$, $300 \mathrm{mM}$ sodium chloride, $10 \mathrm{mM} \beta$-mercaptoethanol and $0.2 \%(\mathrm{v} / \mathrm{v})$ Triton X-100) containing $1 \mathrm{mM}$ PMSF (Sigma) on ice. After disrupting cells with five pulses of sonication using a Vibracell microprobe sonicator (Sonics) at an interval of 1 minute between each pulse, the lysate was centrifuged at 15,600 $\mathrm{x}$ $\mathrm{g}_{\max }$ at $4^{0} \mathrm{C}$ for 30 minutes. The clarified supernatant was mixed with Glutathione Sepharose (GE Life Sciences) beads and incubated with continuous mixing for 2 hours at $4{ }^{0} \mathrm{C}$ on a tube nutator. Beads were collected at $500 \times g_{\max }$ at $4^{0} \mathrm{C}$ and washed four times with ice-cold PBS. Bound protein was eluted three times in Elution Buffer- $25 \mathrm{mM}$ Tris- $\mathrm{HCl}, 250 \mathrm{mM}$ sodium chloride, $10 \mathrm{mM}$ reduced glutathione (Sigma) and $2 \mathrm{mM}$ DTT on ice. After assessing purity and yield of eluted proteins on SDS-PAGE, the elutions were pooled and dialysed overnight in PBS. Final protein concentrations were determined using Bradford method with BSA as standard. All purified proteins were aliquoted and stored at $-80^{\circ} \mathrm{C}$ until further use.

\section{GST pull-down assays and Immunoblotting}

HeLa SS6 cell lysate (prey) for GST- pull down assays were made as described (Umasankar et al., 2012; Umasankar et al., 2014; Ma et al., 2016). Briefly, HeLa SS6 or 1.E cells grown in several $10 \mathrm{~cm}$ tissue culture plates were trypsinized at confluence and pooled into $50 \mathrm{ml}$ polypropylene tubes. Cell pellets were recovered by centrifugation at $1000 \mathrm{x} \mathrm{g}_{\max }$ at $4^{0} \mathrm{C}$ for 10 minutes, washed once with PBS and directly resuspended in ice-cold Cell Lysis Buffer- 25 mM HEPES-KOH, pH 7.2, 125 mM potassium acetate, 5 mM magnesium acetate, 2 mM EDTA, 2 mM EGTA, 2 mM DTT and 1\% Triton X-100 containing cOmplete EDTA- free Protease Inhibitor Cocktail on ice. The suspension was incubated on ice for 30- 45 minutes with occasional mixing and sonicated for 10 seconds. After centrifugation at $20,000 \times g_{\max }$ for 30 minutes to remove insoluble material, the clarified cell lysate was stored in frozen aliquots at $-80^{\circ} \mathrm{C}$.

In pull-down assays, appropriate concentrations of GST or GST- fusion protein was immobilized on $30 \mu 1$ Glutathione Sepharose beads (bait) in microfuge tubes containing $750 \mu 1$ PBS by continuous up-down mixing at $4^{0} \mathrm{C}$. After 2 hours mixing, the beads were recovered at $10,000 \times \mathrm{g}_{\max }$ for 1 minute and were 
762

763

764

765

766

767

768

769

770

771

772

773

774

775

776

777

778

779

780

781

782

783

784

785

786

washed twice with ice-cold assay buffer (25 mM HEPES-KOH, pH 7.2, $125 \mathrm{mM}$ potassium acetate, 5 $\mathrm{mM}$ magnesium acetate, $2 \mathrm{mM}$ EDTA, $2 \mathrm{mM}$ EGTA) containing $2 \mathrm{mM}$ DTT. After second wash, supernatant was completely removed and beads were resuspended in $250 \mu$ l clarified cell lysate (prey) diluted in assay buffer. Beads were further incubated for 1 hour at $4^{0} \mathrm{C}$ with up-down mixing and recovered by centrifugation at $10,000 \times \mathrm{g}_{\max }$ for 1 minute at $4^{0} \mathrm{C}$. After storing $60 \mu \mathrm{l}$ (supernatant fraction), rest of the supernatant was carefully discarded. The assay was terminated by washing the beads (pellet fraction) twice with ice-cold PBS containing $0.2 \%$ Triton-X-100, followed by two washes with only PBS. For pull down assays with AP-2 core, a modified assay buffer (assay buffer with 25 mM Tris$\mathrm{HCl}, \mathrm{pH}-7.2,0.2 \%$ Igepal CA-630 and $10 \mathrm{mM}$ DTT) was used. $250 \mu \mathrm{l}$ clarified prey containing $25 \mu \mathrm{g} /$ $\mathrm{ml}$ purified AP-2 core and $0.1 \mathrm{mg} / \mathrm{ml} \mathrm{BSA}$ in modified assay buffer was added to the immobilized bait. Supernatant and pellet fractions were recovered in a similar fashion. After final wash with PBS, SDSLaemmli buffer was added to both pellet and supernatant fractions to make a final volume of $80 \mu 1$. Supernatant and pellet fractions were resolved on SDS-PAGE and gels were either stained with Coomassie blue or transferred to nitrocellulose membrane for immunoblotting. Blots were blocked in $5 \%$ non-fat dried milk powder in TBST at RT, and then incubated with primary antibodies diluted in $1 \%$ milk-TBST for 1-2 hours at RT. After washing with TBST, blots were incubated with 1: 5000 dilution of HRP- conjugated anti-mouse/ rabbit IgG secondary antibodies (Bio-Rad) in 1\% milk-TBST for another hour. Blots were then washed in TBST and the bands were developed with Amersham ECL (GE Life Sciences) or Clarity ECL (Bio-Rad) western blotting substrates using autoradiography.

\section{Zebrafish maintenance and husbandry}

Danio rerio $\mathrm{AB}$ strains were maintained under standard conditions in accordance with guidelines for use, care and maintenance of experimental animal models and with Institutional Animal Ethical Committee (IAEC) approval. Typically, male and female fishes were grown in multilinked aquatic units (Techniplast) equipped with circulating water at $28.5^{\circ} \mathrm{C}$ and at $\mathrm{pH} 7.5$. Photoperiodicity was set with 14 hours light, 10 hours dark cycle; fishes were provided standard fish food. Male and female fishes from the 
787

788

789

790

same batch were separated overnight in breeding tanks and were mixed together to mate and spawn on the day of experiment. Fertilized embryos from natural matings were obtained in batches and were developmentally staged for various experiments. Atleast two weeks of interval was given in between each breeding cycle to avoid stress to same batch of male and female fishes.

\section{In vitro transcription, morpholinos and microinjections}

pCS2+ vertebrate expression vectors containing human- BMP2K, BMP2K $\Delta \mathrm{CT}$ or FCHO2 coding sequences were used as templates to synthesize capped mRNAs for ectopic expression and rescue experiments. Capped mRNAs were synthesized by in vitro transcription reaction from linearized pCS2+ constructs using SP6 mMessage mMachine kit (Ambion) by following vendor's instructions. Each in vitro transcribed mRNA was extracted with equal volume of phenol/ chloroform and precipitated with chilled isopropanol. Precipitated RNA pellet was dissolved in 10- $20 \mu 1$ nuclease free water (Ambion). After spectrophotometric estimation of concentration, each capped mRNA was stored as aliquots at -800C until used for microinjections.

Translation blocking ATG specific morpholinos were custom synthesized by Gene tools to silence $D$. rerio fcho 2 and ap-2al genes (Key Resource Table) through anti-sense technology as described (Umasankar et al., 2012). Standard control morpholino oligonucleotide was also obtained from Genetools and was used as injection control in various experiments. Lyophilized morpholinos obtained from Genetools were reconstituted in $300 \mu \mathrm{l}$ nuclease free water to obtain $1 \mathrm{mM}$ final stock solutions and were stored as frozen aliquots.

D. rerio embryos at one-cell stage were used for all microinjections. Typically, $1 \mathrm{nl}$ of morpholino or mRNA diluted in nuclease- free water at desired concentrations were microinjected into the yolk along with $1 \%$ phenol red dye using FemtoJet microinjector (Eppendorf) . Microinjections for rescue experiments were performed as two separate sets with initial mRNA injections followed by morpholino injections in the same embryo. Each experiment was repeated in three separate biological replicates to get 
statistically significant numbers to validate our observations. Each time, embryos from the same clutch were used as controls for comparing morphological and molecular parameters. After injections, the embryos were incubated in $\mathrm{E} 3$ embryo medium $(5 \mathrm{mM} \mathrm{NaCl}, 0.17 \mathrm{mM} \mathrm{KCl}, 0.33 \mathrm{mM} \mathrm{CaCl} 2,0.33 \mathrm{mM}$ $\mathrm{MgSO} 4,0.01 \%$ methylene blue) at $28.5^{\circ} \mathrm{C}$ until the desired stage. Unfertilized embryos from both control and experimental samples were identified by microscopic analysis and were removed in all experiments.

\section{In vivo pharmacological experiments}

817 Since pharmacological manipulations in the maternal stages are lethal to developing embryos, we used 818 embryos after $\sim 6 \mathrm{hpf}$ (shield stage) for inhibitor treatments. Embryos from the same clutch were 819 collected and distributed into 24 well plates ensuring that each well receives equal number (ten embryos 820 per well) and that biological samples in triplicates are available for each concentration of inhibitor tested.

821 Triplicates of control samples treated with DMSO were included for each concentration of inhibitor in all experiments. $50 \mathrm{mM}$ stock of SGC-AAK1-1 (AAK1/ BMP2K inhibitor, Tocris) prepared in DMSO was diluted in E3 medium and was used for all experiments. Initially, a pilot assay was performed to normalize the exact concentration of SGC-AAK1-1 to be used for all the experiments. Briefly, embryos were treated with $1,2,5,10,25$ and $50 \mu \mathrm{M}$ concentrations of SGC-AAK1-1 from $6 \mathrm{hpf}$ to $16 \mathrm{hpf}$ and were screened for convergent extension (CE) defects by morphological analysis. $10 \mu \mathrm{M}$ concentration of

827 the drug showed specific CE phenotype in all embryos tested and concentrations above showed high precipitation of SGC-AAK1-1 in E3 medium. Hence, a concentration of $10 \mu \mathrm{M}$ was selected for all experiments. Control embryos and embryos treated with SGC-AAK1-1 were subjected to whole-mount in situ hybridization with molecular markers to confirm CE defects.

\section{Riboprobe synthesis and whole mount in situ hybridization (WISH):}

832 Total RNA was isolated from maternal and zygotic stages of D. rerio embryos using TRIzol reagent

833 (ThermoFisher Scientific). Single strand cDNA was synthesized from the mRNA fraction of the total

834 RNA by using Oligo dT primer and Superscript III First-Strand Synthesis System for RT-PCR

835 (Invitrogen, ThermoFisher Scientific) according to manufacturer's instructions. This cDNA was used as 
837 specific primers for D. rerio bmp $2 k$, ap2al and dusp6 resulted in amplicons of $\sim 1 \mathrm{~kb}$ size. These

838 amplicons were cloned into pCR Blunt II-TOPO vector. After sequence verification of the clones,

839 plasmids were linearized using compatible restriction enzymes and directly used for riboprobe synthesis.

840 Plasmids containing genes for no tail and myo $D$ were generously provided by Michael Tsang. Riboprobe

841 synthesis for WISH was carried out with the linearized plasmid using digoxigenin (DIG) RNA labelling

842 mix and T7 RNA polymerase (Roche) according to manufacturer's recommendations. WISH was

843 performed by standard procedures as described (Umasankar et al., 2012). Briefly, embryos at appropriate

844 developmental stages, with or without chorion, were fixed in $4 \%$ paraformaldehyde for 30 minutes at RT

845 and then at $4^{0} \mathrm{C}$ overnight, washed with PBS and stored in methanol at $-20^{\circ} \mathrm{C}$. The embryos were brought

846 back to PBS-Tween 20, treated with Proteinase-K and incubated in pre-hybridization buffer for 2-4 hrs.

847 The embryos were hybridized with respective DIG-labelled antisense probes overnight at $65^{\circ} \mathrm{C}$. The

848 embryos were washed extensively, blocked with blocking reagent (Roche/Merk) and incubated with anti-

849 DIG antibody conjugated with alkaline phosphatase (AP). BM purple (Roche/Merck) was used as a

850 chromogenic substrate of AP for detecting the gene expression. The reaction was stopped by washing the

851 embryos in PBS several times. Finally, the embryos were mounted in glycerol for imaging.

\section{Embryonic cell culture}

853 D. rerio embryonic cell culture was carried out as described (Westerfield M, 2000). Embryos at $\sim 5$ hpf

854 were collected and decontaminated by treating with $0.05 \%$ bleach in E3 medium. After de-chorionation

855 with $2 \mathrm{mg} / \mathrm{ml}$ Pronase (Sigma) solution in E3, embryos were rinsed in sterile calcium- free Ringer's

856 solution (116 mM NaCl, $2.9 \mathrm{mM} \mathrm{KCl}, 5 \mathrm{mM}$ HEPES, $\mathrm{pH}$-7.2). 50 embryos were pooled in a tissue

857 culture plate and were smashed to dissociate embryonic cells by dropping a sterile coverslip on them. The

858 dissociated embryonic cells were pooled into a microfuge tube in sterile calcium- free Ringer's solution

859 and the suspension was centrifuged at $300 \times g_{\max }$ for 7 minutes. After removing supernatant, the pellet

860 was further triturated through a sterile narrow-bore Pasteur pipette to resuspend the cells. Embryonic cells 
861 were washed twice with embryonic cell growth medium- L-15 (Sigma), $0.3 \mathrm{mg} / \mathrm{ml}$ L- glutamine, 50U/ml

862 penicillin, $0.05 \mathrm{mg} / \mathrm{ml}$ streptomycin and $0.8 \mathrm{mM} \mathrm{CaCl} 2$ and resuspended in the same medium containing

$86310 \%$ embryo extract and 3\% fetal bovine serum. Embryonic cells were plated on sterile glass coverslips

864 coated with $10 \mu \mathrm{g} / \mathrm{ml}$ laminin (Corning) and grown in six well plates at $28^{\circ} \mathrm{C}$, without $\mathrm{CO}_{2}$ atmosphere.

\section{In vivo imaging of embryos}

866 For live in vivo imaging, D. rerio embryos with or without chorion were mounted in $3 \%$ methylcellulose

867 (Sigma) in a small petri dish. Embryos at $30 \mathrm{hpf}$ were temporarily anaesthetized by overlaying with E3

868 containing $0.016 \%$ tricaine to prevent movement during imaging. After orienting laterally, embryos were

869 imaged on Leica MZ16 stereo microscope using Leica LAS X software. For WISH imaging, fixed

870 embryos stained with chromogenic AP substrates were mounted on glycerol in cavity slides and oriented

871 to obtain lateral view. The images were captured with Leica MZ16 stereo microscope. Embryonic cells

872 growing on laminin- coated coverslips were imaged live on a Leica fluorescent microscope using 10x and

$87320 x$ objectives in phase contrast mode. 


\section{Key Resources table}

\begin{tabular}{|c|c|c|c|c|}
\hline $\begin{array}{l}\text { Reagent type } \\
\text { (species) or } \\
\text { resource }\end{array}$ & Designation & $\begin{array}{l}\text { Source or } \\
\text { reference }\end{array}$ & Identifiers & Additional information \\
\hline $\begin{array}{l}\text { Gene (Homo } \\
\text { sapiens) }\end{array}$ & $\mathrm{FCHOI}$ & Uniprot & O14526 & FCH domain only protein 1 \\
\hline $\begin{array}{l}\text { Gene }(H . \\
\text { sapiens })\end{array}$ & $\mathrm{FCHO} 2$ & Uniprot & Q0JRZ9 & FCH domain only protein 2 \\
\hline $\begin{array}{l}\text { Gene }(H . \\
\text { sapiens })\end{array}$ & $A P 2 A 1$ & Uniprot & O95782 & AP-2 complex subunit alpha-1 \\
\hline $\begin{array}{l}\text { Gene }(H . \\
\text { sapiens })\end{array}$ & $A P 2 B 1$ & Uniprot & P63010 & AP-2 complex subunit beta \\
\hline $\begin{array}{l}\text { Gene }(H . \\
\text { sapiens })\end{array}$ & $A P 2 M 1$ & Uniprot & Q96CW1 & AP-2 complex subunit mu \\
\hline $\begin{array}{l}\text { Gene }(H . \\
\text { sapiens })\end{array}$ & $B M P 2 K$ & Uniprot & Q9NSY1 & BMP-2-inducible protein kinase \\
\hline $\begin{array}{l}\text { Gene }(H . \\
\text { sapiens })\end{array}$ & $A A K 1$ & Uniprot & Q2M2I8 & AP2-associated protein kinase 1 \\
\hline $\begin{array}{l}\text { Gene (Danio } \\
\text { rerio) }\end{array}$ & $\begin{array}{l}\text { fcho2 } \\
\text { (zgc:112167) }\end{array}$ & Uniprot & Q502I9 & FCH domain only protein 2 \\
\hline $\begin{array}{l}\text { Gene }(D . \\
\text { rerio) }\end{array}$ & ap2al & Uniprot & X1WD71 & AP-2 complex subunit alpha-1 \\
\hline $\begin{array}{l}\text { Gene }(D . \\
\text { rerio) }\end{array}$ & bmp2k & Uniprot & $\begin{array}{l}\text { A0A0R4IU } \\
\text { S2 }\end{array}$ & BMP-2-inducible protein kinase \\
\hline $\begin{array}{l}\text { Gene }(D . \\
\text { rerio) }\end{array}$ & aakl & Uniprot & E7F2L1 & AP2-associated protein kinase $1 \mathrm{~b}$ \\
\hline $\begin{array}{l}\text { Strain, strain } \\
\text { background } \\
\text { (Escherichia } \\
\text { coli) }\end{array}$ & XL1-Blue & $\begin{array}{l}\text { Agilent } \\
\text { Technologies }\end{array}$ & 200249 & \\
\hline $\begin{array}{l}\text { Strain, strain } \\
\text { background } \\
(E . \text { coli) }\end{array}$ & $\begin{array}{l}\text { BL21-Codon } \\
\text { Plus-RIL }\end{array}$ & $\begin{array}{l}\text { Agilent } \\
\text { Technologies }\end{array}$ & 230240 & \\
\hline $\begin{array}{l}\text { Strain, strain } \\
\text { background }\end{array}$ & BL21(DE3)pLysS & Agilent & 200132 & \\
\hline
\end{tabular}




\begin{tabular}{|c|c|c|c|c|}
\hline (E. coli) & & Technologies & & \\
\hline $\begin{array}{l}\text { Strain, strain } \\
\text { background } \\
\text { (D. rerio) } \\
\text { male }\end{array}$ & $\mathrm{AB}$ & & & Wild type \\
\hline $\begin{array}{l}\text { Strain, strain } \\
\text { background } \\
(D . \text { rerio }) \\
\text { female }\end{array}$ & $\mathrm{AB}$ & & & Wild type \\
\hline $\begin{array}{l}\text { Genetic } \\
\text { reagent-Cell } \\
\text { line }(H . \\
\text { sapiens }) \\
\text { female }\end{array}$ & HeLa SS6 & $\begin{array}{l}\text { Umasankar et } \\
\text { al., } 2014\end{array}$ & $\begin{array}{l}\text { designated } \\
\text { as parental } \\
\text { HeLa in } \\
\text { this paper }\end{array}$ & Wild type \\
\hline $\begin{array}{l}\text { Genetic } \\
\text { reagent- Cell } \\
\text { line }(H . \\
\text { sapiens }) \\
\text { female }\end{array}$ & $\begin{array}{l}\text { HeLa SS6 clone } \\
\# 64 / 1 . \mathrm{E}\end{array}$ & $\begin{array}{l}\text { Umasankar et } \\
\text { al., } 2014\end{array}$ & $\begin{array}{l}\text { designated } \\
\text { as } 1 . E \text { cells } \\
\text { and FCHO } \\
\text { knockout } \\
\text { cells in this } \\
\text { paper }\end{array}$ & $\begin{array}{l}\text { FCHO knockout cells- Generated } \\
\text { by disrupting } F C H O 1 \text { and } F C H O 2 \\
\text { coding genes in HeLa SS6 cells } \\
\text { through TALEN gene-editing } \\
\text { technology }\end{array}$ \\
\hline Antibody & $\begin{array}{l}\text { mouse anti- } \beta \text { - } \\
\text { actin, (clone AC- } \\
15) \mathrm{mAb}\end{array}$ & Sigma-Aldrich & A5441 & 1: 10,000 for immunoblotting \\
\hline Antibody & $\begin{array}{l}\text { mouse anti-AP-2 } \\
\alpha \text { - adaptin } 1 / 2(\mathrm{C} \text { - } \\
\text { 8) mouse mAb }\end{array}$ & $\begin{array}{l}\text { Santa Cruz } \\
\text { Biotechnology }\end{array}$ & sc-17771 & 1:500 for immunoblotting \\
\hline Antibody & $\begin{array}{l}\text { mouse anti-AP-2 } \\
\alpha-\text { adaptin (AP6) } \\
\text { mAb }\end{array}$ & $\begin{array}{l}\text { ThermoFisher } \\
\text { Scientific }\end{array}$ & MA1-064 & 1:500 for immunofluorescence \\
\hline Antibody & $\begin{array}{l}\text { mouse anti-AP-2 } \\
\beta \text { - adaptin } 1 / 2 \\
(100 / 1) \text { mAb }\end{array}$ & $\begin{array}{l}\text { Santa Cruz } \\
\text { Biotechnology }\end{array}$ & sc-58226 & 1:200 for immunoblotting \\
\hline Antibody & $\begin{array}{l}\text { mouse anti-AP-2 } \\
\mu \text { subunit (clone } \\
\text { 31/AP50) purified } \\
\text { mAb }\end{array}$ & $\begin{array}{l}\text { BD } \\
\text { Transduction } \\
\text { Laboratories }\end{array}$ & 611350 & 1:250 for immunoblotting \\
\hline Antibody & $\begin{array}{l}\text { rabbit anti-AP-2 } \mu \\
\text { subunit phospho- } \\
\text { Thr156 (D4F3) } \\
\text { mAb }\end{array}$ & $\begin{array}{l}\text { Cell Signaling } \\
\text { Technology }\end{array}$ & 7399 & $\begin{array}{l}\text { 1:200 for immunoblotting } \\
\text { 1:50 for immunofluorescence }\end{array}$ \\
\hline
\end{tabular}




\begin{tabular}{|c|c|c|c|c|}
\hline Antibody & $\begin{array}{l}\text { rabbit anti-AP-2 } \mu \\
\text { subunit phospho- } \\
\text { Thr156 } \\
\text { (EPR4700) mAb }\end{array}$ & Abcam & ab109397 & $\begin{array}{l}\text { 1:200for immunoblotting } \\
\text { 1:50 for immunofluorescence }\end{array}$ \\
\hline Antibody & $\begin{array}{l}\text { mouse anti- } \\
\text { BMP2K (NQ- } \\
\text { C10) mAb }\end{array}$ & $\begin{array}{l}\text { Santa Cruz } \\
\text { Biotechnology }\end{array}$ & sc-134284 & 1:200 for immunoblotting \\
\hline Antibody & $\begin{array}{l}\text { mouse anti- } \\
\text { BMP2K (E8) } \\
\text { mAb }\end{array}$ & $\begin{array}{l}\text { Santa Cruz } \\
\text { Biotechnology }\end{array}$ & sc-514681 & 1:200 for immunoblotting \\
\hline Antibody & $\begin{array}{l}\text { mouse anti- } \\
\text { CALM (A-2) } \\
\text { mAb }\end{array}$ & $\begin{array}{l}\text { Santa Cruz } \\
\text { Biotechnology }\end{array}$ & sc-271224 & 1:200 for immunoblotting \\
\hline Antibody & $\begin{array}{l}\text { mouse anti- } \\
\text { clathrin heavy } \\
\text { chain (TD.1) } \\
\text { mAb }\end{array}$ & $\begin{array}{l}\text { Santa Cruz } \\
\text { Biotechnology }\end{array}$ & sc-12734 & 1:200 for immunoblotting \\
\hline Antibody & $\begin{array}{l}\text { mouse anti- } \\
\text { Disabled-2 (clone } \\
52 / \text { p96) purified } \\
\text { mAb }\end{array}$ & $\begin{array}{l}\text { BD } \\
\text { Transduction } \\
\text { Laboratories }\end{array}$ & sc-12734 & 1:1000 for immunoblotting \\
\hline Antibody & $\begin{array}{l}\text { rabbit anti- Eps } 15 \\
(\mathrm{C}-20) \text { affinity } \\
\text { purified pAb }\end{array}$ & $\begin{array}{l}\text { Santa Cruz } \\
\text { Biotechnology }\end{array}$ & sc-534 & 1:500 for immunoblotting \\
\hline Antibody & $\begin{array}{l}\text { mouse anti- } \\
\text { Eps15 (E-3) mAb }\end{array}$ & $\begin{array}{l}\text { Santa Cruz } \\
\text { Biotechnology }\end{array}$ & sc-390259 & 1:500 for immunoblotting \\
\hline Antibody & $\begin{array}{l}\text { rabbit anti- } \\
\text { FCHO2 } \\
\text { immunogen } \\
\text { affinity purified } \\
\text { pAb }\end{array}$ & $\begin{array}{l}\text { Novus } \\
\text { Biologicals }\end{array}$ & $\begin{array}{l}\text { NBP2- } \\
32694\end{array}$ & 1:500 for immunoblotting \\
\hline Antibody & $\begin{array}{l}\text { rabbit anti- GFP } \\
\text { pAb }\end{array}$ & $\begin{array}{l}\text { Rockland } \\
\text { antibodies \& } \\
\text { assays }\end{array}$ & $\begin{array}{l}600-401- \\
215\end{array}$ & 1: 1000 forimmunoblotting \\
\hline Antibody & $\begin{array}{l}\text { mouse anti- Hrb- } \\
\text { RIP/Rab (H-2) } \\
\text { mAb }\end{array}$ & $\begin{array}{l}\text { Santa Cruz } \\
\text { Biotechnology }\end{array}$ & sc-166651 & $\begin{array}{l}\text { 1:500for immunoblotting } \\
\text { 1:100 for immunofluorescence }\end{array}$ \\
\hline Antibody & $\begin{array}{l}\text { mouse anti- } \\
\text { intersectin 1/ESE- }\end{array}$ & $\begin{array}{l}\text { BD } \\
\text { Transduction }\end{array}$ & 611574 & 1:100 for immunofluorescence \\
\hline
\end{tabular}




\begin{tabular}{|c|c|c|c|c|}
\hline & 1 (clone 29) $\mathrm{mAb}$ & Laboratories & & \\
\hline Antibody & $\begin{array}{l}\text { goat anti-mouse- } \\
\text { IgG }(\mathrm{H}+\mathrm{L})-\mathrm{HRP} \\
\text { conjugate }\end{array}$ & Bio-Rad & 1721011 & 1:5000 for immunoblotting \\
\hline Antibody & $\begin{array}{l}\text { goat anti-rabbit- } \\
\text { IgG }(\mathrm{H}+\mathrm{L})-\mathrm{HRP} \\
\text { conjugate }\end{array}$ & Bio-Rad & 1721019 & 1:5000 for immunoblotting \\
\hline Antibody & $\begin{array}{l}\text { donkey anti- } \\
\text { mouse- IgG } \\
(\mathrm{H}+\mathrm{L})-\text { Alexa } \\
\text { Fluor } 488 \\
\text { conjugate }\end{array}$ & $\begin{array}{l}\text { Invitrogen, } \\
\text { ThermoFisher } \\
\text { Scientific }\end{array}$ & A-21202 & 1:500 for immunofluorescence \\
\hline Antibody & $\begin{array}{l}\text { donkey anti- } \\
\text { mouse- IgG } \\
(\mathrm{H}+\mathrm{L})-\text { Alexa } \\
\text { Fluor } 568 \\
\text { conjugate }\end{array}$ & $\begin{array}{l}\text { Invitrogen, } \\
\text { ThermoFisher } \\
\text { Scientific }\end{array}$ & A-10037 & 1:500 for immunofluorescence \\
\hline Antibody & $\begin{array}{l}\text { goat anti-mouse- } \\
\text { IgG }(\mathrm{H}+\mathrm{L})-\text { Alexa } \\
\text { Fluor } 647 \\
\text { conjugate }\end{array}$ & $\begin{array}{l}\text { Cell Signaling } \\
\text { Technology }\end{array}$ & 4410 & 1:500 for immunofluorescence \\
\hline Antibody & $\begin{array}{l}\text { donkey anti- } \\
\text { rabbit- IgG } \\
(\mathrm{H}+\mathrm{L})-\text { Alexa } \\
\text { Fluor } 488 \\
\text { conjugate }\end{array}$ & $\begin{array}{l}\text { Invitrogen, } \\
\text { ThermoFisher } \\
\text { Scientific }\end{array}$ & A-21206 & 1:500 for immunofluorescence \\
\hline Antibody & $\begin{array}{l}\text { donkey anti- } \\
\text { rabbit- IgG } \\
(\mathrm{H}+\mathrm{L})-\text { Alexa } \\
\text { Fluor } 568 \\
\text { conjugate }\end{array}$ & $\begin{array}{l}\text { Invitrogen, } \\
\text { ThermoFisher } \\
\text { Scientific }\end{array}$ & A-10042 & 1:500 for immunofluorescence \\
\hline Antibody & $\begin{array}{l}\text { Anti- } \\
\text { Digoxigenin-AP, } \\
\text { Fab fragments }\end{array}$ & Merck, Roche & $\begin{array}{l}110932749 \\
10\end{array}$ & $\begin{array}{l}\text { 1:5000 for whole mount in situ } \\
\text { hybridization }\end{array}$ \\
\hline $\begin{array}{l}\text { Recombinant } \\
\text { DNA reagent }\end{array}$ & pEGFP-N1 & Clontech & & See Table-1 for details \\
\hline $\begin{array}{l}\text { Recombinant } \\
\text { DNA reagent }\end{array}$ & BMP2K-GFP & This paper & & See Table-1 for details \\
\hline
\end{tabular}




\begin{tabular}{|c|c|c|c|}
\hline $\begin{array}{l}\text { Recombinant } \\
\text { DNA reagent }\end{array}$ & BMP2K $\Delta \mathrm{CT}$-GFP & This paper & See Table-1 for details \\
\hline $\begin{array}{l}\text { Recombinant } \\
\text { DNA reagent }\end{array}$ & BMP2KCT-GFP & This paper & See Table-1 for details \\
\hline $\begin{array}{l}\text { Recombinant } \\
\text { DNA reagent }\end{array}$ & $\begin{array}{l}\text { BMP2K } \Delta \mathrm{Q} / \mathrm{H}- \\
\text { GFP }\end{array}$ & This paper & See Table-1 for details \\
\hline $\begin{array}{l}\text { Recombinant } \\
\text { DNA reagent }\end{array}$ & $\begin{array}{l}\text { BMP2K } \Delta \text { KD- } \\
\text { GFP }\end{array}$ & This paper & See Table-1 for details \\
\hline $\begin{array}{l}\text { Recombinant } \\
\text { DNA reagent }\end{array}$ & GFP-FCHO1 & $\begin{array}{l}\text { Umasankar et } \\
\text { al., } 2014\end{array}$ & See Table-1 for details \\
\hline $\begin{array}{l}\text { Recombinant } \\
\text { DNA reagent }\end{array}$ & $\begin{array}{l}\text { GFP-FCHO1 (1- } \\
609)\end{array}$ & $\begin{array}{l}\text { Umasankar et } \\
\text { al., } 2014\end{array}$ & See Table-1 for details \\
\hline $\begin{array}{l}\text { Recombinant } \\
\text { DNA reagent }\end{array}$ & pGEX-4T-1 & Pharmacia & See Table-1 for details \\
\hline $\begin{array}{l}\text { Recombinant } \\
\text { DNA reagent }\end{array}$ & $\begin{array}{l}\text { pGEX-BMP2K- } \\
\text { KD }\end{array}$ & This paper & See Table-1 for details \\
\hline $\begin{array}{l}\text { Recombinant } \\
\text { DNA reagent }\end{array}$ & $\begin{array}{l}\text { pGEX-BMP2K- } \\
\text { Q/H }\end{array}$ & This paper & See Table-1 for details \\
\hline $\begin{array}{l}\text { Recombinant } \\
\text { DNA reagent }\end{array}$ & $\begin{array}{l}\text { pGEX-BMP2K- } \\
\text { CT\#1 }\end{array}$ & This paper & See Table-1 for details \\
\hline $\begin{array}{l}\text { Recombinant } \\
\text { DNA reagent }\end{array}$ & $\begin{array}{l}\text { pGEX-BMP2K- } \\
\text { CT\#2 }\end{array}$ & This paper & See Table-1 for details \\
\hline $\begin{array}{l}\text { Recombinant } \\
\text { DNA reagent }\end{array}$ & pCS2+ & Michael Tsang & See Table-1 for details \\
\hline $\begin{array}{l}\text { Recombinant } \\
\text { DNA reagent }\end{array}$ & pCS2-Hs FCHO2 & This paper & See Table-1 for details \\
\hline $\begin{array}{l}\text { Recombinant } \\
\text { DNA reagent }\end{array}$ & pCS2-Hs BMP2K & This paper & See Table-1 for details \\
\hline Recombinant & $\mathrm{pCS} 2-H s$ & This paper & See Table-1 for details \\
\hline
\end{tabular}




\begin{tabular}{|c|c|c|c|c|}
\hline DNA reagent & $B M P 2 K \triangle C T$ & & & \\
\hline $\begin{array}{l}\text { Recombinant } \\
\text { DNA reagent }\end{array}$ & TOPO-Dr bmp $2 k$ & This paper & & See Table-1 for details \\
\hline $\begin{array}{l}\text { Recombinant } \\
\text { DNA reagent }\end{array}$ & TOPO-Dr ap $2 a 1$ & This paper & & See Table-1 for details \\
\hline $\begin{array}{l}\text { Recombinant } \\
\text { DNA reagent }\end{array}$ & TOPO-Dr dusp6 & This paper & & See Table-1 for details \\
\hline $\begin{array}{l}\text { Sequence } \\
\text { based reagent }\end{array}$ & $\begin{array}{l}\text { PCR oligo } \\
\text { nucleotides }\end{array}$ & $\begin{array}{l}\text { Integrated } \\
\text { DNA } \\
\text { Technologies }\end{array}$ & & See Table- 1 for detailed list \\
\hline $\begin{array}{l}\text { Sequence } \\
\text { based reagent }\end{array}$ & $\begin{array}{l}\text { siGENOME } H \text {. } \\
\text { sapiens } \\
\text { BMP2K(55589) } \\
\text { siRNA- } \\
\text { SMARTPOOL }\end{array}$ & Dharmacon & $\begin{array}{l}\text { M-005071- } \\
01-0005\end{array}$ & $\begin{array}{l}5 \text { ' GAACAUAGACCUGAUAUAU } \\
3, \\
5 \text {, GGACUGUGCUGUUAAUUCA } \\
3 \text {, } \\
5 \text {, GGAACUAUGUACUUUGUGA } \\
3 \text {, } \\
5 \text {, CGAUGUGCAUUGAAGCGAA } \\
3 \text {, }\end{array}$ \\
\hline $\begin{array}{l}\text { Sequence } \\
\text { basedreagent }\end{array}$ & $\begin{array}{l}\text { H. sapiens AP-2- } \\
\alpha \text { Custom siRNA }\end{array}$ & Dharmacon & $\begin{array}{l}\text { CTM- } \\
\text { 445898:DI } \\
\text { RTL- } \\
000015\end{array}$ & $\begin{array}{l}\text { 5'GCAUGUGCACGCUGGCCAdTd } \\
\text { T 3' } \\
\text { 5'UGGCCAGCGUGCACAUGCdTd } \\
\text { T 3', }\end{array}$ \\
\hline $\begin{array}{l}\text { Sequence } \\
\text { based reagent }\end{array}$ & $\begin{array}{l}\text { D. rerio fcho2 } \\
\text { morpholino }\end{array}$ & $\begin{array}{l}\text { Gene tools } \\
\text { (Umasankar } e t \\
\text { al., 2012) }\end{array}$ & fcho2 MO & $\begin{array}{l}\text { 5'TCTCCAGGAAATAGGGCGT } \\
\text { TATCAT 3' }\end{array}$ \\
\hline $\begin{array}{l}\text { Sequence } \\
\text { based reagent }\end{array}$ & $\begin{array}{l}\text { D. rerio ap } 2 a 1 \\
\text { morpholino }\end{array}$ & $\begin{array}{l}\text { Gene tools } \\
\text { (Umasankar et } \\
\text { al., 2012) }\end{array}$ & ap2al MO & $\begin{array}{l}\text { 5'CCGGCATGTTTGCAGGGTT } \\
\text { CTTCTC 3' }\end{array}$ \\
\hline $\begin{array}{l}\text { Peptide, } \\
\text { recombinant } \\
\text { protein }\end{array}$ & $\begin{array}{l}\text { Thrombin } \\
\text { protease }\end{array}$ & GE Healthcare & 27084601 & \\
\hline $\begin{array}{l}\text { Peptide, } \\
\text { recombinant } \\
\text { protein }\end{array}$ & $\begin{array}{l}\text { Bovine serum } \\
\text { albumin (BSA) }\end{array}$ & Pierce & 23209 & \\
\hline
\end{tabular}




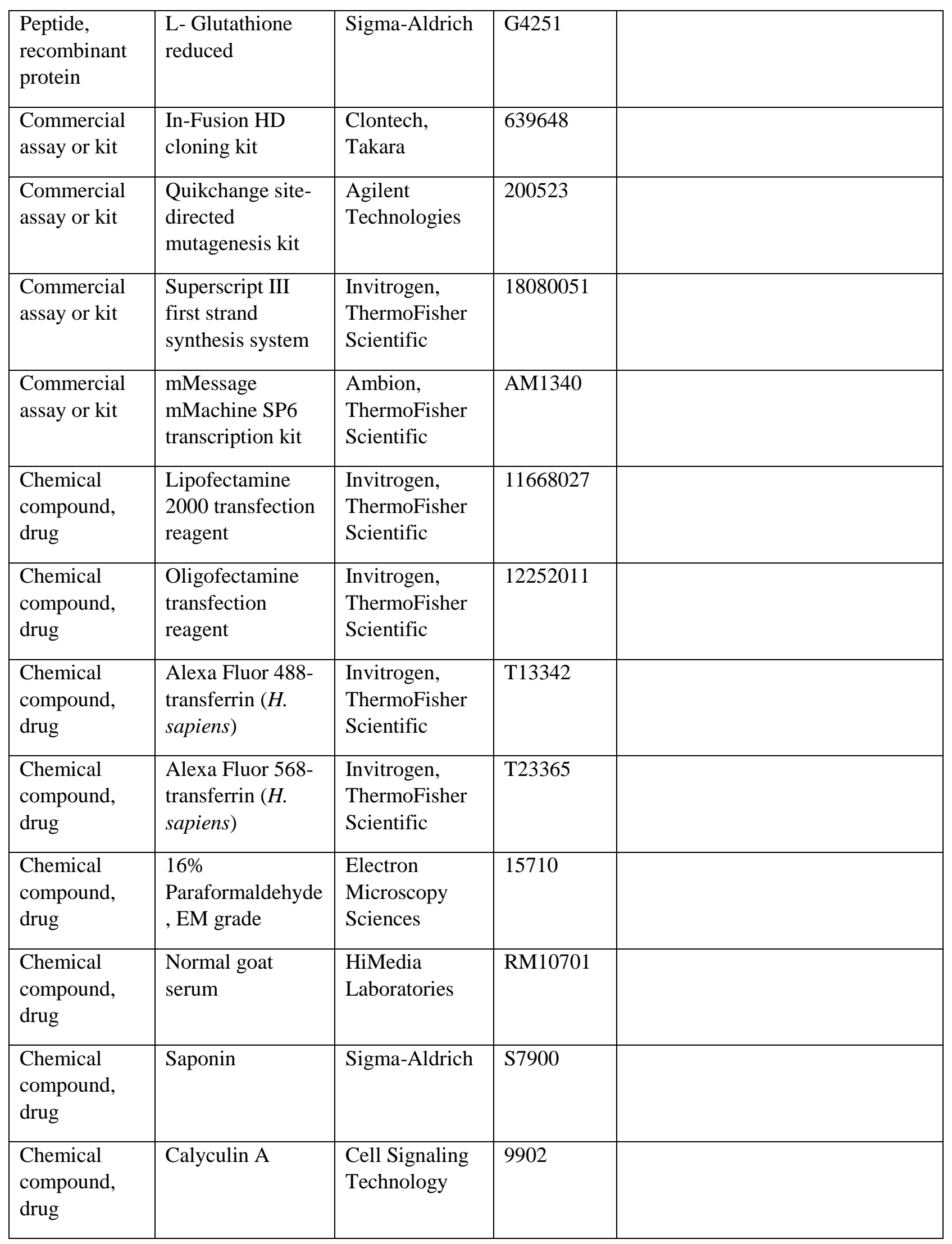




\begin{tabular}{|c|c|c|c|c|}
\hline $\begin{array}{l}\text { Chemical } \\
\text { compound, } \\
\text { drug }\end{array}$ & SGC-AAK1-1 & $\begin{array}{l}\text { Tocris } \\
\text { Bioscience }\end{array}$ & 6528 & \\
\hline $\begin{array}{l}\text { Chemical } \\
\text { compound, } \\
\text { drug }\end{array}$ & $\begin{array}{l}\text { Isopropyl } \beta \text {-D-1- } \\
\text { thiogalactopyrano } \\
\text { side (IPTG) }\end{array}$ & Sigma-Aldrich & I6758 & \\
\hline $\begin{array}{l}\text { Chemical } \\
\text { compound, } \\
\text { drug }\end{array}$ & $\begin{array}{l}\text { Glutathione } \\
\text { Sepharose 4B }\end{array}$ & GE Healthcare & $\begin{array}{l}\text { GE170756 } \\
01\end{array}$ & \\
\hline $\begin{array}{l}\text { Chemical } \\
\text { compound, } \\
\text { drug }\end{array}$ & Ni-NTA Agarose & Qiagen & 30210 & \\
\hline $\begin{array}{l}\text { Chemical } \\
\text { compound, } \\
\text { drug }\end{array}$ & $\begin{array}{l}\text { Ethyl 3- } \\
\text { aminobenzoate } \\
\text { methanesulfonate } \\
\text { (Tricaine) }\end{array}$ & Sigma-Aldrich & $\begin{array}{l}\text { E10521- } \\
10 G\end{array}$ & \\
\hline $\begin{array}{l}\text { Chemical } \\
\text { compound, } \\
\text { drug }\end{array}$ & BM purple & Roche/Merck & $\begin{array}{l}114420740 \\
01\end{array}$ & \\
\hline $\begin{array}{l}\text { Chemical } \\
\text { compound, } \\
\text { drug }\end{array}$ & Laminin & Corning & 354232 & \\
\hline $\begin{array}{l}\text { Software, } \\
\text { algorithm }\end{array}$ & NIS elements & Nikon & & \\
\hline $\begin{array}{l}\text { Software, } \\
\text { algorithm }\end{array}$ & $\begin{array}{l}\text { NIS Elements AR } \\
3.2 \text { analysis } \\
\text { package }\end{array}$ & Nikon & & \\
\hline $\begin{array}{l}\text { Software, } \\
\text { algorithm }\end{array}$ & LAS X & Leica & & \\
\hline $\begin{array}{l}\text { Software, } \\
\text { algorithm }\end{array}$ & Fiji & $\begin{array}{l}\text { Schindelin et } \\
\text { al., } 2012\end{array}$ & & \\
\hline $\begin{array}{l}\text { Software, } \\
\text { algorithm }\end{array}$ & $\begin{array}{l}\text { AutoQuant X3: } \\
\text { 2D and 3D image } \\
\text { deconvolution }\end{array}$ & $\begin{array}{l}\text { Media } \\
\text { Cybernetics }\end{array}$ & & \\
\hline
\end{tabular}


Table-1: PCR oligonucleotides

\begin{tabular}{|c|c|c|c|c|}
\hline PCR oligos & Plasmid & $\begin{array}{l}\text { Cloning } \\
\text { strategy }\end{array}$ & Forward oligo sequence & Reverse oligo sequence \\
\hline $\begin{array}{l}\text { BMP2K IF } \\
\text { FOR \& } \\
\text { BMP2K IF } \\
\text { REV }\end{array}$ & $\begin{array}{l}\text { BMP2K-GFP } \\
\text { pEGFP-N1 }\end{array}$ & $\begin{array}{l}\text { In-Fusion } \\
\text { cloning }\end{array}$ & $\begin{array}{l}\text { 5'- CAG ATC TCG AGC } \\
\text { TCA AGC TTA TGA } \\
\text { AGA AGT TCT CTC } \\
\text { GGA TGC CC -3' }\end{array}$ & $\begin{array}{l}\text { 5'- GCA GAA TTC GAA } \\
\text { GCT TCT GTT TAG AAG } \\
\text { GAA ATG GAG CAG } \\
\text { CAC -3' }\end{array}$ \\
\hline $\begin{array}{l}\text { BMP2K IF } \\
\text { FOR \& } \\
\text { BMP2K- } \\
\text { Q/H IF REV }\end{array}$ & $\begin{array}{l}\text { BMP2K } \Delta C T- \\
\text { GFP pEGFP- } \\
\text { N1 }\end{array}$ & $\begin{array}{l}\text { In-Fusion } \\
\text { cloning }\end{array}$ & $\begin{array}{l}\text { 5'- CAG ATC TCG AGC } \\
\text { TCA AGC TTA TGA } \\
\text { AGA AGT TCT CTC } \\
\text { GGA TGC CC -3' }\end{array}$ & $\begin{array}{l}\text { 5'- GCA GAA TTC GAA } \\
\text { GCT TTG CCT GTT GTT } \\
\text { GAG ACG GCT -3' }\end{array}$ \\
\hline $\begin{array}{l}\text { BMP2K-CT } \\
\text { IF FOR \& } \\
\text { BMP2K IF } \\
\text { REV }\end{array}$ & $\begin{array}{l}\text { BMP2KCT- } \\
\text { GFP pEGFP- } \\
\text { N1 }\end{array}$ & $\begin{array}{l}\text { In-Fusion } \\
\text { cloning }\end{array}$ & $\begin{array}{l}\text { 5'- CAG ATC TCG AGC } \\
\text { TCA AGC TTA TGT } \\
\text { CAC CTG AAT ATC } \\
\text { TTA CCT CCC CTC A -3' }\end{array}$ & $\begin{array}{l}\text { 5'- GCA GAA TTC GAA } \\
\text { GCT TCT GTT TAG AAG } \\
\text { GAA ATG GAG CAG } \\
\text { CAC -3' }\end{array}$ \\
\hline $\begin{array}{l}\text { BMP2K-KD } \\
\text { IF FOR \& } \\
\text { BMP2K-KD } \\
\text { IF REV }\end{array}$ & $\begin{array}{l}\text { BMP2K } \\
\Delta \mathrm{Q} / \mathrm{H}-\mathrm{GFP} \\
\mathrm{pEGFP-N1}\end{array}$ & $\begin{array}{l}\text { In-Fusion } \\
\text { cloning }\end{array}$ & $\begin{array}{l}\text { 5'- GAA CCG TCA GAT } \\
\text { CCG CTA GCA TGA } \\
\text { AGA AGT TCT CTC } \\
\text { GGA TGC C -3' }\end{array}$ & $\begin{array}{l}\text { 5'- GTC CGG TAG CGC } \\
\text { TAG CGC TTC ACT AGC } \\
\text { AGT CAT CGG TTC -3' }\end{array}$ \\
\hline $\begin{array}{l}\text { BMP2K- } \\
\text { Q/H IF FOR } \\
\text { \& BMP2K- } \\
\text { Q/H IF REV }\end{array}$ & $\begin{array}{l}\text { BMP2K } \Delta \mathrm{KD} \\
\text {-GFP } \\
\text { pEGFP-N1 }\end{array}$ & $\begin{array}{l}\text { In-Fusion } \\
\text { cloning }\end{array}$ & $\begin{array}{l}\text { 5'- GAA CCG TCA GAT } \\
\text { CCG CTA GCA TGG } \\
\text { CAG CTG CTA GGA } \\
\text { AAA GCC AAA T -3' }\end{array}$ & $\begin{array}{l}\text { 5'- GTC CGG TAG CGC } \\
\text { TAG CGA TGC CTG TTG } \\
\text { TTG AGA CGG -3' }\end{array}$ \\
\hline $\begin{array}{l}\text { BMP2K-KD } \\
\text { EcoRI FOR } \\
\& \text { BMP2K- } \\
\text { KD NotI } \\
\text { REV }\end{array}$ & $\begin{array}{l}\text { GST- } \\
\text { BMP2K-KD } \\
(38-345) \\
\text { pGEX-4T-1 }\end{array}$ & $\begin{array}{l}\text { Directional } \\
\text { cloning }\end{array}$ & $\begin{array}{l}\text { 5'- GTG AAT TCT CCG } \\
\text { TGG GGG TCC GGG } \\
\text { TGT TC -3' }\end{array}$ & $\begin{array}{l}\text { 5'- ATG CGG CCG CCT } \\
\text { ATT CAC TAG CAG TCA } \\
\text { TCG GTT CAG G -3' }\end{array}$ \\
\hline $\begin{array}{l}\text { BMP2K- } \\
\text { Q/H EcoRI } \\
\text { FOR \& } \\
\text { BMP2K- } \\
\text { Q/H NotI } \\
\text { REV }\end{array}$ & $\begin{array}{l}\text { GST- } \\
\text { BMP2K-Q/H } \\
(346-560) \\
\text { pGEX-4T-1 }\end{array}$ & $\begin{array}{l}\text { Directional } \\
\text { cloning }\end{array}$ & $\begin{array}{l}\text { 5'- GTG AAT TCG CAG } \\
\text { CTG CTA GGA AAA } \\
\text { GCC AAA T -3' }\end{array}$ & $\begin{array}{l}\text { 5'- ATG CGG CCG CCT } \\
\text { ACC TGT TGT TGA GAC } \\
\text { GGC TGA T -3' }\end{array}$ \\
\hline $\begin{array}{l}\text { BMP2K- } \\
\text { CT\#1 EcoRI } \\
\text { FOR \& } \\
\text { BMP2K- }\end{array}$ & $\begin{array}{l}\text { GST- } \\
\text { BMP2K- } \\
\text { CT\#1 (561- } \\
\text { 850) pGEX- }\end{array}$ & $\begin{array}{l}\text { Directional } \\
\text { cloning }\end{array}$ & $\begin{array}{l}\text { 5'- GTG AAT TCT CAC } \\
\text { CTG AAT ATC TTA } \\
\text { CCT CCC C -3' }\end{array}$ & $\begin{array}{l}\text { 5'- ATG CGG CCG CCT } \\
\text { AAG TCT CCA CTG CAA } \\
\text { CAT CAG AGG -3' }\end{array}$ \\
\hline
\end{tabular}




\begin{tabular}{|c|c|c|c|c|}
\hline $\begin{array}{l}\text { CT\#1 NotI } \\
\text { REV }\end{array}$ & $4 \mathrm{~T}-1$ & & & \\
\hline $\begin{array}{l}\text { BMP2K- } \\
\text { CT\#2 EcoRI } \\
\text { FOR \& } \\
\text { BMP2K- } \\
\text { CT\#2 NotI } \\
\text { REV }\end{array}$ & $\begin{array}{l}\text { GST-BMP2K } \\
\text { CT\#2 (851- } \\
\text { 1161) pGEX- } \\
\text { 4T-1 }\end{array}$ & $\begin{array}{l}\text { Directional } \\
\text { cloning }\end{array}$ & $\begin{array}{l}\text { 5'- GTG AAT TCC CCA } \\
\text { AAC AGG AGT TTG } \\
\text { ATG TAT TTG GC -3' }\end{array}$ & $\begin{array}{l}\text { 5'- ATG CGG CCG CCT } \\
\text { ACT GTT TAG AAG GAA } \\
\text { ATG GAG CAG C -3' }\end{array}$ \\
\hline $\begin{array}{l}H s \text { BMP2K } \\
\text { EcoRI IF } \\
\text { FOR \& } H s \\
\text { BMP2K } \\
\text { EcoRI IF } \\
\text { REV }\end{array}$ & $\begin{array}{l}\text { Hs BMP2K } \\
\text { pCS2+ }\end{array}$ & $\begin{array}{l}\text { In-Fusion } \\
\text { cloning }\end{array}$ & $\begin{array}{l}\text { 5'- GAT CCC ATC GAT } \\
\text { TCG AAT TCC CAG } \\
\text { CCA TGA AGA AGT } \\
\text { TCT CTC GGA TG -3' }\end{array}$ & $\begin{array}{l}\text { 5'- GAG AGG CCT TGA } \\
\text { ATT CCT ACT GTT TAG } \\
\text { AAG GAA ATG GAG C - } \\
3^{\prime}\end{array}$ \\
\hline $\begin{array}{l}H s \text { FCHO2 } \\
\text { EcoRI IF } \\
\text { FOR \& Hs } \\
\text { FCHO2 } \\
\text { EcoRI IF } \\
\text { REV }\end{array}$ & $\begin{array}{l}\text { Hs } \mathrm{FCHO} 2 \\
\text { pCS2+ }\end{array}$ & $\begin{array}{l}\text { In-Fusion } \\
\text { cloning }\end{array}$ & $\begin{array}{l}\text { 5'- GAT CCC ATC GAT } \\
\text { TCG AAT TCC CAG } \\
\text { CCA TGG TCA TGG } \\
\text { CGT ATT TCG TC -3' }\end{array}$ & $\begin{array}{l}\text { 5'- GAG AGG CCT TGA } \\
\text { ATT CTC AAC AAT CCG } \\
\text { CCA GGT ATC G -3' }\end{array}$ \\
\hline $\begin{array}{l}\text { QC Hs } \\
\text { BMP2K } 561 \\
\text { stop FOR \& } \\
\text { QC Hs } \\
\text { BMP2K } 561 \\
\text { stop REV }\end{array}$ & $\begin{array}{l}H s \text { BMP2K } \\
\Delta \mathrm{CT} \mathrm{pCS} 2+\end{array}$ & $\begin{array}{l}\text { QuikChange } \\
\text { mutagenesis }\end{array}$ & $\begin{array}{l}\text { 5'- CGT CTC AAC AAC } \\
\text { AGG CAT GAC CTG } \\
\text { AAT ATC TTA CCT C -3' }\end{array}$ & $\begin{array}{l}\text { 5'- GAG GTA AGA TAT } \\
\text { TCA GGT CAT GCC TGT } \\
\text { TGT TGA GAC G -3' }\end{array}$ \\
\hline $\begin{array}{l}\text { Dr bmp } 2 k \\
\text { FOR \& Dr } \\
b m p 2 k \text { REV }\end{array}$ & $\begin{array}{l}\text { Dr bmp2k } \\
\text { pCR Blunt- } \\
\text { II-TOPO }\end{array}$ & $\begin{array}{l}\text { Blunt TOPO } \\
\text { PCR cloning }\end{array}$ & $\begin{array}{l}\text { 5'- GATCAAGAAGTAC } \\
\text { ACGACTCTGTCATAC - } \\
\text { 3' }\end{array}$ & $\begin{array}{l}\text { 5'- GTCTGGAACTCTAG } \\
\text { AGGGGAGATATAG -3' }\end{array}$ \\
\hline $\begin{array}{l}\text { Dr ap2al } \\
\text { FOR \& Dr } \\
\text { ap2al REV }\end{array}$ & $\begin{array}{l}\text { Dr ap2al } \\
\text { pCR Blunt II- } \\
\text { TOPO }\end{array}$ & $\begin{array}{l}\text { Blunt TOPO } \\
\text { PCR cloning }\end{array}$ & $\begin{array}{l}\text { 5'- TGCTGTCAGCCTAT } \\
\text { ATTAAGTTCATT -3' }\end{array}$ & $\begin{array}{l}\text { 5'- CAGTAACTTAGCTT } \\
\text { TGATCACCTCAG -3' }\end{array}$ \\
\hline $\begin{array}{l}\text { Dr dusp6 } \\
\text { FOR \& Dr } \\
\text { dusp6 REV }\end{array}$ & $\begin{array}{l}\text { Drdusp6 } \\
\text { pCR Blunt II- } \\
\text { TOPO }\end{array}$ & $\begin{array}{l}\text { Blunt TOPO } \\
\text { PCR cloning }\end{array}$ & $\begin{array}{l}\text { 5'- TTGCAGGCATCAG } \\
\text { TCGTTCT -3' }\end{array}$ & $\begin{array}{l}\text { 5'- GGCAAGGCTTACCG } \\
\text { ACATCT -3' }\end{array}$ \\
\hline
\end{tabular}




\section{References}

Agajanian, M. J., Walker, M. P., Axtman, A. D., Ruela-de-Sousa, R. R., Serafin, D. S., Rabinowitz, A. D., ... Major, M. B. (2019). WNT Activates the AAK1 Kinase to Promote Clathrin-Mediated Endocytosis of LRP6 and Establish a Negative Feedback Loop. Cell Rep, 26(1), 79-93 e78. doi: 10.1016/j.celrep.2018.12.023

Aguet, F., Antonescu, C. N., Mettlen M., Schmid S. L., Danuser, G. (2013). Advances in analysis of low signal-to-noise images link dynamin and AP2 to the functions of an endocytic checkpoint. Dev Cell. 26(3), 279-91. doi: 10.1016/j.devcel.2013.06.019.

Akimov, V., Barrio-Hernandez, I., Hansen, S. V. F., Hallenborg, P., Pedersen, A. K., Bekker-Jensen, D. B., .. . Blagoev, B. (2018). UbiSite approach for comprehensive mapping of lysine and N-terminal ubiquitination sites. Nat Struct Mol Biol, 25(7), 631-640. doi: 10.1038/s41594-018-0084-y.

Avinoam, O., Schorb, M., Beese, C. J, Briggs J. A., \& Kaksonen, M. (2015). Endocytic sites mature by continuous bending and remodeling of the clathrin coat. Science, 348(6241):1369-72. doi:

10.1126/science.aaa9555.

Beacham, G. M., Partlow, E. A., Lange, J. J., \& Hollopeter, G. (2018). NECAPs are negative regulators of the AP2 clathrin adaptor complex. Elife, 7. doi: 10.7554/eLife.32242

Benmerah, A., Lamaze, C., Bègue, B., Schmid, S.L., Dautry-Varsat, A., \& Cerf-Bensussan, N. (1998). AP-2/Eps15 interaction is required for receptor-mediated endocytosis. J Cell Biol, 140(5), 1055-62. doi: 10.1083/jcb.140.5.1055

Borner, G. H., Antrobus, R., Hirst, J., Bhumbra, G. S., Kozik, P., Jackson, L. P., . . Robinson, M. S. (2012). Multivariate proteomic profiling identifies novel accessory proteins of coated vesicles. J Cell Biol, 197(1), 141-160. doi: 10.1083/jcb.201111049

Brehme, M., Hantschel, O., Colinge, J., Kaupe, I., Planyavsky, M., Kocher, T., . . Superti-Furga, G. (2009). Charting the molecular network of the drug target Bcr-Abl. Proc Natl Acad Sci U S A, 106(18), 7414-7419. doi: 10.1073/pnas.0900653106

Brodsky, F. M., Chen, C. Y., Knuehl, C., Towler, M. C., \& Wakeham, D. E. (2001). Biological basket weaving: formation and function of clathrin-coated vesicles. Annu Rev Cell Dev Biol, 17, 517-568. doi: 10.1146/annurev.cellbio.17.1.517

Buchenberg, S., Sittel, F., Stock, G. (2017). Time resolved observation of protein allosteric communication. Proc Natl Acad Sci U S A. 114(33), E6804-E6811. doi: 10.1073/pnas.1707694114.

Chamberland, J. P., Antonow, L. T., Dias Santos, M., \& Ritter, B. (2016). NECAP2 controls clathrin coat recruitment to early endosomes for fast endocytic recycling. J Cell Sci, 129(13), 2625-37. doi: $10.1242 /$ jcs. 173708 .

Chen Y, Yong J, Martínez-Sánchez A, Yang Y, Wu Y, De Camilli P, Fernández-Busnadiego R, Wu M. (2019). Dynamic instability of clathrin assembly provides proofreading control for endocytosis.

J Cell Biol. 26, pii: jcb.201804136. doi: 10.1083/jcb.201804136.

Cocucci, E., Aguet, F., Boulant, S., \& Kirchhausen, T. (2012). The first five seconds in the life of a 
clathrin-coated pit. Cell, 150(3), 495-507. doi: 10.1016/j.cell.2012.05.047

Collins, B. M., McCoy, A. J., Kent, H. M., Evans, P. R., \& Owen, D. J. (2002). Molecular architecture and functional model of the endocytic AP2 complex. Cell, 109(4), 523-535. doi: 10.1016/s00928674(02)00735-3

Conner, S. D., \& Schmid, S. L. (2002). Identification of an adaptor-associated kinase, AAK1, as a regulator of clathrin-mediated endocytosis. J Cell Biol, 156(5), 921-929. doi: 10.1083/jcb.200108123

Conner, S. D., \& Schmid, S. L. (2003). Differential requirements for AP-2 in clathrin-mediated endocytosis. J Cell Biol, 162(5), 773-779. doi: 10.1083/jcb.200304069

Conner, S. D., Schroter, T., \& Schmid, S. L. (2003). AAK1-mediated micro2 phosphorylation is stimulated by assembled clathrin. Traffic, 4(12), 885-890.

Dergai M, Iershov A, Novokhatska O, Pankivskyi S, \& Rynditch A. (2016). Evolutionary Changes on the Way to Clathrin-Mediated Endocytosis in Animals. Genome Biol Evol, 8(3), 588-606. doi: 10.1093/gbe/evw028.

Edeling, M. A., Mishra, S. K., Keyel, P. A., Steinhauser, A. L., Collins, B. M., Roth, R., . . Traub, L. M. (2006). Molecular switches involving the AP-2 beta2 appendage regulate endocytic cargo selection and clathrin coat assembly. Dev Cell, 10(3), 329-342. doi: 10.1016/j.devcel.2006.01.016

Elkins, J.M., Fedele, V., Szklarz, M., Abdul Azeez, K.R., Salah, E., Mikolajczyk, J., Romanov, S., Sepetov, N., Huang, X.P., Roth, B.L., et al. (2016). Comprehensive characterization of the Published Kinase Inhibitor Set. Nat. Biotechnol, 34(1), 95-103. doi: 10.1038/nbt.3374

Ferguson, S. M., \& De Camilli, P. (2012). Dynamin, a membrane-remodelling GTPase. Nat Rev Mol Cell Biol, 13(2), 75-88. doi: 10.1038/nrm3266

Ghosh, P., \& Kornfeld, S. (2003a). AP-1 binding to sorting signals and release from clathrin-coated vesicles is regulated by phosphorylation. J Cell Biol, 160(5), 699-708. doi: 10.1083/jcb.200211080

Ghosh, P., \& Kornfeld, S. (2003b). Phosphorylation-induced conformational changes regulate GGAs 1 and 3 function at the trans-Golgi network. J Biol Chem, 278(16), 14543-14549. doi:

$10.1074 / \mathrm{jbc} . \mathrm{M} 212543200$

Godlee, C., \& Kaksonen, M. (2013). Review series: From uncertain beginnings: initiation mechanisms of clathrin-mediated endocytosis. J Cell Biol, 203(5), 717-725. doi: 10.1083/jcb.201307100

Gu, M., Liu, Q., Watanabe, S., Sun, L., Hollopeter, G., Grant, B. D., \& Jorgensen, E. M. (2013). AP2 hemicomplexes contribute independently to synaptic vesicle endocytosis. Elife, 2, e00190. doi:

10.7554/eLife.00190

Gulbranson, D. R., Crisman, L., Lee, M., Ouyang, Y., Menasche, B. L., Demmitt, B. A., . . Shen, J. (2019). AAGAB Controls AP2 Adaptor Assembly in Clathrin-Mediated Endocytosis. Dev Cell, 50(4), 436-446 e435. doi: 10.1016/j.devcel.2019.06.013

Hagemann, A. I., Kurz, J., Kauffeld, S., Chen, Q., Reeves, P. M., Weber, S., . . S Scholpp, S. (2014). In vivo analysis of formation and endocytosis of the Wnt/beta-catenin signaling complex in zebrafish embryos. J Cell Sci, 127(Pt 18), 3970-3982. doi: 10.1242/jcs. 148767 
Hammerschmidt, M., Pelegri, F., Mullins, M. C., Kane, D. A., Brand, M., van Eeden, F. J., . . NussleinVolhard, C. (1996). Mutations affecting morphogenesis during gastrulation and tail formation in the zebrafish, Danio rerio. Development, 123, 143-151.

Hein, M. Y., Hubner, N. C., Poser, I., Cox, J., Nagaraj, N., Toyoda, Y., . . Mann, M. (2015). A human interactome in three quantitative dimensions organized by stoichiometries and abundances. Cell, 163(3), 712-723. doi: 10.1016/j.cell.2015.09.053

Henderson, D. M., \& Conner, S. D. (2007). A novel AAK1 splice variant functions at multiple steps of the endocytic pathway. Mol Biol Cell, 18(7), 2698-2706. doi: 10.1091/mbc.e06-09-0831

Henne, W. M., Boucrot, E., Meinecke, M., Evergren, E., Vallis, Y., Mittal, R., \& McMahon, H. T. (2010). FCHo proteins are nucleators of clathrin-mediated endocytosis. Science, 328(5983), 1281-1284. doi: $10.1126 /$ science. 1188462

Hinrichsen, L., Harborth, J., Andrees, L., Weber, K., \& Ungewickell, E. J. (2003). Effect of clathrin heavy chain- and alpha-adaptin-specific small inhibitory RNAs on endocytic accessory proteins and receptor trafficking in HeLa cells. J Biol Chem, 278(46), 45160-70. doi: 10.1074/jbc.M307290200

Hollopeter, G., Lange, J. J., Zhang, Y., Vu, T. N., Gu, M., Ailion, M., . . Jorgensen, E. M. (2014). The membrane-associated proteins FCHo and SGIP are allosteric activators of the AP2 clathrin adaptor complex. Elife, 3. doi: 10.7554/eLife.03648

Honing, S., Ricotta, D., Krauss, M., Spate, K., Spolaore, B., Motley, A., . . Owen, D. J. (2005). Phosphatidylinositol-(4,5)-bisphosphate regulates sorting signal recognition by the clathrin-associated adaptor complex AP2. Mol Cell, 18(5), 519-531. doi: 10.1016/j.molcel.2005.04.019

Howe, K., Clark, M. D., Torroja, C. F., Torrance, J., Berthelot, C., Muffato, M., . . Stemple, D. L. (2013). The zebrafish reference genome sequence and its relationship to the human genome. Nature, 496(7446), 498-503. doi: 10.1038/nature12111

Hurley, J. H. (2006). Membrane binding domains. Biochim Biophys Acta, 1761(8), 805-811. doi: 10.1016/j.bbalip.2006.02.020

Itoh, T., \& De Camilli, P. (2006). BAR, F-BAR (EFC) and ENTH/ANTH domains in the regulation of membrane-cytosol interfaces and membrane curvature. Biochim Biophys Acta, 1761(8), 897-912. doi: 10.1016/j.bbalip.2006.06.015

Itzhak, D. N., Tyanova, S., Cox, J., \& Borner, G. H. (2016). Global, quantitative and dynamic mapping of protein subcellular localization. Elife, 5. doi: 10.7554/eLife.16950

Jackson, A. P., Flett, A., Smythe, C., Hufton, L., Wettey, F. R., \& Smythe, E. (2003). Clathrin promotes incorporation of cargo into coated pits by activation of the AP2 adaptor micro2 kinase. J Cell Biol, 163(2), 231-236. doi: 10.1083/jcb.200304079

Jackson, L. P., Kelly, B. T., McCoy, A. J., Gaffry, T., James, L. C., Collins, B. M., . . Owen, D. J. (2010). A large-scale conformational change couples membrane recruitment to cargo binding in the AP2 clathrin adaptor complex. Cell, 141(7), 1220-1229. doi: 10.1016/j.cell.2010.05.006

Kadlecova, Z., Spielman, S. J., Loerke, D., Mohanakrishnan, A., Reed, D. K., \& Schmid, S. L. (2017). 
Regulation of clathrin-mediated endocytosis by hierarchical allosteric activation of AP2. J Cell Biol, 216(1), 167-179. doi: 10.1083/jcb.201608071

Kaksonen, M., \& Roux, A. (2018). Mechanisms of clathrin-mediated endocytosis. Nat Rev Mol Cell Biol, 19(5), 313-326. doi: 10.1038/nrm.2017.132

Kane, D. A., McFarland, K. N., \& Warga, R. M. (2005). Mutations in half baked/E-cadherin block cell behaviors that are necessary for teleost epiboly. Development, 132(5), 1105-1116. doi: 10.1242/dev.01668

Kearns, A. E., Donohue, M. M., Sanyal, B., \& Demay, M. B. (2001). Cloning and characterization of a novel protein kinase that impairs osteoblast differentiation in vitro. J Biol Chem, 276(45), 42213-42218. doi: 10.1074/jbc.M106163200

Kelly, B. T., Graham, S. C., Liska, N., Dannhauser, P. N., Honing, S., Ungewickell, E. J., \& Owen, D. J. (2014). Clathrin adaptors. AP2 controls clathrin polymerization with a membrane-activated switch.

Science, 345(6195), 459-463. doi: 10.1126/science.1254836

Kelly, B. T., McCoy, A. J., Spate, K., Miller, S. E., Evans, P. R., Honing, S., \& Owen, D. J. (2008). A structural explanation for the binding of endocytic dileucine motifs by the AP2 complex. Nature, 456(7224), 976-979. doi: 10.1038/nature07422

Kenyon, E. J., Campos, I., Bull, J. C., Williams, P. H., Stemple, D. L., \& Clark, M. D. (2015). Zebrafish Rab5 proteins and a role for Rab5ab in nodal signalling. Dev Biol, 397(2), 212-224. doi: 10.1016/j.ydbio.2014.11.007

Keyel, P. A., Thieman, J. R., Roth, R., Erkan, E., Everett, E. T., Watkins, S. C., . . Traub, L. M. (2008). The AP-2 adaptor beta2 appendage scaffolds alternate cargo endocytosis. Mol Biol Cell, 19(12), 53095326. doi: 10.1091/mbc.E08-07-0712

Kirchhausen, T., Owen, D., \& Harrison, S. C. (2014). Molecular structure, function, and dynamics of clathrin-mediated membrane traffic. Cold Spring Harb Perspect Biol, 6(5), a016725. doi:

10.1101/cshperspect.a016725

Krieger, J. R., Taylor, P., Gajadhar, A. S., Guha, A., Moran, M. F., \& McGlade, C. J. (2013). Identification and selected reaction monitoring (SRM) quantification of endocytosis factors associated with Numb. Mol Cell Proteomics, 12(2), 499-514. doi: 10.1074/mcp.M112.020768

Lampe, M., Vassilopoulos, S., \& Merrifield, C. (2016). Clathrin coated pits, plaques and adhesion. J Struct Biol, 196(1), 48-56. doi: 10.1016/j.jsb.2016.07.009

Lazetic V \& Fay DS (2017). Conserved ankyrin repeat proteins and their NIMA kinase partners regulate extracellular matrix remodeling and intracellular trafficking in Caenorhabditis elegans. Genetics, 205, 273-93.

Lazetic V, Joseph BB, Bernazzani SM, \& Fay DS. (2018). Actin organization and endocytic trafficking are controlled by a network linking NIMA-related kinases to the CDC-42-SID-3/ACK1 pathway. PLoS Genet,14(4), e1007313. doi: 10.1371/journal.pgen.1007313.

Lepage, S. E., Tada, M., \& Bruce, A. E. (2014). Zebrafish Dynamin is required for maintenance of enveloping layer integrity and the progression of epiboly. Dev Biol, 385(1), 52-66. doi: 


\subsection{6/j.ydbio.2013.10.015}

Leyton-Puig, D., Isogai, T., Argenzio, E., van den Broek, B., Klarenbeek, J., Janssen, H., . . Innocenti, M. (2017). Flat clathrin lattices are dynamic actin-controlled hubs for clathrin-mediated endocytosis and signalling of specific receptors. Nat Commun, 8, 16068. doi: 10.1038/ncomms 16068

Liu, H. P., Lin, Y. J., Lin, W. Y., Wan, L., Sheu, J. J., Lin, H. J., . . Tsai, F. J. (2009). A novel genetic variant of BMP2K contributes to high myopia. J Clin Lab Anal, 23(6), 362-367. doi: 10.1002/jcla.20344

Loerke, D., Mettlen, M., Yarar, D., Jaqaman, K., Jaqaman, H., Danuser, G., Schmid, S. L. (2009). Cargo and dynamin regulate clathrin-coated pit maturation. PLoS Biol, 7(3), e57. doi:

10.1371/journal.pbio.1000057.

Lu, Z., \& Hunter, T. Degradation of activated protein kinases by ubiquitination. (2009). Annu Rev Biochem, 78, 435-75. doi: 10.1146/annurev.biochem.013008.092711.

Ma, L., Umasankar, P. K., Wrobel, A. G., Lymar, A., McCoy, A. J., Holkar, S. S., . . Traub, L. M. (2016). Transient Fcho1/2.Eps15/R.AP-2 Nanoclusters Prime the AP-2 Clathrin Adaptor for Cargo Binding. Dev Cell, 37(5), 428-443. doi: 10.1016/j.devcel.2016.05.003

Mayers, J. R., Wang, L., Pramanik, J., Johnson, A., Sarkeshik, A., Wang, Y., . . Audhya, A. (2013). Regulation of ubiquitin-dependent cargo sorting by multiple endocytic adaptors at the plasma membrane. Proc Natl Acad Sci U S A, 110(29), 11857-11862. doi: 10.1073/pnas.1302918110

McMahon HT, \& Boucrot E. (2011). Molecular mechanism and physiological functions of clathrinmediated endocytosis. Nat Rev Mol Cell Biol,12(8), 517-33. doi: 10.1038/nrm3151.

Mercado-Matos, J., Janusis, J., Zhu, S., Chen, S. S., \& Shaw, L. M. (2018). Identification of a Novel Invasion-Promoting Region in Insulin Receptor Substrate 2. Mol Cell Biol, 38(14). doi:

10.1128/MCB.00590-17

Mettlen, M., Stoeber, M., Loerke, D., Antonescu, C. N., Danuser, G., Schmid, S. L. (2009). Endocytic accessory proteins are functionally distinguished by their differential effects on the maturation of clathrincoated pits. Mol Biol Cell, 20(14), 3251-60. doi: 10.1091/mbc.E09-03-0256.

Mettlen, M., Chen, P. H., Srinivasan, S., Danuser, G., \& Schmid, S. L. (2018). Regulation of ClathrinMediated Endocytosis. Annu Rev Biochem, 87, 871-896. doi:10.1146/annurev-biochem-062917-012644

Mishra, S. K., Hawryluk, M. J., Brett, T. J., Keyel, P. A., Dupin, A. L., Jha, A., . . Traub, L. M. (2004). Dual engagement regulation of protein interactions with the AP-2 adaptor alpha appendage. $J$ Biol Chem, 279(44), 46191-46203. doi: 10.1074/jbc.M408095200

Mitsunari, T., Nakatsu, F., Shioda, N., Love, P. E., Grinberg, A., Bonifacino, J. S., \& Ohno, H. (2005). Clathrin adaptor AP-2 is essential for early embryonal development. Mol Cell Biol, 25(21), 9318-9323. doi: 10.1128/MCB.25.21.9318-9323.2005

Molina, G., Vogt, A., Bakan, A., Dai, W., Queiroz de Oliveira, P., Znosko, W., . . Tsang, M. (2009). Zebrafish chemical screening reveals an inhibitor of Dusp6 that expands cardiac cell lineages. Nat Chem Biol, 5(9), 680-687. doi: 10.1038/nchembio.190 
Motley, A., Bright, N. A., Seaman, M. N., \& Robinson, M. S. (2003). Clathrin-mediated endocytosis in AP-2-depleted cells. J Cell Biol 162(5), 909-18. doi: 10.1083/jcb.200305145

Mulkearns, E. E., \& Cooper, J. A. (2012). FCH domain only-2 organizes clathrin-coated structures and interacts with Disabled-2 for low-density lipoprotein receptor endocytosis. Mol Biol Cell, 23(7), 13301342. doi: 10.1091/mbc.E11-09-0812

Nie, Z., Boehm, M., Boja, E. S., Vass, W. C., Bonifacino, J. S., Fales, H. M., \& Randazzo, P. A. (2003). Specific regulation of the adaptor protein complex AP-3 by the Arf GAP AGAP1. Dev Cell, 5(3), 513521.

Nunez, D., Antonescu, C., Mettlen, M., Liu, A., Schmid, S. L., Loerke, D., \& Danuser, G. (2011). Hotspots organize clathrin-mediated endocytosis by efficient recruitment and retention of nucleating resources. Traffic, 12(12), 1868-1878. doi: 10.1111/j.1600-0854.2011.01273.x

Ohkawara, B., Glinka, A., \& Niehrs, C. (2011). Rspo3 binds syndecan 4 and induces Wnt/PCP signaling via clathrin-mediated endocytosis to promote morphogenesis. Dev Cell, 20(3), 303-314. doi:

10.1016/j.devcel.2011.01.006

Olusanya, O., Andrews, P. D., Swedlow, J. R., \& Smythe, E. (2001). Phosphorylation of threonine 156 of the mu2 subunit of the AP2 complex is essential for endocytosis in vitro and in vivo. Curr Biol, 11(11), 896-900. doi: 10.1016/s0960-9822(01)00240-8

Orr, H. T., \& Zoghbi, H. Y. (2007). Trinucleotide repeat disorders. Annu Rev Neurosci, 30, 575-621. doi: 10.1146/annurev.neuro.29.051605.113042

Owen, D. J., Collins, B. M., \& Evans, P. R. (2004). Adaptors for clathrin coats: structure and function. Annu Rev Cell Dev Biol, 20, 153-191. doi: 10.1146/annurev.cellbio.20.010403.104543

Pandzic, T., Larsson, J., He, L., Kundu, S., Ban, K., Akhtar-Ali, M., . . Hellstrom, M. (2016). Transposon Mutagenesis Reveals Fludarabine Resistance Mechanisms in Chronic Lymphocytic Leukemia. Clin Cancer Res, 22(24), 6217-6227. doi: 10.1158/1078-0432.CCR-15-2903

Partlow, E. A., Baker, R. W., Beacham, G. M., Chappie, J. S., Leschziner, A. E., \& Hollopeter, G. (2019). A structural mechanism for phosphorylation-dependent inactivation of the AP2 complex. Elife, 8. doi: 10.7554/eLife.50003

Pauloin, A., \& Thurieau, C. (1993). The $50 \mathrm{kDa}$ protein subunit of assembly polypeptide (AP) AP-2 adaptor from clathrin-coated vesicles is phosphorylated on threonine-156 by AP-1 and a soluble AP50 kinase which co-purifies with the assembly polypeptides. Biochem J, 296 ( Pt 2), 409-415. doi: $10.1042 / \mathrm{bj} 2960409$

Piper, R. C., Dikic, I., \& Lukacs, G. L. (2014). Ubiquitin-dependent sorting in endocytosis. Cold Spring Harb Perspect Biol. 6(1), pii: a016808. doi: 10.1101/cshperspect.a016808.

Praefcke, G. J., Ford, M. G., Schmid, E. M., Olesen, L. E., Gallop, J. L., Peak-Chew, S. Y., . . . McMahon, H. T. (2004). Evolving nature of the AP2 alpha-appendage hub during clathrin-coated vesicle endocytosis. EMBO J, 23(22), 4371-4383. doi: 10.1038/sj.emboj.7600445

Pryor, P. R., Jackson, L., Gray, S. R., Edeling, M. A., Thompson, A., Sanderson, C. M., . . Luzio, J. P. (2008). Molecular basis for the sorting of the SNARE VAMP7 into endocytic clathrin-coated vesicles by 
the ArfGAP Hrb. Cell, 134(5), 817-827. doi: 10.1016/j.cell.2008.07.023

Reider, A., Barker, S. L., Mishra, S. K., Im, Y. J., Maldonado-Baez, L., Hurley, J. H., . . Wendland, B. (2009). Syp1 is a conserved endocytic adaptor that contains domains involved in cargo selection and membrane tubulation. EMBO J, 28(20), 3103-3116. doi: 10.1038/emboj.2009.248

Reis, C. R., Chen, P. H., Srinivasan, S., Aguet, F., Mettlen, M., \& Schmid, S. L. (2015). Crosstalk between Akt/GSK3beta signaling and dynamin-1 regulates clathrin-mediated endocytosis. EMBO J, 34(16), 2132-2146. doi: 10.15252/embj.201591518

Ren, X., Farias, G. G., Canagarajah, B. J., Bonifacino, J. S., \& Hurley, J. H. (2013). Structural basis for recruitment and activation of the AP-1 clathrin adaptor complex by Arf1. Cell, 152(4), 755-767. doi: 10.1016/j.cell.2012.12.042

Ricotta, D., Conner, S. D., Schmid, S. L., von Figura, K., \& Honing, S. (2002). Phosphorylation of the AP2 mu subunit by AAK1 mediates high affinity binding to membrane protein sorting signals. $J$ Cell Biol, 156(5), 791-795. doi: 10.1083/jcb.200111068

Ritter, B., Philie, J., Girard, M., Tung, E. C., Blondeau, F., \& McPherson, P. S. (2003). Identification of a family of endocytic proteins that define a new alpha-adaptin ear-binding motif. EMBO Rep., 4(11), 108995. doi: 10.1038/sj.embor.embor7400004

Ritter, B., Murphy, S., Dokainish, H., Girard, M., Gudheti, M. V., Kozlov, G., . . McPherson, P. S. (2013). NECAP 1 regulates AP-2 interactions to control vesicle size, number, and cargo during clathrinmediated endocytosis. PLoS Biol, 11(10), e1001670. doi: 10.1371/journal.pbio.1001670

Robinson, M. S. (2004). Adaptable adaptors for coated vesicles. Trends Cell Biol, 14(4), 167-174. doi: 10.1016/j.tcb.2004.02.002

Roszko, I., Sawada, A., \& Solnica-Krezel, L. (2009). Regulation of convergence and extension movements during vertebrate gastrulation by the Wnt/PCP pathway. Semin Cell Dev Biol, 20(8), 986-997. doi: 10.1016/j.semcdb.2009.09.004

Schaefer, M. H., Wanker, E. E., \& Andrade-Navarro, M. A. (2012). Evolution and function of CAG/polyglutamine repeats in protein-protein interaction networks. Nucleic Acids Res, 40(10), 42734287. doi: $10.1093 / \mathrm{nar} / \mathrm{gks} 011$

Schindelin, J., Arganda-Carreras, I., Frise, E., Kaynig, V., Longair, M., Pietzsch, T., Preibisch, S., \& Cardona A. (2012). Fiji: an open-source platform for biological-image analysis. Nature methods 9(7), 676-682. doi: 10.1038/nmeth.2019

Schmid, E. M., \& McMahon, H. T. (2007). Integrating molecular and network biology to decode endocytosis. Nature, 448(7156), 883-888. doi: 10.1038/nature06031

Schmid, S. L., \& Frolov, V. A. (2011). Dynamin: functional design of a membrane fission catalyst. Annu Rev Cell Dev Biol, 27, 79-105. doi: 10.1146/annurev-cellbio-100109-104016

Shih, W., Gallusser, A., \& Kirchhausen, T. (1995). A clathrin-binding site in the hinge of the beta 2 chain of mammalian AP-2 complexes. J Biol Chem, 270(52), 31083-31090. doi: 10.1074/jbc.270.52.31083

Smythe, E. (2002). Regulating the clathrin-coated vesicle cycle by AP2 subunit phosphorylation. Trends 
Cell Biol, 12(8), 352-354.

Solnica-Krezel, L. (2006). Gastrulation in zebrafish -- all just about adhesion? Curr Opin Genet Dev, 16(4), 433-441. doi: 10.1016/j.gde.2006.06.009

Song, S., Eckerle, S., Onichtchouk, D., Marrs, J. A., Nitschke, R., \& Driever, W. (2013). Pou5f1dependent EGF expression controls E-cadherin endocytosis, cell adhesion, and zebrafish epiboly movements. Dev Cell, 24(5), 486-501. doi: 10.1016/j.devcel.2013.01.016

Sorkin, A. (2004). Cargo recognition during clathrin-mediated endocytosis: a team effort. Curr Opin Cell Biol, 16(4), 392-399. doi: 10.1016/j.ceb.2004.06.001

Sorrell, F. J., Szklarz, M., Abdul Azeez, K. R., Elkins, J. M., \& Knapp, S. (2016). Family-wide Structural Analysis of Human Numb-Associated Protein Kinases. Structure, 24(3), 401-411. doi:

10.1016/j.str.2015.12.015

Tada, M., \& Heisenberg, C. P. (2012). Convergent extension: using collective cell migration and cell intercalation to shape embryos. Development, 139(21), 3897-3904. doi: 10.1242/dev.073007

Taylor, M. J., Perrais, D., \& Merrifield, C. J. (2011). A high precision survey of the molecular dynamics of mammalian clathrin-mediated endocytosis. PLoS Biol, 9(3), e1000604. doi:

10.1371/journal.pbio.1000604

Totzeck, F., Andrade-Navarro, M. A., \& Mier, P. (2017). The Protein Structure Context of PolyQ Regions. PLoS One, 12(1), e0170801. doi: 10.1371/journal.pone.0170801

Traub, L. M. (2009). Tickets to ride: selecting cargo for clathrin-regulated internalization. Nat Rev Mol Cell Biol, 10(9), 583-596. doi: 10.1038/nrm2751

Traub, L. M. (2019). A nanobody-based molecular toolkit provides new mechanistic insight into clathrincoat initiation. Elife, 8. doi: 10.7554/eLife.41768

Traub, L. M., \& Bonifacino, J. S. (2013). Cargo recognition in clathrin-mediated endocytosis. Cold Spring Harb Perspect Biol, 5(11), a016790. doi: 10.1101/cshperspect.a016790

Traub, L. M., Downs, M. A., Westrich, J. L., \& Fremont, D. H. (1999). Crystal structure of the alpha appendage of AP-2 reveals a recruitment platform for clathrin-coat assembly. Proc Natl Acad Sci U S A, 96(16), 8907-8912. doi: 10.1073/pnas.96.16.8907

Tsang, M., Maegawa, S., Kiang, A., Habas, R., Weinberg, E., \& Dawid, I. B. (2004). A role for MKP3 in axial patterning of the zebrafish embryo. Development, 131(12), 2769-2779. doi: 10.1242/dev.01157

Umasankar, P. K., Ma, L., Thieman, J. R., Jha, A., Doray, B., Watkins, S. C., \& Traub, L. M. (2014). A clathrin coat assembly role for the muniscin protein central linker revealed by TALEN-mediated gene editing. Elife, 3. doi: 10.7554/eLife.04137

Umasankar, P. K., Sanker, S., Thieman, J. R., Chakraborty, S., Wendland, B., Tsang, M., \& Traub, L. M. (2012). Distinct and separable activities of the endocytic clathrin-coat components Fcho1/2 and AP-2 in developmental patterning. Nat Cell Biol, 14(5), 488-501. doi: 10.1038/ncb2473

Westerfield, M. (2000). The Zebrafish Book. A Guide for the Laboratory Use of Zebrafish (Danio rerio). 
Wieteska, L., Shahidi, S., Zhuravleva, A. (2017). Allosteric fine-tuning of the conformational equilibrium poises the chaperone BiP for post-translational regulation. Elife, 6, pii: e29430. doi: 10.7554/eLife.29430.

Wilde, A., \& Brodsky, F. M. (1996). In vivo phosphorylation of adaptors regulates their interaction with clathrin. J Cell Biol, 135(3), 635-645. doi: 10.1083/jcb.135.3.635

Wrobel, A. G., Kadlecova, Z., Kamenicky, J., Yang, J. C., Herrmann, T., Kelly, B. T., . . Owen, D. J. (2019). Temporal Ordering in Endocytic Clathrin-Coated Vesicle Formation via AP2 Phosphorylation. Dev Cell, 50(4), 494-508 e411. doi: 10.1016/j.devcel.2019.07.017

Yochem J, Lazetic V, Bell L, Chen L, \& Fay D. C. elegans NIMA-related kinases NEKL-2 and NEKL-3 are required for the completion of molting. (2015). Dev Biol,398(2), 255-66. doi: S0012-1606(14)00634-4 [pii] 10.1016/j.ydbio.2014.12.008.

Yu, A., Rual, J. F., Tamai, K., Harada, Y., Vidal, M., He, X., \& Kirchhausen, T. (2007). Association of Dishevelled with the clathrin AP-2 adaptor is required for Frizzled endocytosis and planar cell polarity signaling. Dev Cell, 12(1), 129-141. doi: 10.1016/j.devcel.2006.10.015

Zhao, L., Zhou, Z., Wang, S., Jiao, Q., Wu, J., Ma, F., . . Ying, H. (2017). A recurrent mutation in bone morphogenetic proteins-2-inducible kinase gene is associated with developmental dysplasia of the hip. Exp Ther Med, 13(5), 1773-1778. doi: 10.3892/etm.2017.4191

Zhou, H., Xu, M., Huang, Q., Gates, A. T., Zhang, X. D., Castle, J. C., . . Espeseth, A. S. (2008).

Genome-scale RNAi screen for host factors required for HIV replication. Cell Host Microbe, 4(5), 495504. doi: 10.1016/j.chom.2008.10.004 


\section{Figure 1}
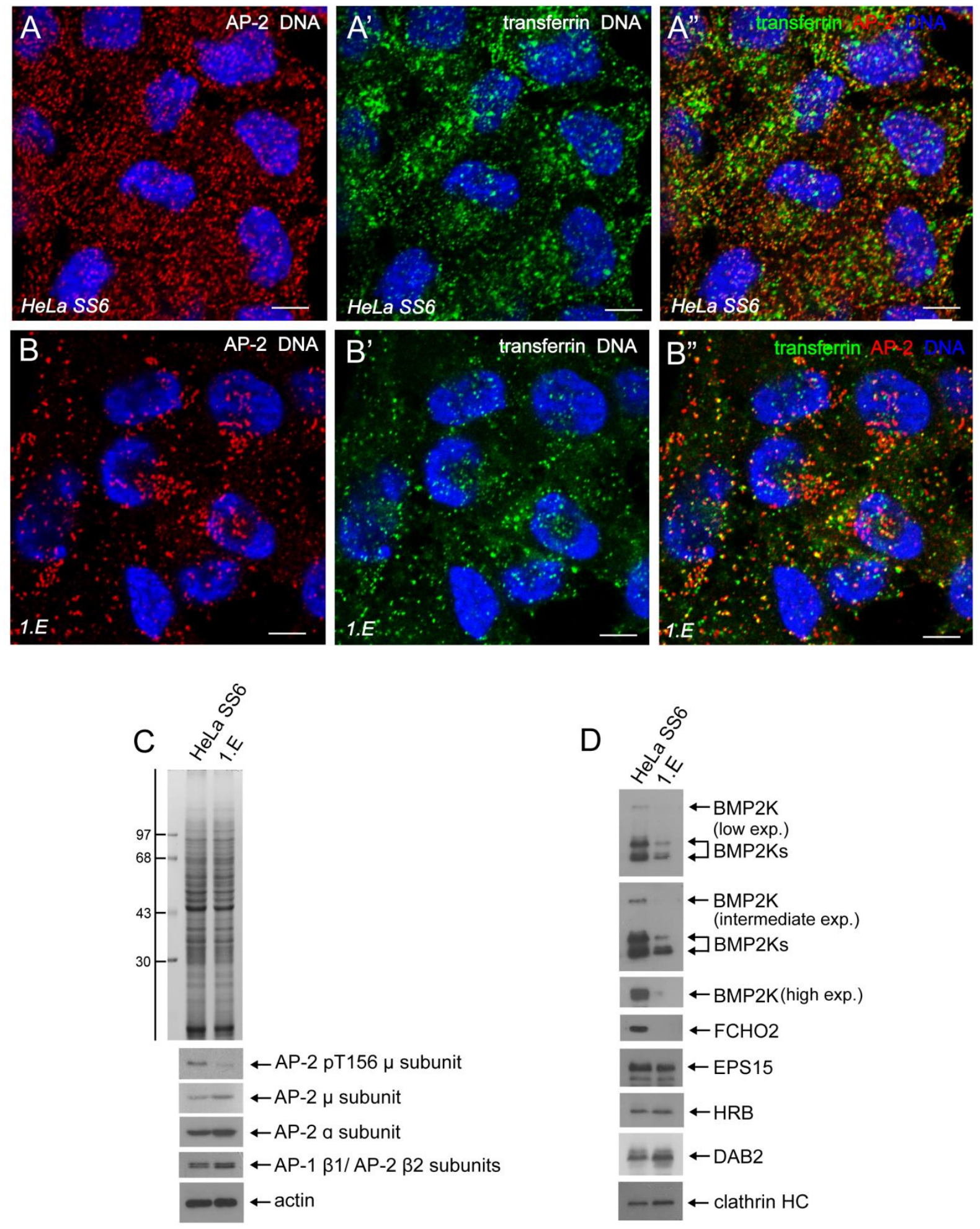


\section{Figure 2}
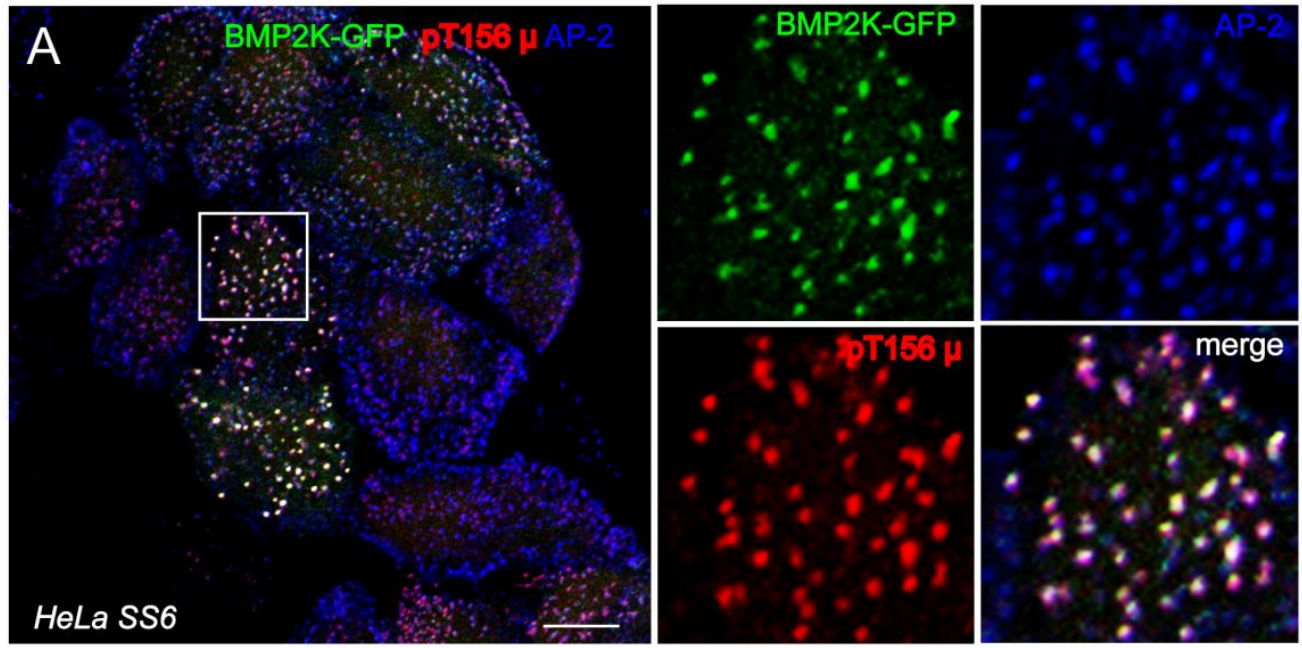

B

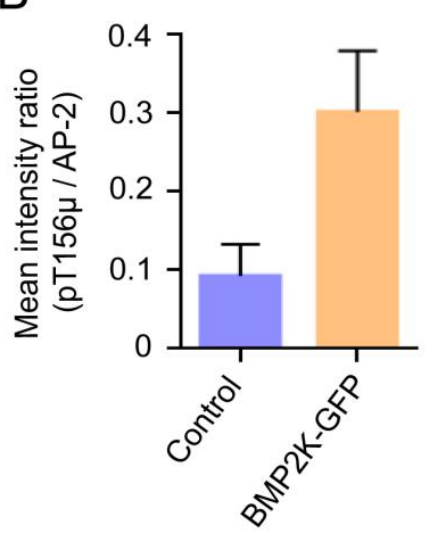

C

D

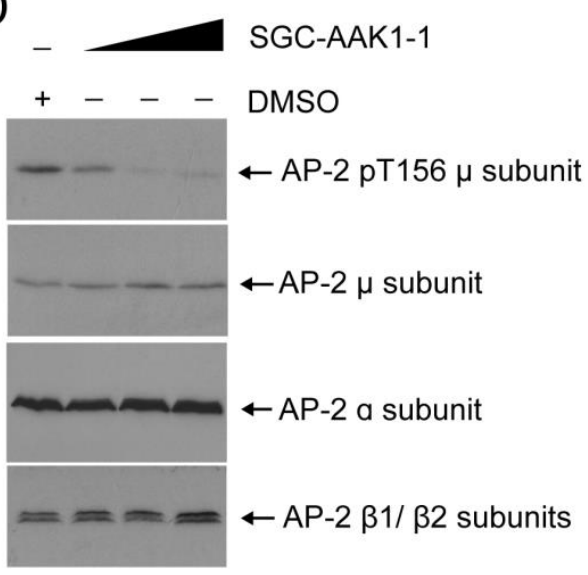

BMP2K-GFP $--\quad+$

BMP2K --+-

Calyculin -+--

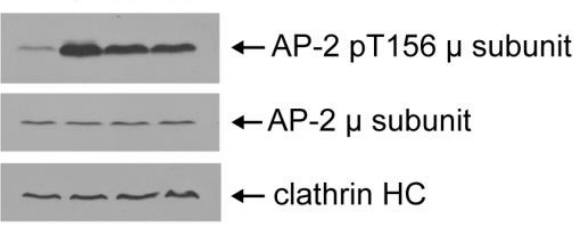

E

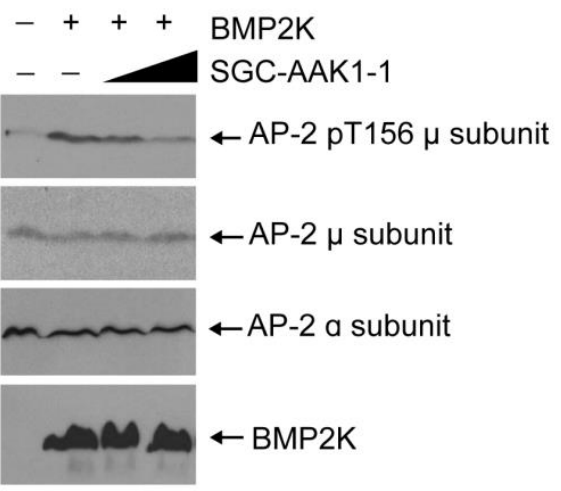




\section{Figure 2- figure supplement 1}

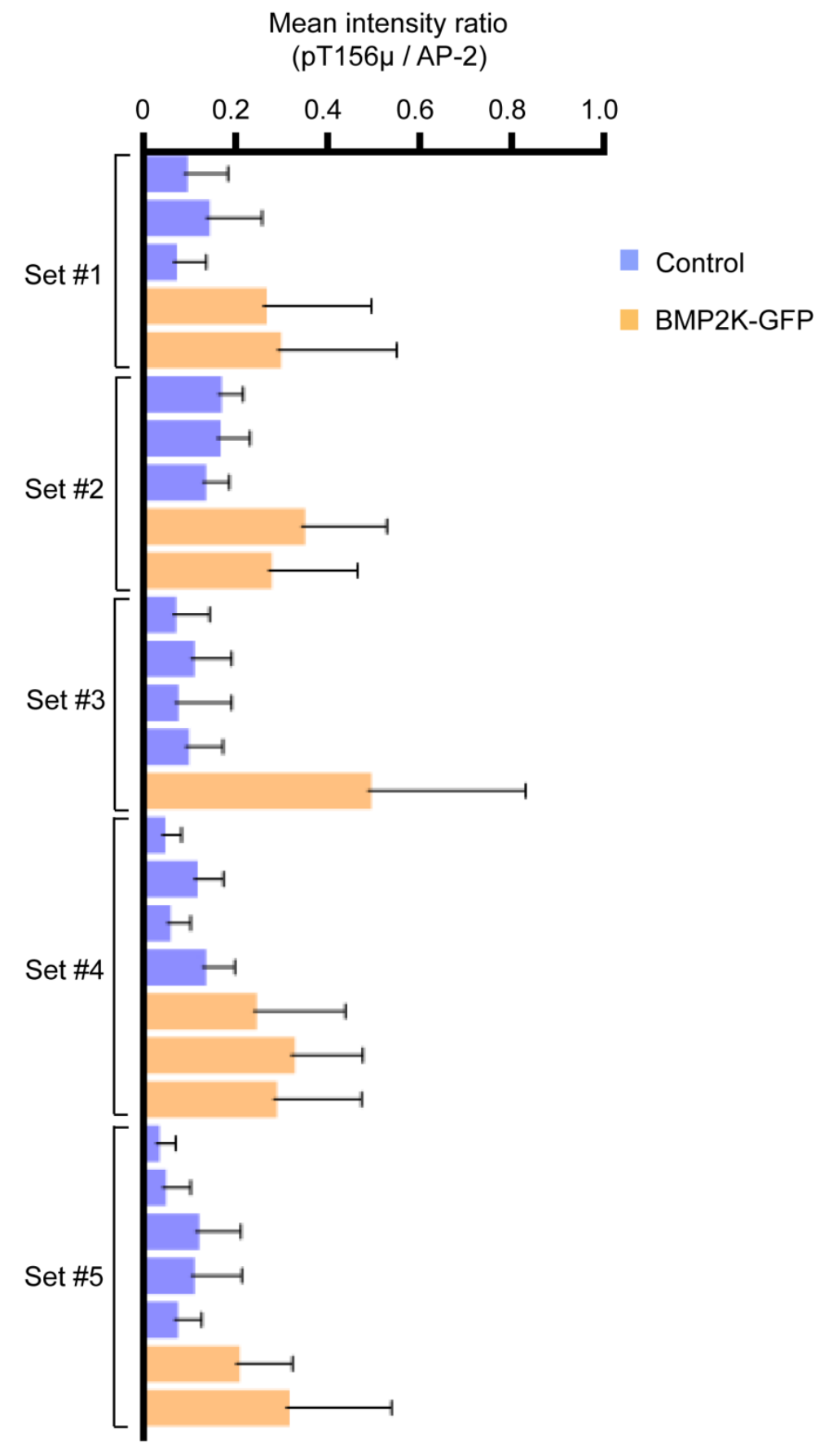




\section{Figure 3}
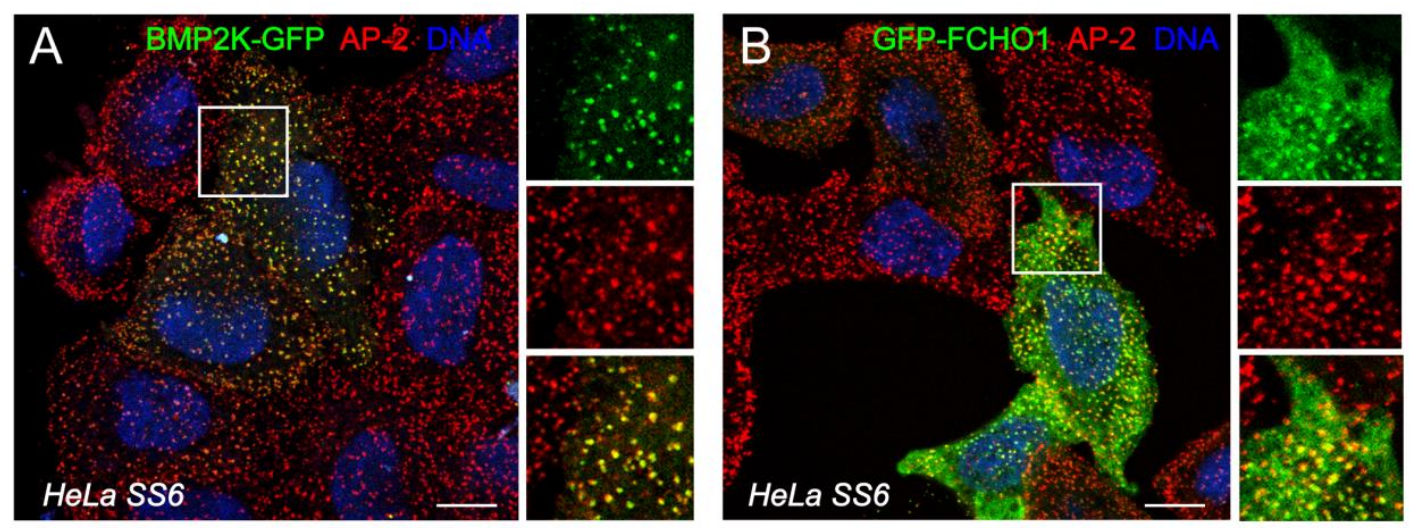

C
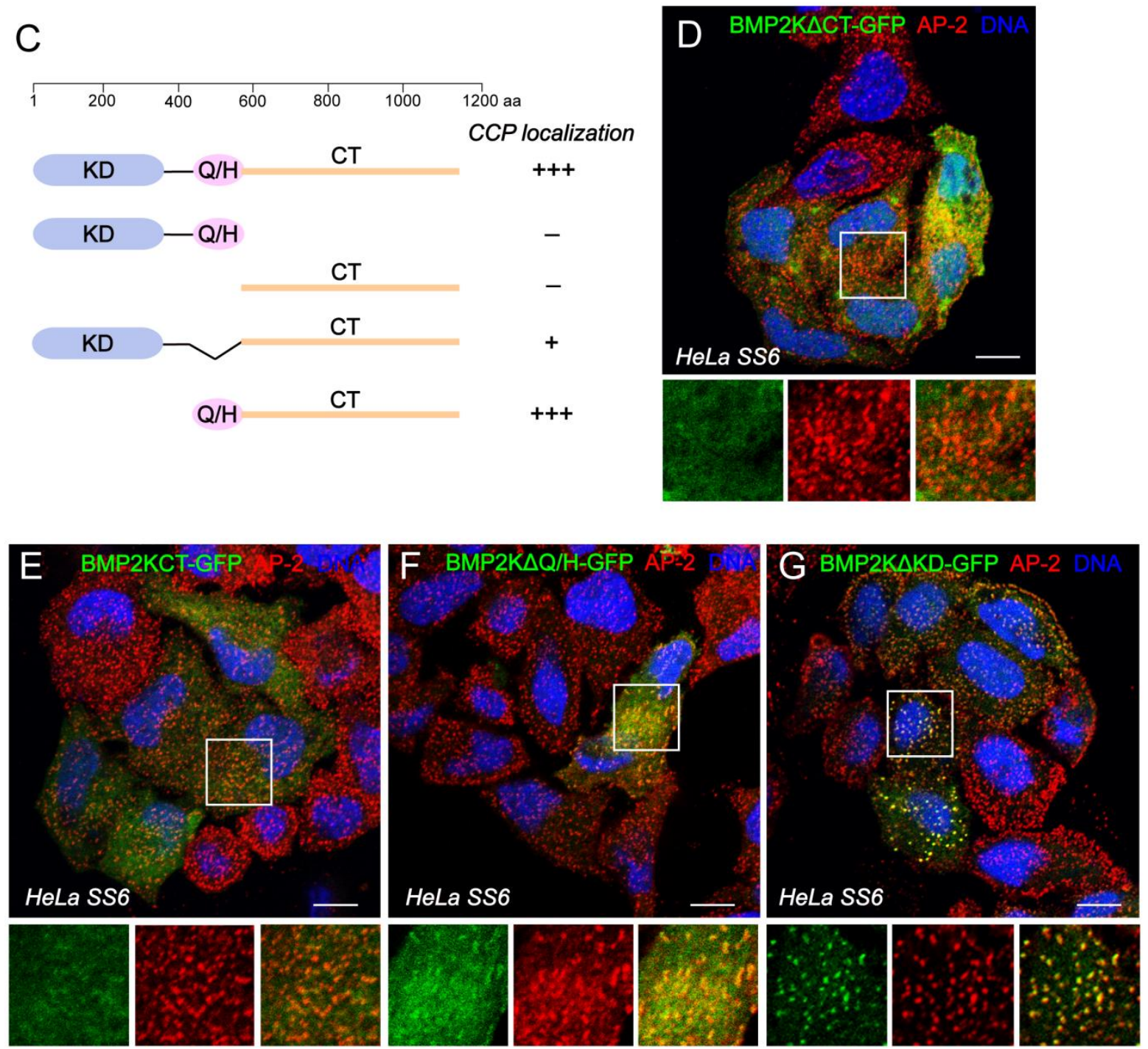


\section{Figure 3- figure supplement 1}
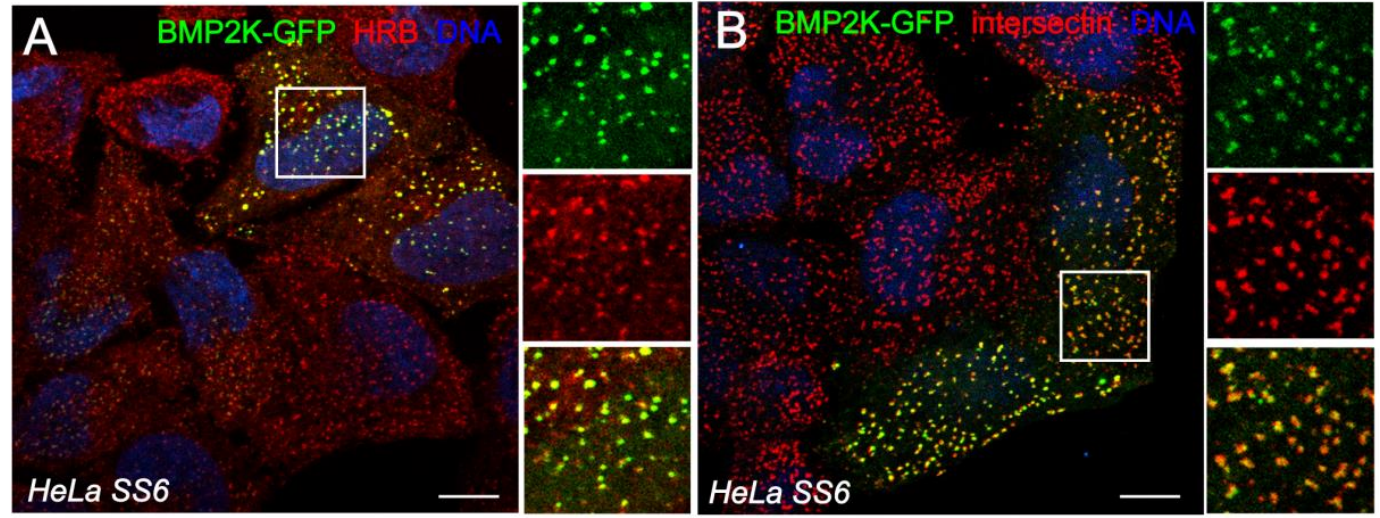


\section{Figure 4}

A

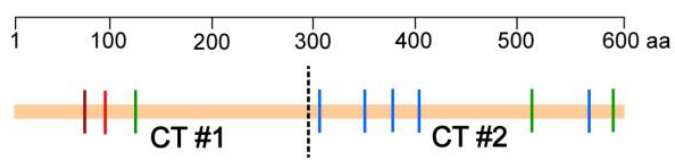

$\begin{array}{ll}\text { |WXXF } & \text { DPF } \\ \text { DLL } & \text { |DXFXXXPF }\end{array}$
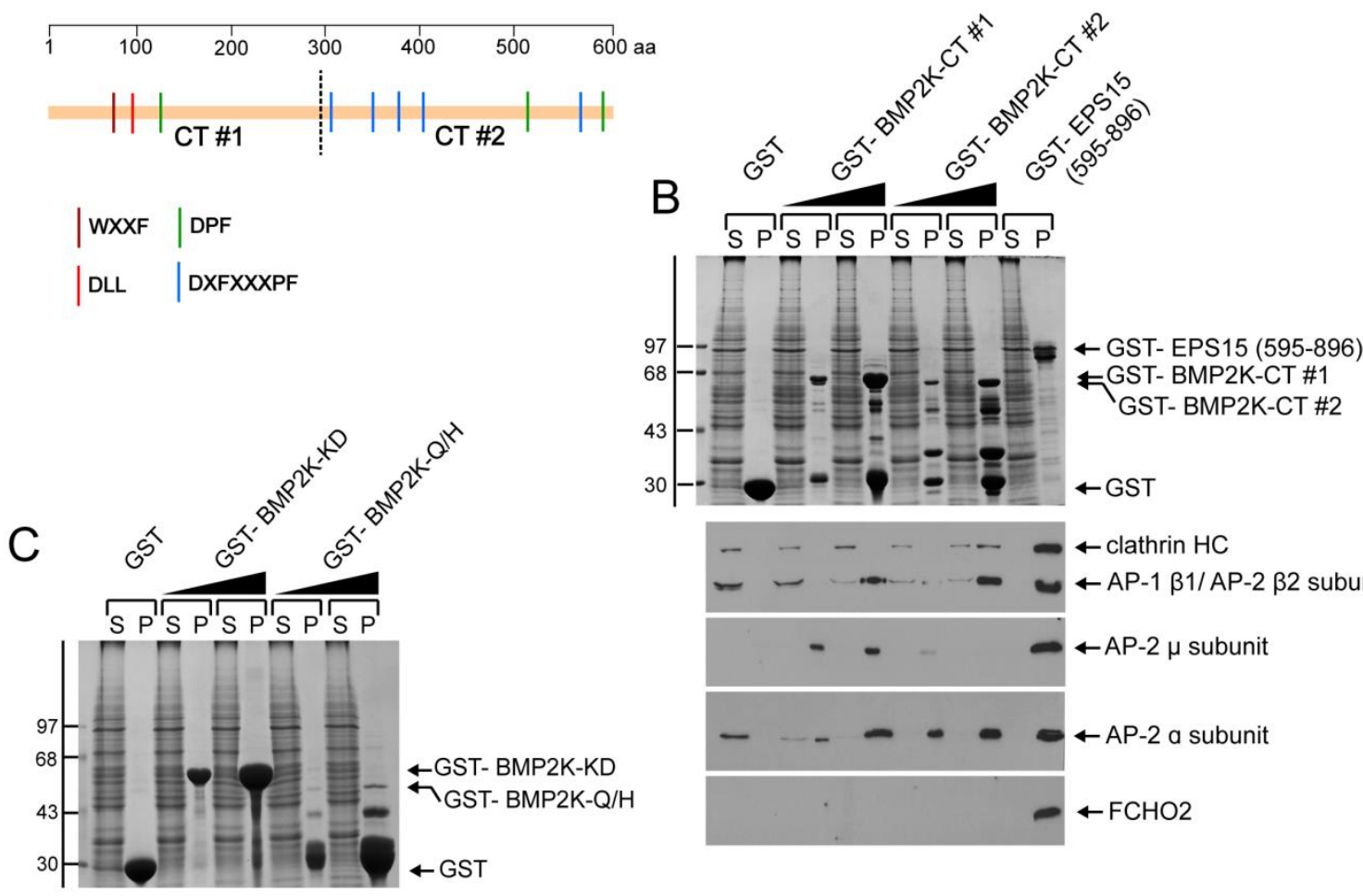

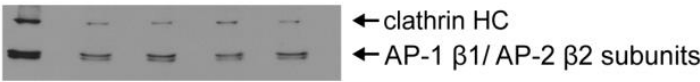
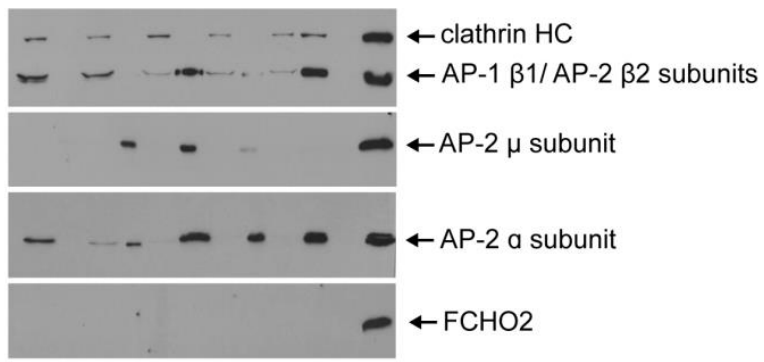
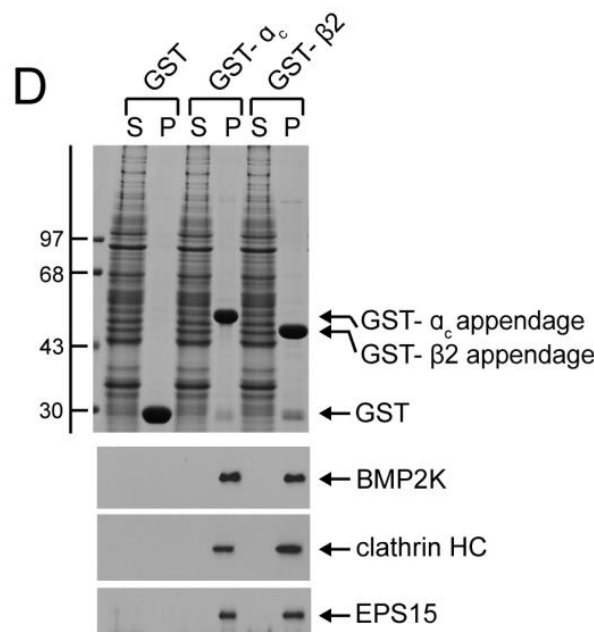

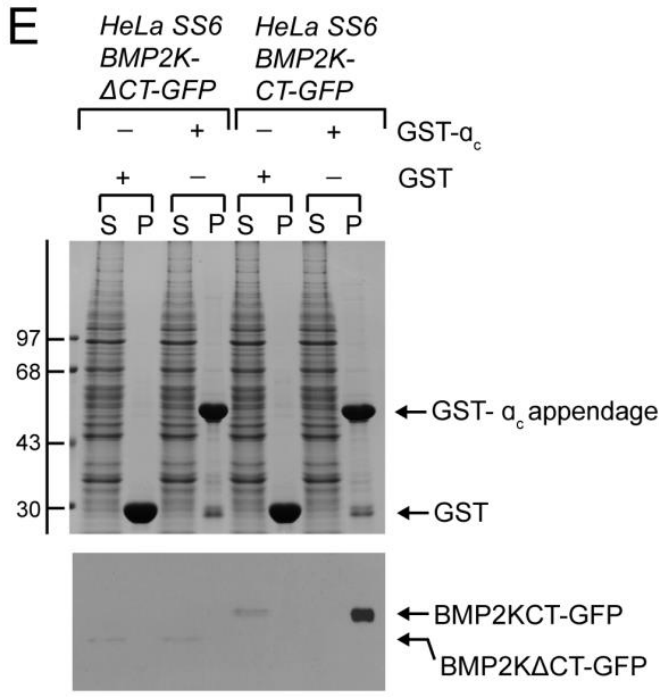




\section{Figure 5}

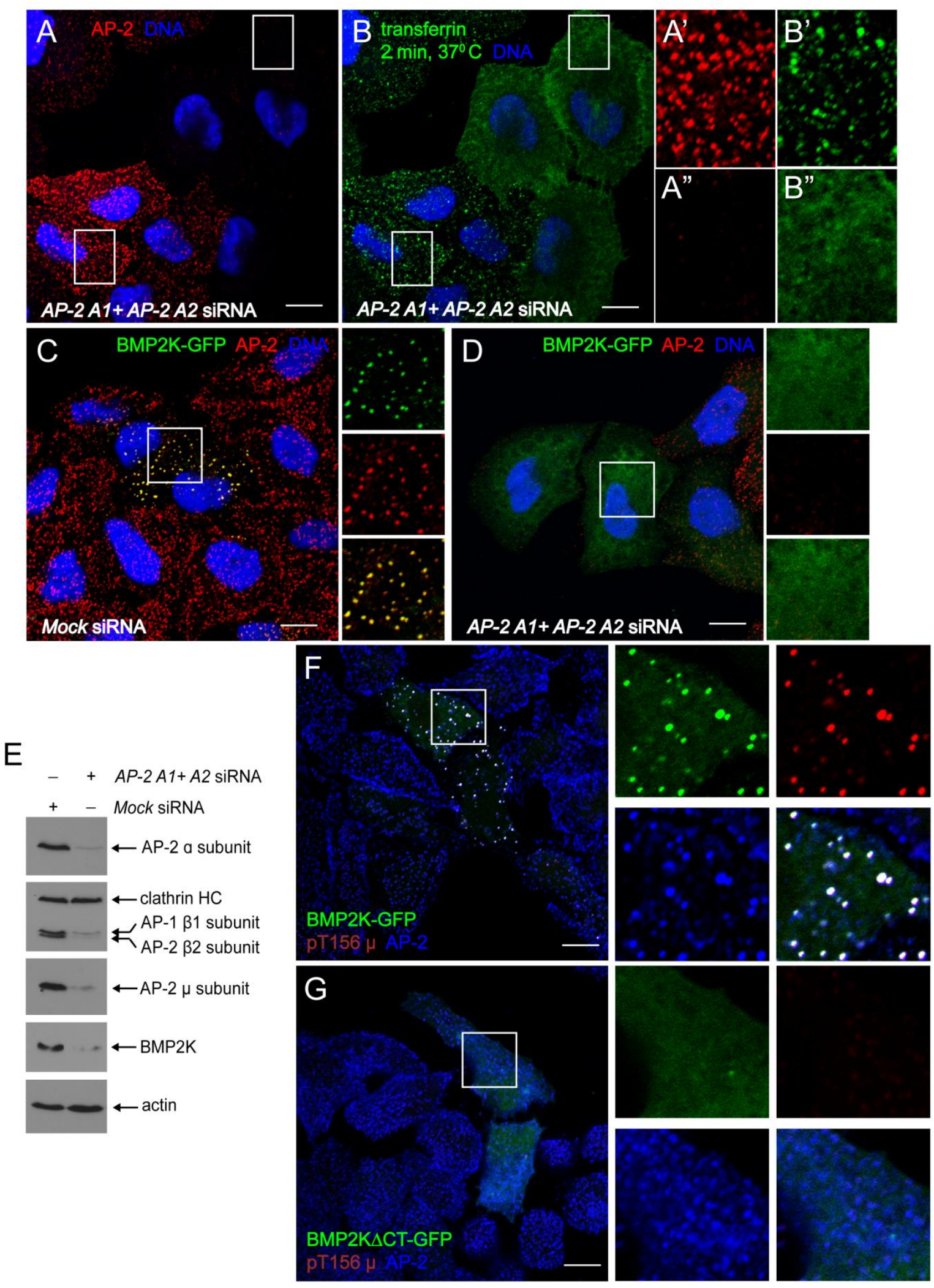




\section{Figure 6}
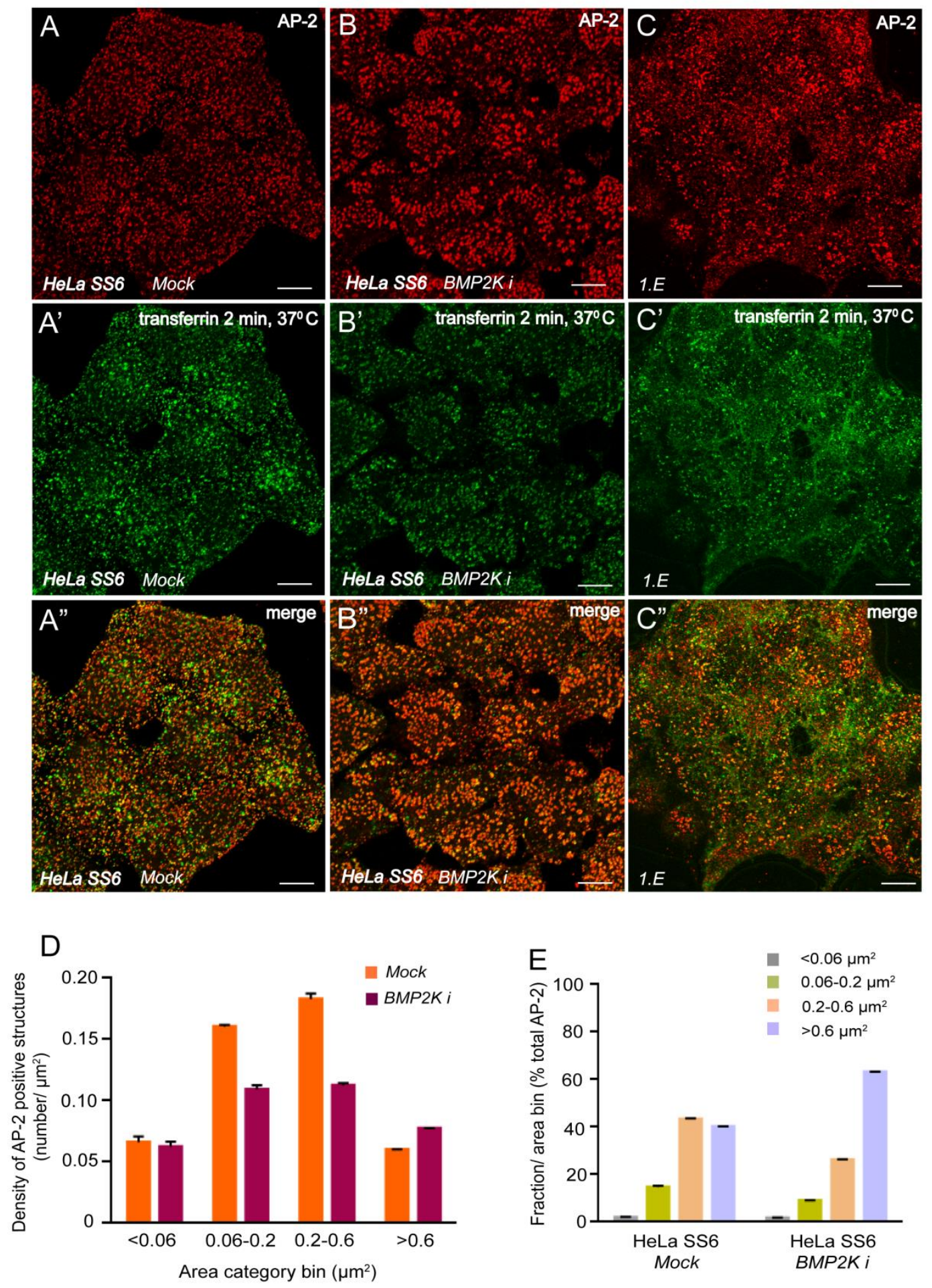


\section{Figure 6- figure supplement 1}
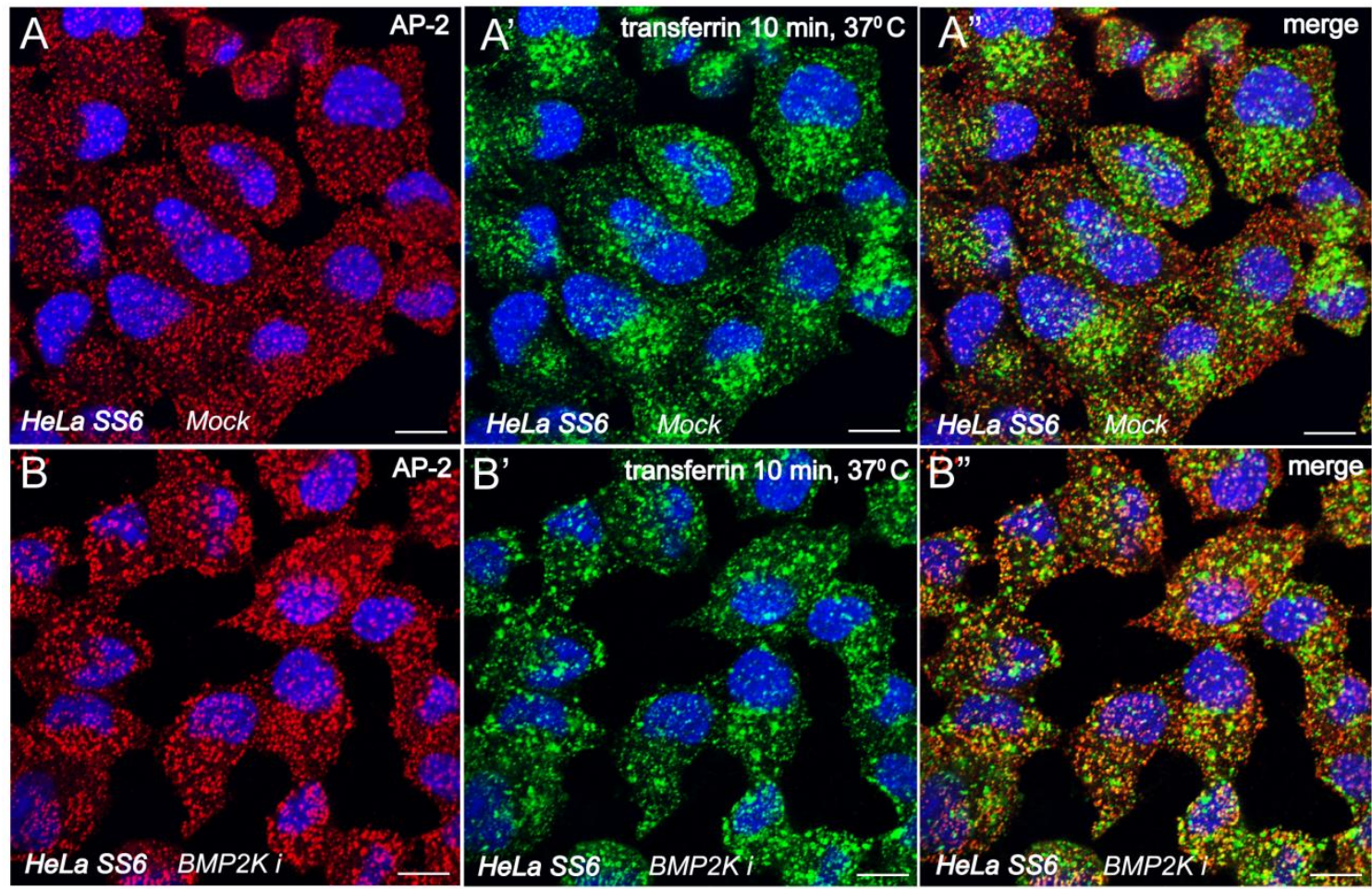


\section{Figure 7}

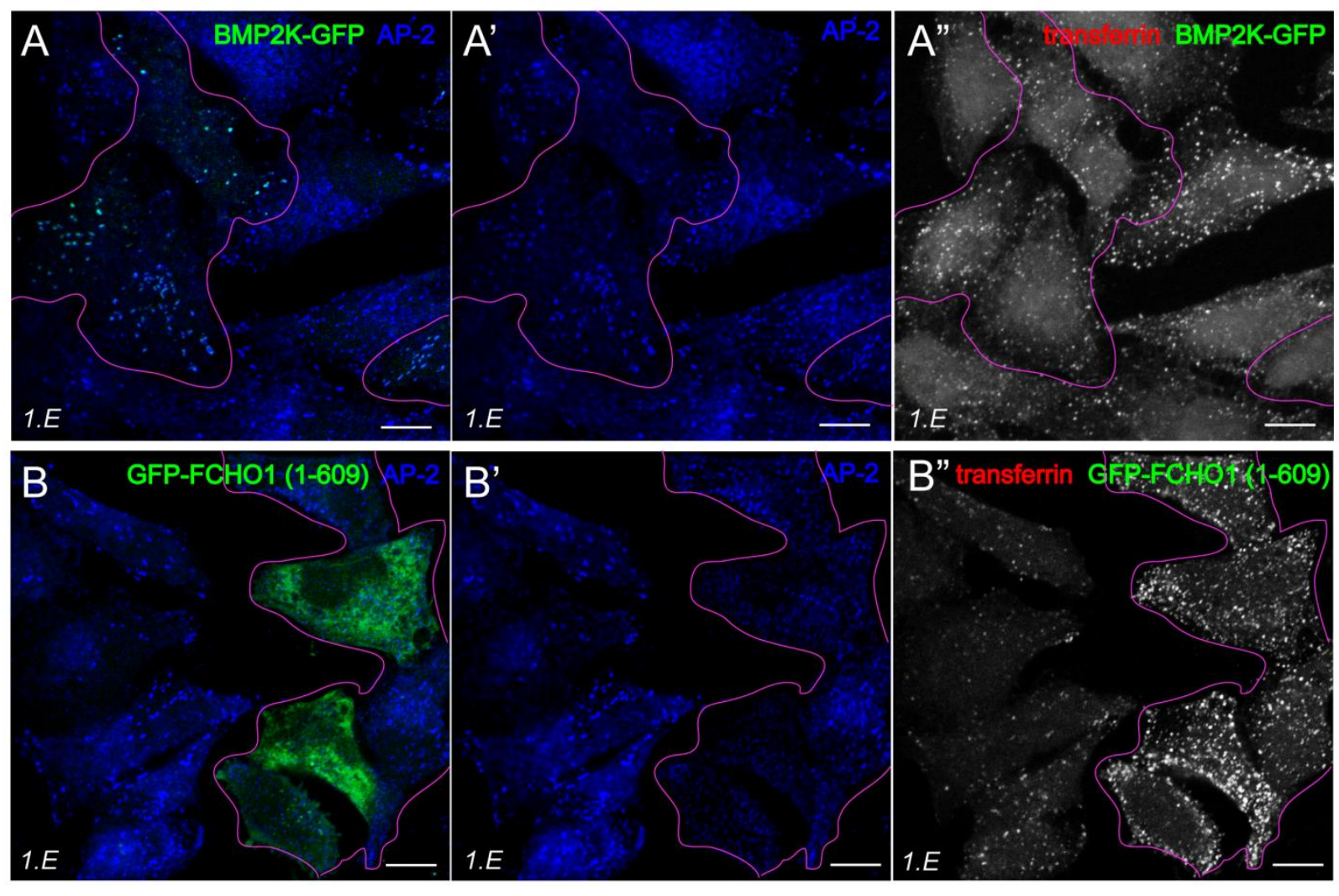

\section{C}

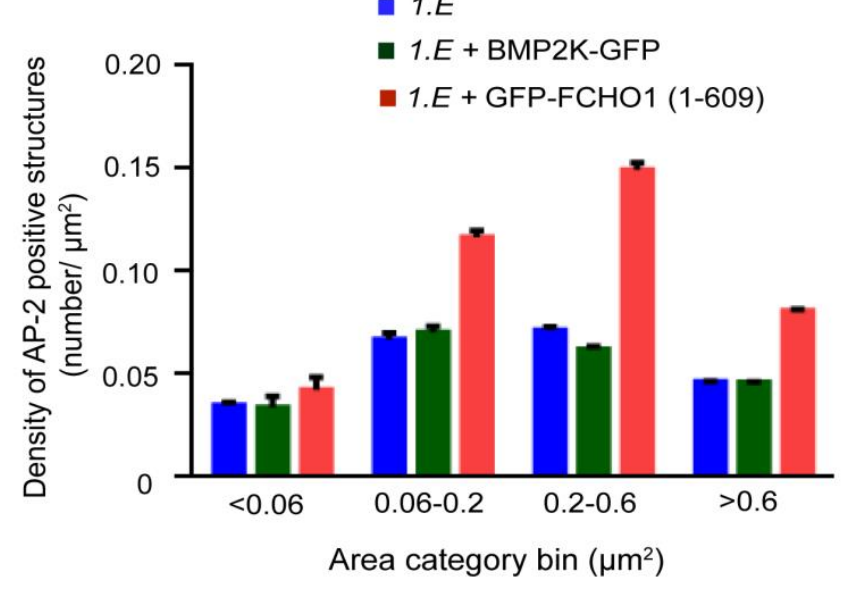

D

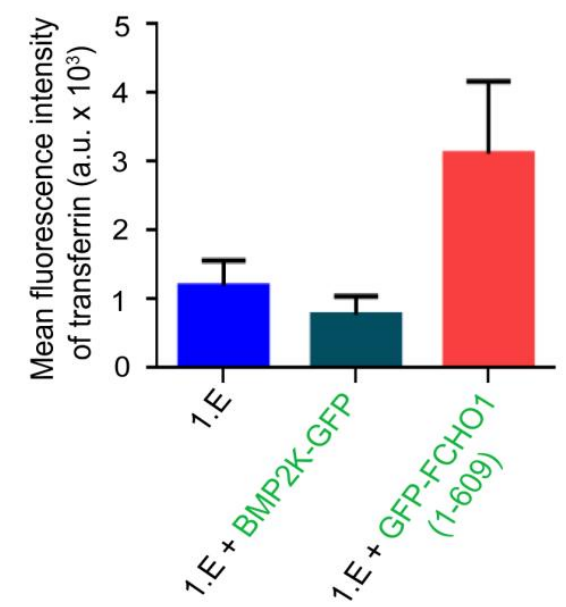




\section{Figure 8}
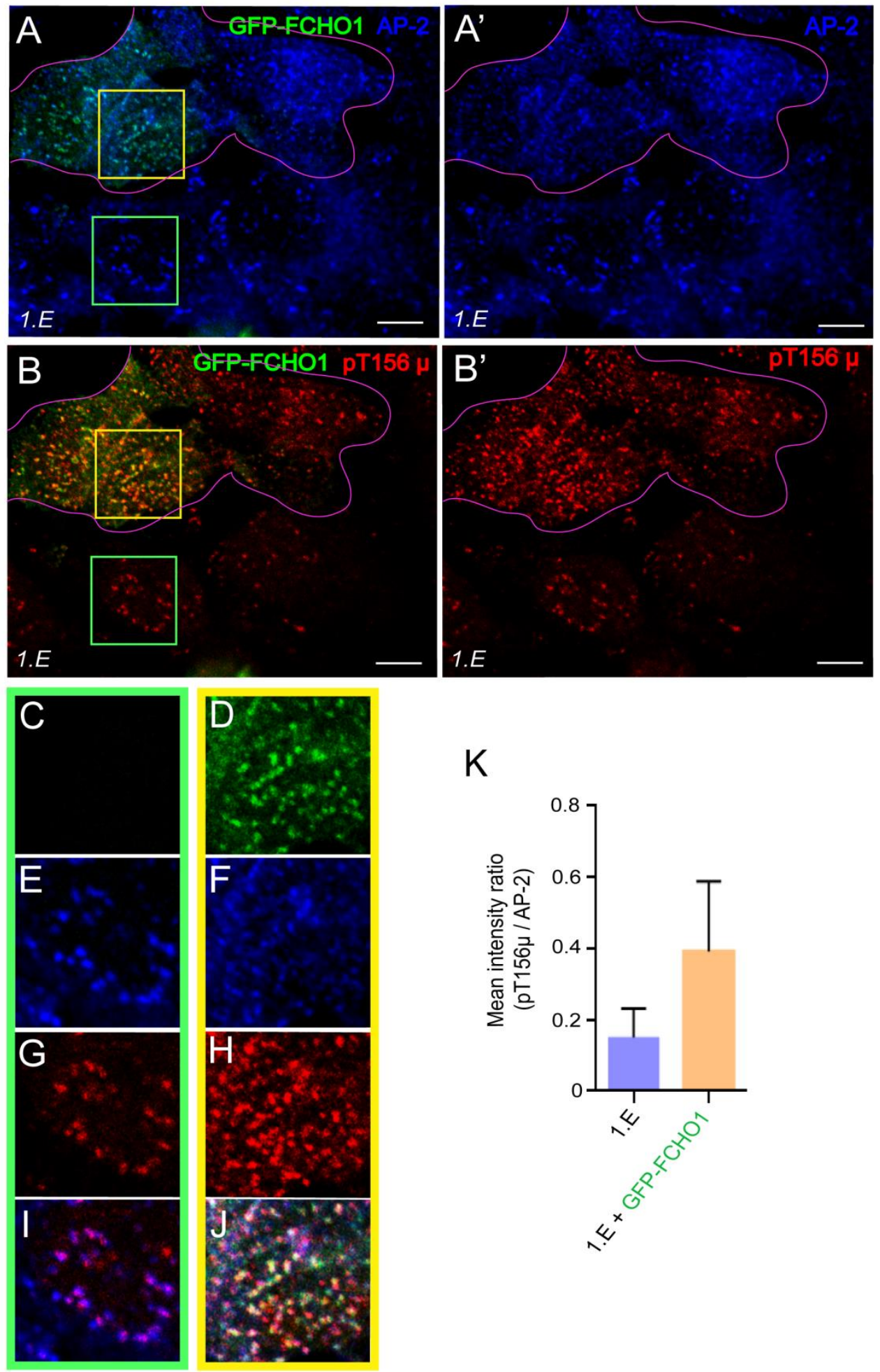


\section{Figure 9}
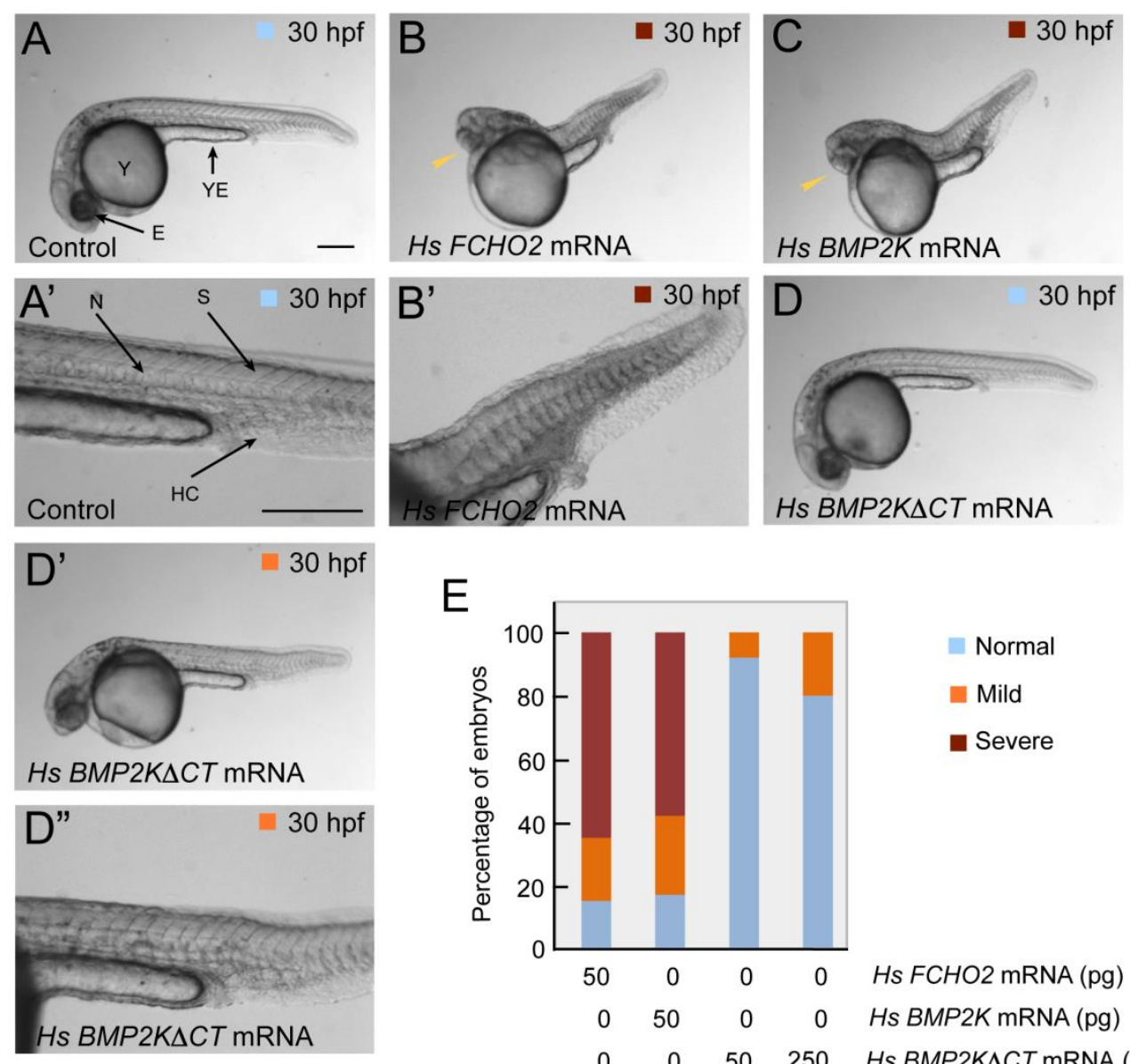

\section{E}

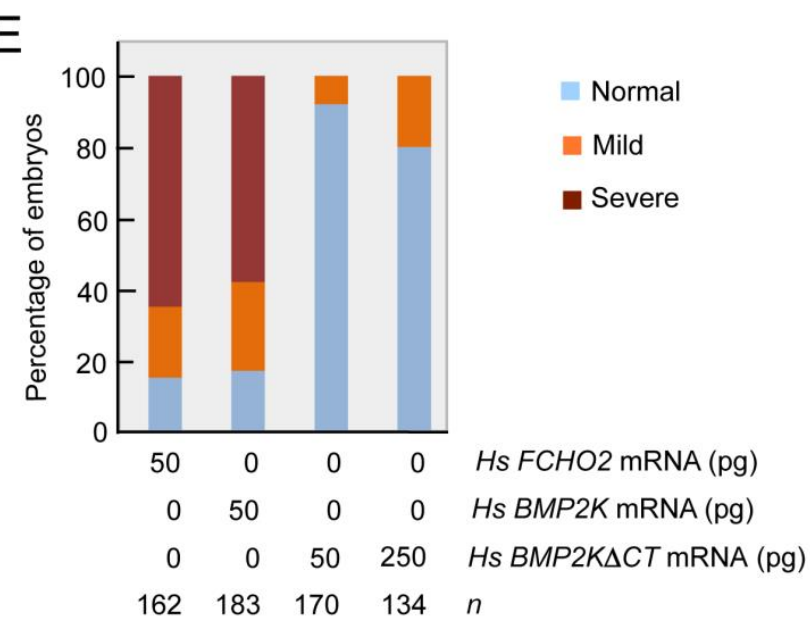

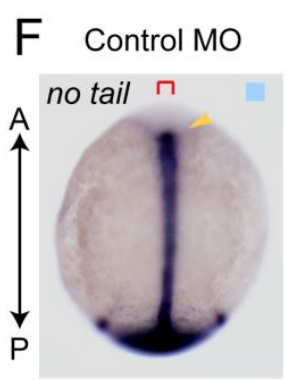

myoD

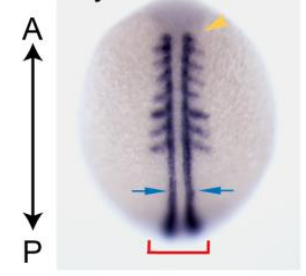

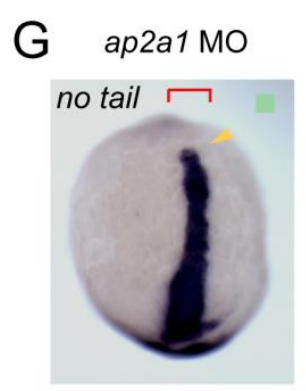

myoD

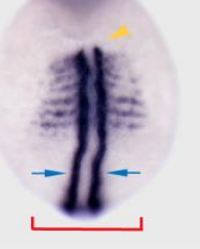

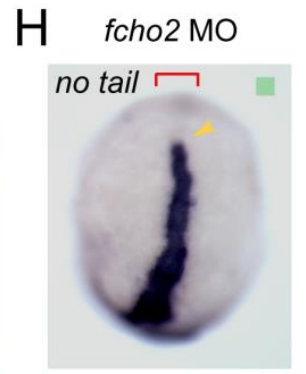

myoD

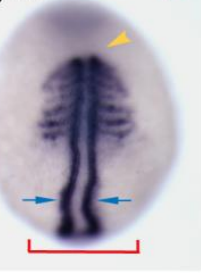

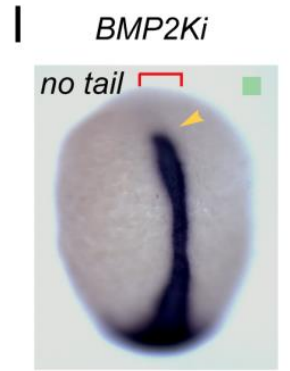

myoD 


\section{Figure 9- figure supplement 1}

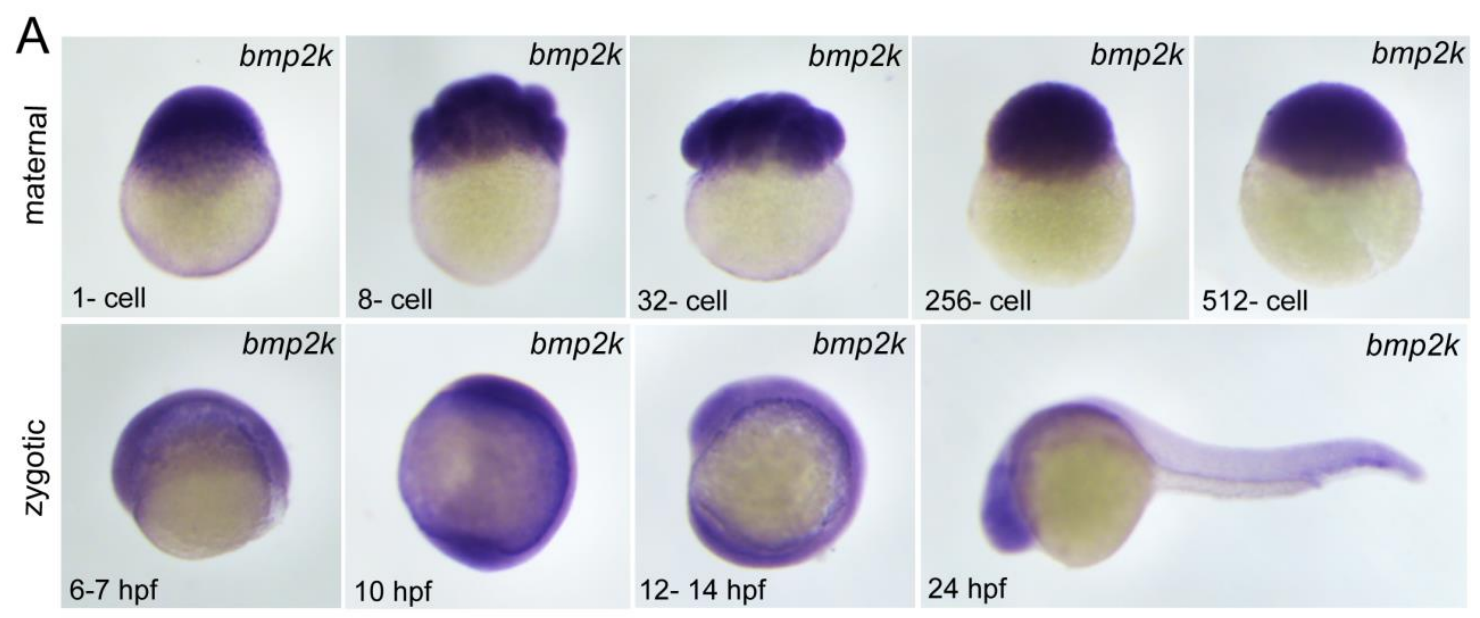

B
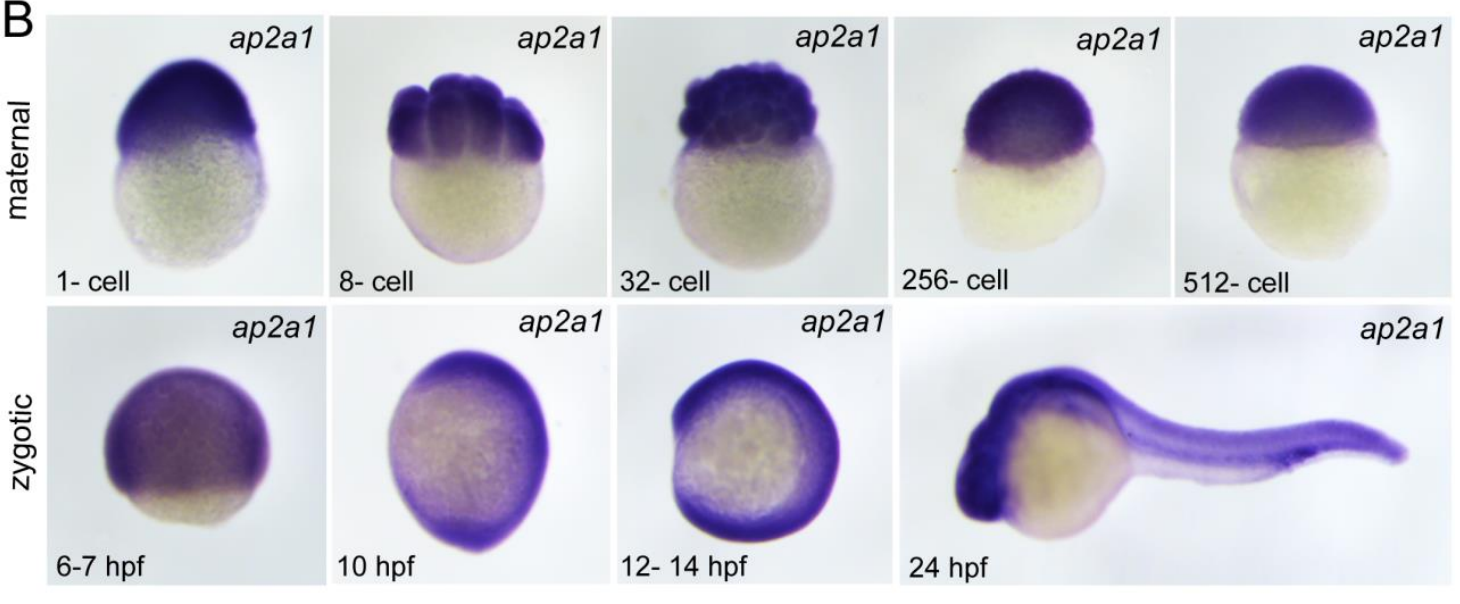

\section{C}
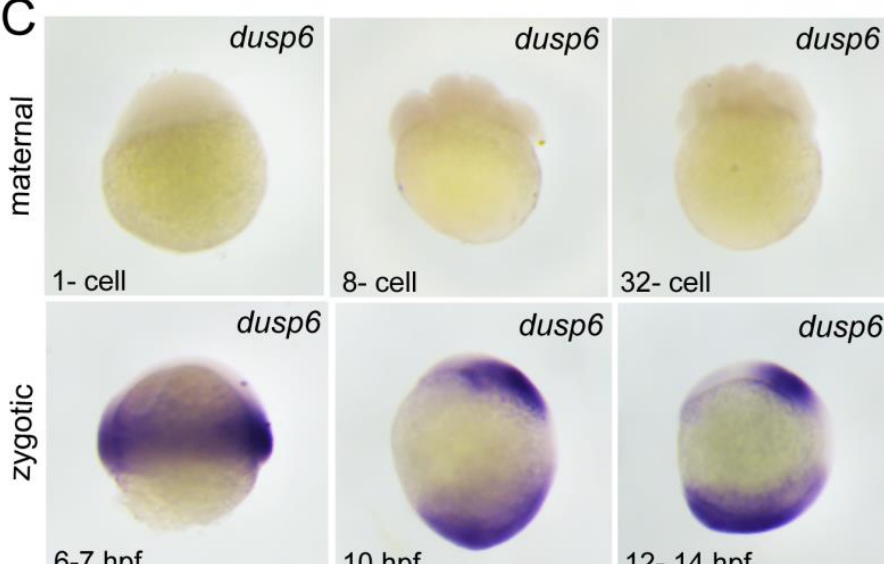

6-7 hpf

$10 \mathrm{hpf}$

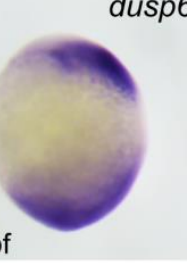

256- cell
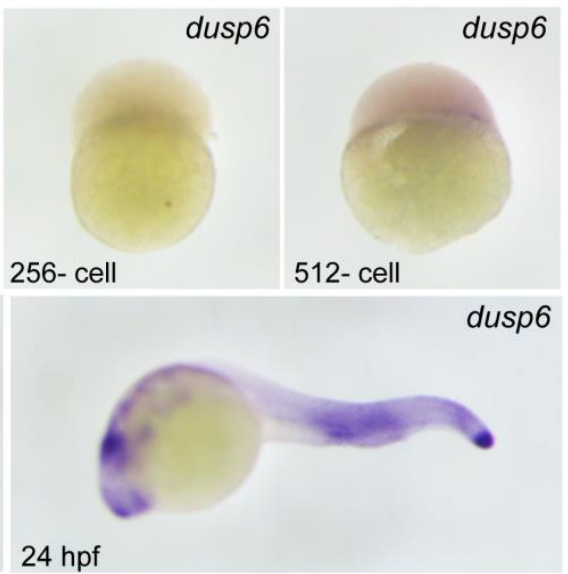


\section{Figure 9- figure supplement 2}
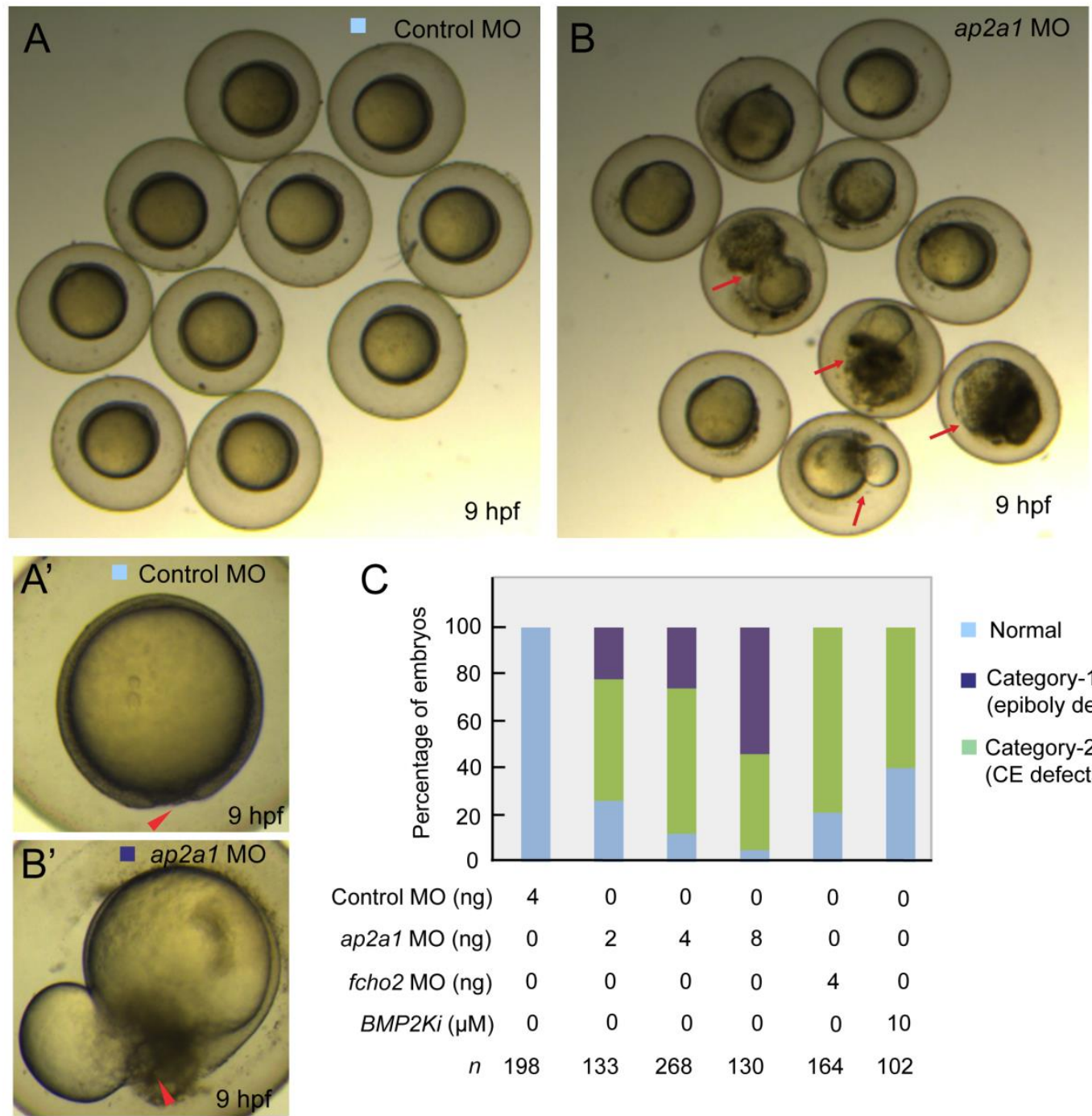

C

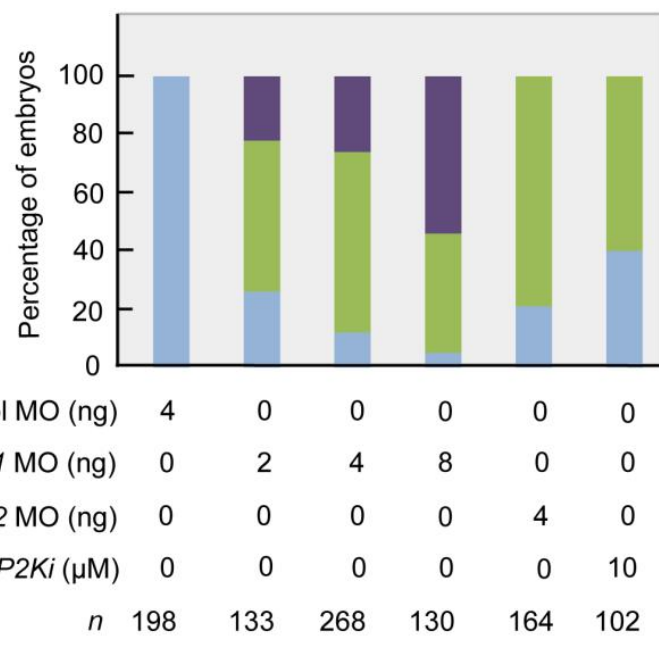

normal

Category-1 (epiboly defects)

- Category-2 (CE defects)
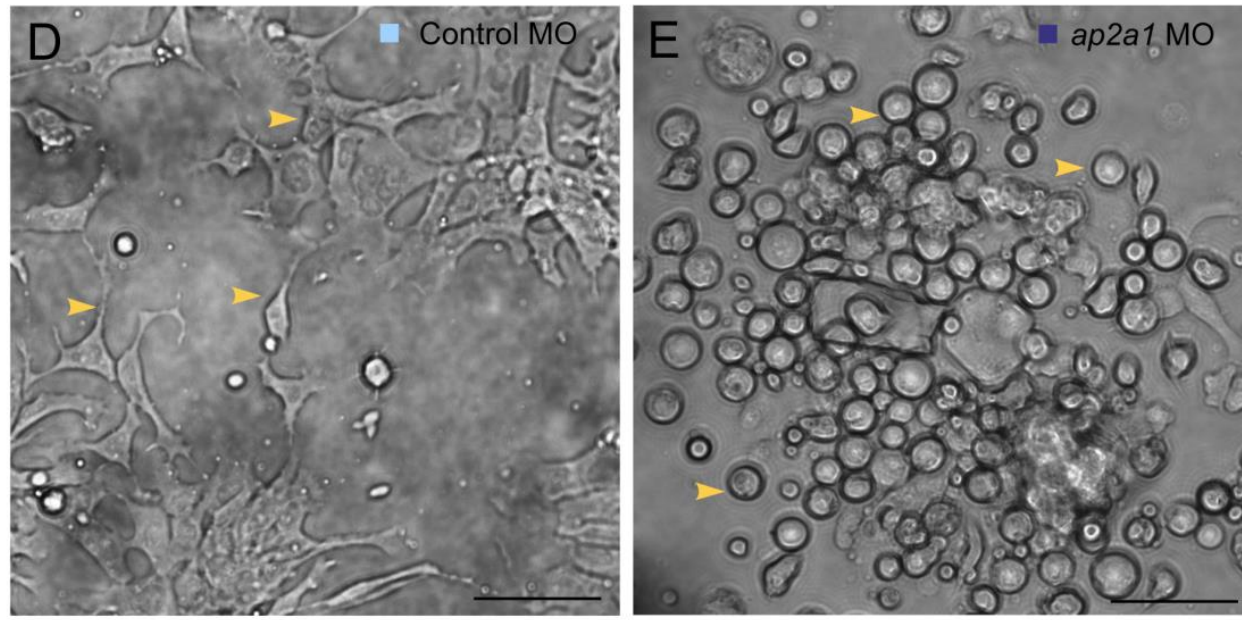


\section{Figure 10}

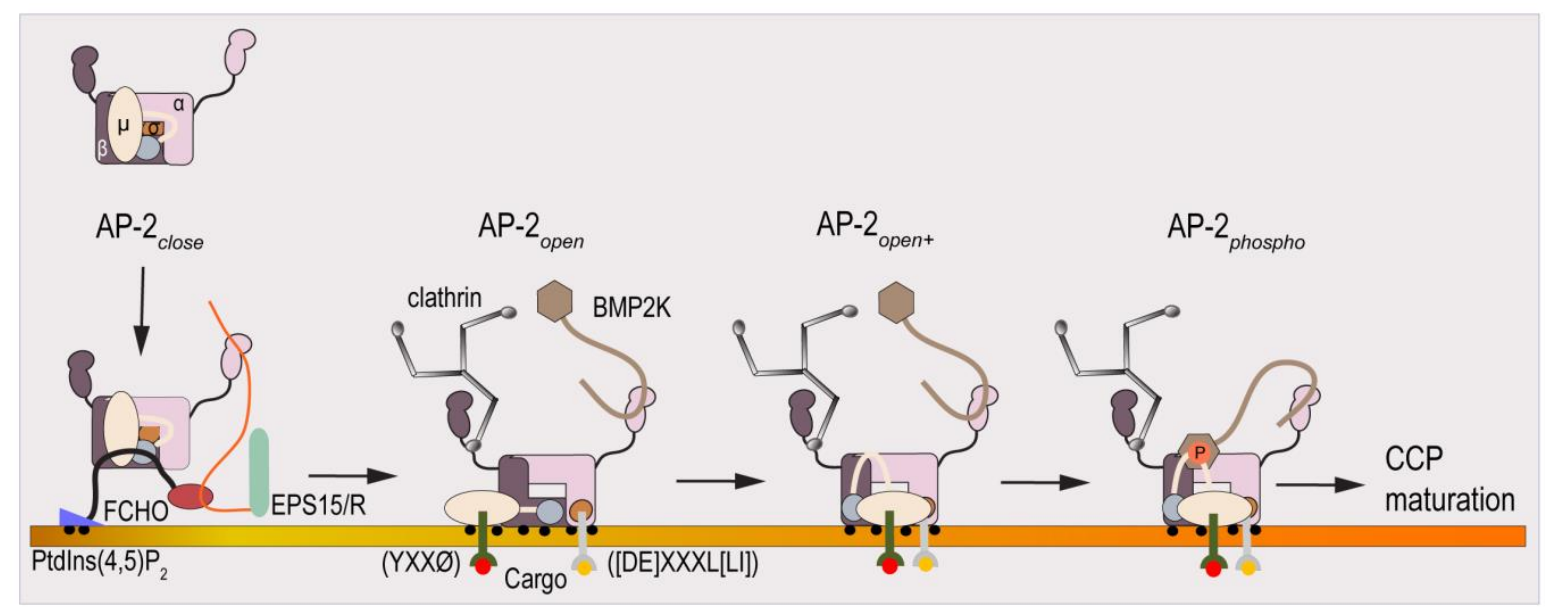

